\title{
Modeled and observed properties related to the direct aerosol radiative effect of biomass burning aerosol over the southeastern Atlantic
}

\author{
Sarah J. Doherty ${ }^{1,2}$, Pablo E. Saide ${ }^{3,4}$, Paquita Zuidema ${ }^{5}$, Yohei Shinozuka ${ }^{6,7}$, Gonzalo A. Ferrada ${ }^{8}$, \\ Hamish Gordon $^{9}$, Marc Mallet ${ }^{10}$, Kerry Meyer ${ }^{11}$, David Painemal ${ }^{12,13}$, Steven G. Howell ${ }^{14}$, \\ Steffen Freitag ${ }^{14}$, Amie Dobracki ${ }^{5}$, James R. Podolske ${ }^{7}$, Sharon P. Burton ${ }^{13}$, Richard A. Ferrare ${ }^{13}$, \\ Calvin Howes ${ }^{3}$, Pierre Nabat ${ }^{10}$, Gregory R. Carmichael ${ }^{8}$, Arlindo da Silva ${ }^{15}$, Kristina Pistone ${ }^{6,7}$, \\ Ian Chang ${ }^{16}$, Lan Gao ${ }^{16}$, Robert Wood ${ }^{2}$, and Jens Redemann ${ }^{16}$ \\ ${ }^{1}$ Cooperative Institute for Climate, Ocean and Ecosystem Studies, University of Washington, Seattle, WA, USA \\ ${ }^{2}$ Department of Atmospheric Science, University of Washington, Seattle, WA, USA \\ ${ }^{3}$ Department of Atmospheric and Oceanic Sciences, University of California, Los Angeles, CA, USA \\ ${ }^{4}$ Institute of the Environment and Sustainability, University of California, Los Angeles, CA, USA \\ ${ }^{5}$ Rosenstiel School of Marine and Atmospheric Science, University of Miami, Miami, FL, USA \\ ${ }^{6}$ Bay Area Environmental Research Institute, Moffett Field, CA, USA \\ ${ }^{7}$ Atmospheric Science Branch, NASA Ames Research Center, Moffett Field, CA, USA \\ ${ }^{8}$ Center for Global and Regional Environmental Research, The University of Iowa, Iowa City, IA, USA \\ ${ }^{9}$ Engineering Research Accelerator and Center for Atmospheric Particle Studies, \\ Carnegie Mellon University, Pittsburgh, PA, USA \\ ${ }^{10}$ CNRM, Université de Toulouse, Météo-France, CNRS, Toulouse, France \\ ${ }^{11}$ Climate and Radiation Laboratory, NASA Goddard Space Flight Center, \\ Greenbelt, Maryland, MD 20771, USA \\ ${ }^{12}$ Science Systems and Applications Inc., Hampton, VA 23666, USA \\ ${ }^{13}$ NASA Langley Research Center, Hampton, VA 23691 USA \\ ${ }^{14}$ School of Ocean and Earth Science and Technology, University of Hawaii at Manoa, Honolulu, HI, USA \\ ${ }^{15}$ Global Modeling and Assimilation Office, NASA Goddard Space Flight Center, Greenbelt, MD, USA \\ ${ }^{16}$ School of Meteorology, University of Oklahoma, Norman, OK, USA
}

Correspondence: Sarah J. Doherty (sarahd@ @atmos.washington.edu)

Received: 16 April 2021 - Discussion started: 30 April 2021

Revised: 24 September 2021 - Accepted: 5 November 2021 - Published: 3 January 2022

\begin{abstract}
Biomass burning smoke is advected over the southeastern Atlantic Ocean between July and October of each year. This smoke plume overlies and mixes into a region of persistent low marine clouds. Model calculations of climate forcing by this plume vary significantly in both magnitude and sign. NASA EVS-2 (Earth Venture Suborbital-2) ORACLES (ObseRvations of Aerosols above CLouds and their intEractionS) had deployments for field campaigns off the west coast of Africa in 3 consecutive years (September 2016, August 2017, and October 2018) with the goal of better characterizing this plume as a function of the monthly evolution by measuring the parameters necessary to calculate the direct aerosol radiative effect. Here, this dataset and satellite retrievals of cloud properties are used to test the representation of the smoke plume and the underlying cloud layer in two regional models (WRF-CAM5 and CNRM-ALADIN) and two global models (GEOS and UM-UKCA). The focus is on the comparisons of those aerosol and cloud properties that are the primary determinants of the direct aerosol radiative effect and on the vertical distribution of the plume and its properties. The representativeness of the observations to monthly averages are tested for each field campaign, with the sampled mean aerosol light extinction generally found to be within $20 \%$ of the monthly mean at plume altitudes. When compared to
\end{abstract}


the observations, in all models, the simulated plume is too vertically diffuse and has smaller vertical gradients, and in two of the models (GEOS and UM-UKCA), the plume core is displaced lower than in the observations. Plume carbon monoxide, black carbon, and organic aerosol masses indicate underestimates in modeled plume concentrations, leading, in general, to underestimates in mid-visible aerosol extinction and optical depth. Biases in mid-visible single scatter albedo are both positive and negative across the models. Observed vertical gradients in single scatter albedo are not captured by the models, but the models do capture the coarse temporal evolution, correctly simulating higher values in October (2018) than in August (2017) and September (2016). Uncertainties in the measured absorption Ångstrom exponent were large but propagate into a negligible $(<4 \%)$ uncertainty in integrated solar absorption by the aerosol and, therefore, in the aerosol direct radiative effect. Model biases in cloud fraction, and, therefore, the scene albedo below the plume, vary significantly across the four models. The optical thickness of clouds is, on average, well simulated in the WRF-CAM5 and ALADIN models in the stratocumulus region and is underestimated in the GEOS model; UM-UKCA simulates cloud optical thickness that is significantly too high. Overall, the study demonstrates the utility of repeated, semi-random sampling across multiple years that can give insights into model biases and how these biases affect modeled climate forcing. The combined impact of these aerosol and cloud biases on the direct aerosol radiative effect (DARE) is estimated using a first-order approximation for a subset of five comparison grid boxes. A significant finding is that the observed grid box average aerosol and cloud properties yield a positive (warming) aerosol direct radiative effect for all five grid boxes, whereas DARE using the grid-box-averaged modeled properties ranges from much larger positive values to small, negative values. It is shown quantitatively how model biases can offset each other, so that model improvements that reduce biases in only one property (e.g., single scatter albedo but not cloud fraction) would lead to even greater biases in DARE. Across the models, biases in aerosol extinction and in cloud fraction and optical depth contribute the largest biases in DARE, with aerosol single scatter albedo also making a significant contribution.

\section{Introduction}

Climate forcing by both direct aerosol-radiation interactions and aerosol-cloud interactions offsets about a third of greenhouse gas forcing and also contributes the largest uncertainty to total anthropogenic forcing (Forster et al., 2021). Forcing by aerosols is, in general, dependent on the vertical location of the aerosol relative to clouds and especially so for absorbing aerosol (e.g., Samset et al., 2013). In the southeastern Atlantic region, this is particularly true. From August through October there is a spatially broad, high-concentration smoke plume that overlies, and in places and times mixes with, a persistent boundary layer cloud deck. As such, direct radiative forcing in the region is a strong function not only of smoke concentration, composition, and vertical distribution but also of the albedo below the plume. Over the SE Atlantic, this albedo is arguably driven primarily by cloud fraction and liquid water path, as well as by the cloud droplet number concentration, with the latter controlled by aerosol-cloud microphysical interaction. Large-scale models have been shown to have large uncertainties and biases in their simulations of both aerosol absorption (e.g., Sand et al., 2021; Brown et al., 2021) and low marine clouds (e.g., Noda and Sato, 2014; Kawai and Shige, 2020) in this region.

Modeled direct radiative forcing across the SE Atlantic has ranged from strongly negative to strongly positive, with much of this range determined by modeled cloud fraction (e.g., see Fig. 2 of Zuidema et al., 2016; Stier et al., 2013).
In one study, the direct aerosol radiative effect in the region changed from negative to positive as cloud fraction increased above $40 \%$ (Chand et al., 2009), assuming a midvisible aerosol single scatter albedo (SSA) of 0.85 and for cloud optical depths averaging 7.8 (or cloud albedo of 0.5 ). For aerosol with lower SSA or for higher cloud albedo, this transition would occur at a lower cloud fraction (Mallet et al., 2020). The sign and magnitude of the responses to this forcing (i.e., cloud adjustments formerly referred to as the semidirect effect) also depend strongly on the underlying cloud properties and the relative vertical locations of the aerosol and cloud (e.g., Penner et al., 2003; Johnson et al., 2004; Sakaeda et al., 2011; Bond et al., 2013; Matus et al., 2015). Absorbing aerosol aloft has been linked to increased lower tropospheric stability and enhanced cloud cover and thickness compared to cleaner environmental conditions. This has been attributed to the heating of the air aloft, limiting the entrainment of dry air from the free troposphere into the marine boundary layer (Wilcox, 2010; Gordon et al., 2018), in turn enhancing the low cloud cover (e.g., Johnson et al., 2004; Wilcox, 2010), with Herbert et al. (2020) indicating a dependence on the cloud-aerosol layer distance. However, if the aerosol mixes into the clouds, the atmospheric heating there may reduce cloud cover (Koch and Del Genio, 2010; Zhang and Zuidema, 2019).

The large uncertainty in aerosol climate forcing in the SE Atlantic was the impetus for the NASA ORACLES (ObseRvations of Aerosols above CLouds and their intEractionS) 


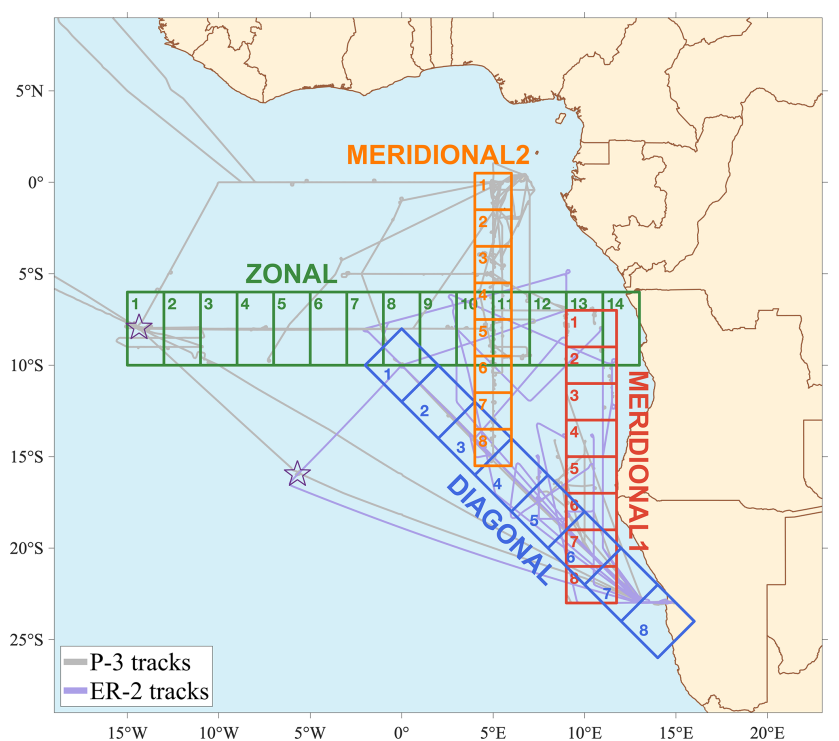

Figure 1. The four transects used in the model-observation comparison are shown along with the P-3 (2016, 2017, and 2018) and ER-2 (2016) aircraft flight tracks. Grid boxes within each transect are numbered from north-west to south-east. See Table S1 in the Supplement for the grid box coordinates. The locations of Ascension Island $\left(8^{\circ} \mathrm{S}, 14^{\circ} \mathrm{W}\right)$ and St. Helena island $\left(16^{\circ} \mathrm{S}, 6^{\circ} \mathrm{W}\right)$ are indicated with stars.

project, funded through the NASA Earth Venture Suborbital (EVS-2) program (Redemann et al., 2021), as well as complementary campaigns (Zuidema et al., 2016; Formenti et al., 2019; Haywood et al., 2021). The ORACLES project explicitly measured aerosol properties necessary to calculate the direct aerosol radiative effect (DARE). The campaign included deployments of the NASA P-3 research aircraft to the SE Atlantic region based out of Walvis Bay, Namibia (27 August-27 September 2016), and São Tomé, São Tomé and Príncipe (9 August-2 September 2017 and 24 September25 October 2018). The NASA ER-2 aircraft also deployed to Walvis Bay on 26 August-29 September 2016. The P-3 carried a suite of instruments to measure in situ gas concentrations and aerosol microphysical, optical, and chemical properties, to measure cloud microphysical properties, and to remotely sense both aerosols and clouds. It generally flew between $100 \mathrm{~m}$ and $6 \mathrm{~km}$ above the sea surface, capturing in situ data in ramped or spiral profiles, horizontal variations in level legs, and aerosol and trace gas columnar properties (e.g., aerosol optical depth - AOD) when flying below aerosol layers. The ER-2 flew at a high altitude $(19 \mathrm{~km})$ and carried remote sensing instruments only, observing both aerosols and clouds (see Redemann et al., 2021, for a more complete overview of the ORACLES campaigns).

Here, aerosol and cloud properties observed during the three ORACLES deployment periods are compared to two regional models, namely the Weather Research and Forecasting model coupled with the physics package of
Community Atmosphere Model (WRF-CAM5) and the Centre National de Recherches Aire Limitée Adaptation dynamique Développement InterNational model (CNRMALADIN; hereafter simply ALADIN), and two global models, namely the Goddard Earth Observing System model (GEOS) and the United Kingdom Chemistry and Aerosols Unified Model (UM-UKCA). Descriptions of each model are given below. The WRF-CAM5 and GEOS models are included because they were used for aerosol and meteorological forecasting during the ORACLES campaign. Similarly, the UM-UKCA modeling team participated in the UK CLARIFY (Cloud-Aerosol-Radiation Interactions and Forcing) campaign, which deployed out of Ascension Island (Fig. 1) in 2017 (Haywood et al., 2021). In 2016, both ORACLES and the French AEROCLO-SA (AERosol, radiatiOn, and CLOuds in Southern Africa; Formenti et al., 2019) campaign deployed out of Walvis Bay, Namibia, with the latter focusing on near-coast aerosols. The ALADIN regional model version 6 used here (Mallet al., 2019, 2020; Nabat et al., 2020) simulated aerosol and clouds over the SE Atlantic as part of the AEROCLO-SA campaign.

The properties included here (Sect. 2.1) allow for a first-order calculation of DARE (Sect. 5). Forcing through aerosol-cloud interactions is driven by a more complex set of processes, including the time history of aerosols and clouds (Diamond et al., 2018), aerosol physical and chemical properties (e.g., McFiggans et al., 2006; Kacarab et al., 2020), the micro- and macro-physical properties of the clouds (e.g., Stevens and Feingold, 2009; Koren et al., 2014; Gupta et al., 2021), and the thermodynamic state of the atmosphere. There is limited treatment herein of this broader set of variables, though testing model accuracy in representing cloud fraction does provide a critical zero-order step toward determining whether models might be capturing processes key to quantifying forcing through aerosol-cloud interactions.

This study builds on the work of Shinozuka et al. (2020), which compared modeled and observed column aerosol properties for the September 2016 ORACLES deployment only. There, comparisons were presented as box-and-whisker plots of two-dimensional (2D; i.e., column) and threedimensional (3D) variables. For 3D variables, values were binned into three discrete layers, i.e., the marine boundary layer, the free troposphere below $3 \mathrm{~km}$, and $3-6 \mathrm{~km}$ altitude. The Shinozuka et al. (2020) study focused on comparisons of layer-averaged carbon monoxide (CO) and aerosol properties, as well as the smoke layer bottom and top altitudes. Comparisons were made to six models; in addition to the four included herein, the EAM-E3SM and GEOS-Chem models provided statistics for the variables analyzed in Shinozuka et al. (2020). 

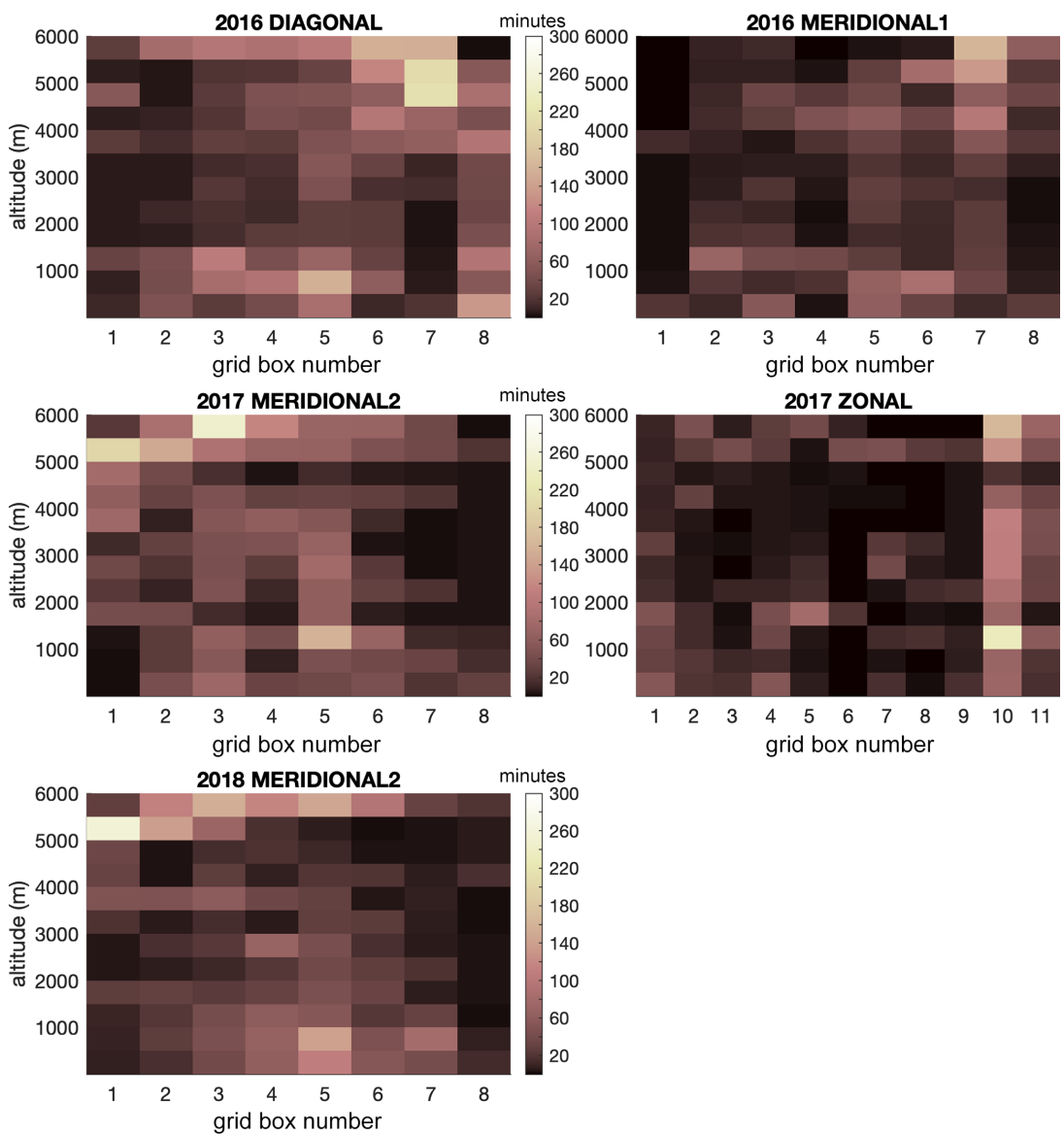

Figure 2. The number of minutes the P-3 aircraft spent in each grid box and $500 \mathrm{~m}$ altitude bin for the comparison transects shown in Fig. 1 . The 2016 diagonal and 2017 and 2018 meridional 2 transects cover the routine flight tracks, which targeted semi-random sampling. Not all in situ measurements have data available for all times, so the number of minutes of available data may be less than the number of minutes the P-3 was present in a given grid box and altitude bin.

\section{Comparison overview}

The comparisons presented here focus on vertically resolved aerosol properties, where data are averaged into $500 \mathrm{~m}$ altitude bins from the surface up to $6 \mathrm{~km}$ and on the clouds below the biomass burning smoke plume. The observed and modeled aerosol and cloud properties are compared for multiple transects across the SE Atlantic (Fig. 1). Observed values of the aerosol properties are from the ORACLES research flights, while observed cloud properties are from satellite retrievals, since the calculation of cloud fraction and optical depth from observations made from the aircraft are too limited to be of use in the statistical comparison presented here.

\subsection{Comparison variables}

The focus is on variables that are strongly related to the direct aerosol radiative effect of biomass burning aerosol. Vertically resolved comparisons are made to variables measured in situ from the NASA P-3 and measured with the NASA High Spectral Resolution Lidar, HSRL-2 ( $\sigma_{\text {ep }}$ only), which deployed on the ER-2 in 2016 and the P-3 in 2017 and 2018. The compared variables are as follows:

- carbon monoxide $(\mathrm{CO})$ mixing ratio

- black carbon (BC) concentration

- organic aerosol (OA) concentration

- light extinction $\left(\sigma_{\mathrm{ep}} ; 530 \mathrm{~nm}\right.$ from the in situ observations; $532 \mathrm{~nm}$ from the HSRL-2; $550 \mathrm{~nm}$ from the models)

- single scatter albedo (SSA; $530 \mathrm{~nm}$ from the observations; $550 \mathrm{~nm}$ from the models)

- aerosol absorption Ångström exponent (AAE; 440$670 \mathrm{~nm}$ for the observations; $400-600 \mathrm{~nm}$ for the WRFCAM5, GEOS, and ALADIN models; $380-550 \mathrm{~nm}$ for UM-UKCA)

- aerosol scattering Ångström exponent (SAE; 440$670 \mathrm{~nm}$ for the observations; $400-600 \mathrm{~nm}$ for the WRF- 
CAM5, GEOS, and ALADIN models; 380-550 nm for UM-UKCA)

- relative humidity $(\mathrm{RH})$.

The aerosol optical properties $\sigma_{\mathrm{ep}}$, SSA, AAE, and SAE are measured in situ at low $\mathrm{RH}$. The values of $\sigma_{\mathrm{ep}}$ retrieved from HSRL-2 and simulated by all four models are reported at ambient RH; the UM-UKCA model additionally reports dry $\sigma_{\mathrm{ep}}$.

The properties most critical to the underlying cloud albedo - the cloud fraction and cloud optical thickness - are evaluated by comparing the following $2 \mathrm{D}$ cloud variables:

- mean warm cloud fraction $\left(\mathrm{CF}_{\text {warm }}\right)$

- geometric mean warm cloud optical thickness $\left(\mathrm{COT}_{\text {warm }}\right)$.

These properties from the models are compared with those retrieved from the polar-orbiting Moderate Resolution Imaging Spectroradiometer (MODIS; $\mathrm{CF}_{\text {warm }}$ and $\mathrm{COT}_{\text {warm }}$ ) and geostationary Spinning Enhanced Visible and InfraRed Imager (SEVIRI; $\mathrm{CF}_{\text {warm }}$ only).

\subsection{Comparison transects, altitude bins, and statistics}

Comparisons are made along several transects of grid boxes (Fig. 1; Table S1 in the Supplement). The locations of the transects are dictated by frequent research flight paths, which varied across the 3 years of the project. A decided focus of the ORACLES field campaigns was to devote about half of the P-3 flight hours in each year to sampling along routine flight tracks (Redemann et al., 2021). The explicit goal was to sample the transect across a set of randomly distributed days throughout the field deployment in order to build a dataset representative of the deployment month.

During ORACLES 2016, the routine flights followed a diagonal latitude/longitude transect (diagonal transect, shown in Fig. 1, terminating near Namibia). With deployment based out of São Tomé in 2017 and 2018, the routine flights were along a north-south-oriented track centered on 5E (meridional 2; see Fig. 1). The routine flight pattern usually consisted of a series of in-transit profiles and horizontal legs in the aerosol layer and in the boundary layer clouds. In 2017 and 2018, with the HSRL-2 lidar on board the P-3, the south-bound leg on routine flights was usually flown at an aircraft maximum altitude (approximately 5-6 km) to survey the aerosol and cloud layers below. The north-bound run was then a combination of vertical profiling, horizontal legs, and sawtooth legs (for clouds). Each routine flight included a different combination of legs and profiles, so only the latitude/longitude line of the flights (not their altitudes) were common to all. In 2016, on most routine flight days, the NASA ER-2 would also fly along the routine track and, in some cases, overfly the P-3.

In addition to the dedicated routine track in 2016, a significant number of P-3 target of opportunity flights (Redemann et al., 2021) were flown along a north-south transect near the southern African coast. As such, the meridional 1 (Fig. 1) set of comparison grid boxes is also selected. Finally, for all 3 years a zonal transect is established, running from Ascension Island to the west African coast. The zonal transect is located approximately at the latitudinal center of the southern African biomass burning plume, along the northern edge of the main stratocumulus deck. Free troposphere transport in this region is driven by the southern African easterly jet, which is centered around $8^{\circ} \mathrm{S}$ (Adebiyi and Zuidema, 2016); as such, in the free troposphere, the zonal transect, to first order, covers a gradient in age from east (younger) to west (more aged).

The zonal transect is located significantly farther from the deployment bases than the other comparison transects, so most grid boxes in this transect have little P-3 data. In 2016, only the ER-2 had sufficient sampling for meaningful comparisons with models along this transect. In 2017, when the P-3 did a suitcase flight to Ascension Island (Redemann et al., 2021), there was some coverage of the westernmost zonal grid boxes. For the zonal transect, the only aerosol observations included in the comparison are profiles of $\sigma_{\mathrm{ep}}$ from the HSRL-2 on board the ER-2 in 2016. In all 3 years, comparisons of $\mathrm{CF}_{\text {warm }}$ and $\mathrm{COT}_{\text {warm }}$ are included along the zonal transect, since these observations are from satellites and thus have good statistics in all 3 years.

In the discussions below, grid boxes are numbered from northwest to southeast for the diagonal transect, north to south for the two meridional transects, and west to east for the zonal transect (Fig. 1). Averages within each deployment year cover the following dates:

- 30 August through 27 September 2016,

- 9 August through 2 September 2017, and

- 24 September through 25 October 2018.

These include the transit flights from Namibia (2016) and to and from São Tomé (2017 and 2018). For ease of reference, we refer to these as the September 2016, August 2017, and October 2018 monthly averages.

Observed and modeled statistics are calculated for $500 \mathrm{~m}$ deep altitude bins from the surface to $6 \mathrm{~km}$, with two exceptions. Relative humidity is aggregated into $250 \mathrm{~m}$ deep bins to more clearly show the transition from the boundary layer to the free troposphere. Light extinction from the HSRL-2 has a $315 \mathrm{~m}$ vertical resolution, and this resolution is retained. Mean biases are calculated as the averages of the ratios in $1 \mathrm{~km}$ altitude bins for more robust statistics. For the in situ observations, data are included in statistics whether made on level legs or during profiles, so the number of data points included in statistics can vary significantly with altitude within a given grid box (Fig. 2).

The aerosol properties compared here were measured from the aircraft, and so are available on specific days and for 
specific locations on each flight. In the aerosol comparisons, the model statistics used are calculated for only those dates and locations where the aircraft was present. In contrast, the observed $\mathrm{CF}_{\text {warm }}$ and $\mathrm{COT}_{\text {warm }}$ statistics are from satellitebased measurements (Sect. 3.2) and thus are available for every day of each year's deployment. In this case, both observed and model statistics are calculated for every day of the deployment period across every comparison grid box.

To test for the representativeness of the observed aerosol properties, for some variables two sets of modeled statistics are calculated for each grid box and altitude layer, i.e., first for only those locations and times when the aircraft was present and second for all daylight hours (defined here as 06:00-18:00 UTC - universal coordinated time) across the duration of that year's deployment. Comparison of the two allows for testing the representativeness of the observations for assessing monthly averages, assuming that the model realistically captures aerosol variability. To test this, we calculated the fractional variability in $\sigma_{\text {ep }}$ in the $2-5 \mathrm{~km}$ altitude range within the comparison grid boxes in the WRF-CAM5 and GEOS models and in the observations. We found that the three are similar for the 2016 diagonal and meridional 1 transect grid boxes, with the models alternately having lower and higher fractional variability than was observed. Along the 2017 meridional 2 transect, WRF-CAM5 and the observed variability were similar, but the GEOS variability was $10 \%-$ $30 \%$ higher. Along the 2018 meridional 2 transect, the converse was true; the relative variability in $\sigma_{\mathrm{ep}}$ was similar for GEOS and the observations but was about $20 \%$ lower for WRF-CAM5.

Shinozuka et al. (2020) also tested the representativeness of observed column properties (aerosol optical depth) for the September 2016 campaign only. The vertically resolved data provide additional, more detailed information on representativeness, which is something columnar passive satellite observations cannot provide. In addition, here representativeness is tested for all 3 campaign years.

\section{Dataset descriptions}

\subsection{Observed aerosol properties, $\mathrm{CO}$ concentrations, and relative humidity}

Detailed descriptions of the instruments used to measure aerosols and gases are given in Appendix 9.1 of Shinozuka et al. (2020). Here, the characteristics of each measurement most relevant to the presented comparison are discussed. All in situ observations are derived from the $1 \mathrm{~s}$ resolution data collected on the P-3, which are available from the NASA public data archive (see the Data Availability at the end of the paper). Several of the measurements used here (e.g., absorption; see below) are very noisy at this resolution. To reduce noise, the $1 \mathrm{~s}$ resolution data are smoothed using a weighted average, calculated with a Gaussian weighting function covering $\pm 30 \mathrm{~s}$ on either side of each $1 \mathrm{~s}$ resolution data point.
The weighting function has 61 values, with the peak at value 31 . The standard deviation was set to 12 ; this produces a weighting function such that the data points at time $t-30$ and $t+30 \mathrm{~s}$ are weighted at $4.4 \%$ of the value at time $t$. A much larger standard deviation would have weighted values more than $30 \mathrm{~s}$ from the time of interest too heavily (e.g., by $17 \%$ for a value of 16), and a much smaller standard deviation would have produced a weighting function that approached zero in less than $30 \mathrm{~s}$. Values of in situ $\sigma_{\mathrm{ep}}$, SSA, $\mathrm{SAE}$, and AAE are derived after this smoothing function is applied to the scattering and absorption data. In all cases, statistics for a given altitude bin and comparison grid box are included for the in situ observations only if at least $10 \mathrm{~min}$ of data in total are available.

Aerosol optical properties were measured in situ at low $(<40 \%)$ RH via an aerosol inlet with a $50 \%$ cutoff diameter of approximately $5 \mu \mathrm{m}$ (McNaughton et al., 2007). Above the boundary layer, the aerosol during ORACLES was dominated by accumulation mode biomass burning smoke, with a volumetric mean diameter of $<0.4 \mu \mathrm{m}$ (e.g., see Fig. 8 of Shinozuka et al., 2020), so it is expected that the in situ instruments capture the properties of the vast majority of aerosol contributing to column radiative impacts and all of the biomass aerosol.

Carbon monoxide was measured with an ABB (Los Gatos Research) $\mathrm{CO} / \mathrm{CO}_{2} / \mathrm{H}_{2} \mathrm{O}$ analyzer modified for flight operations, with a precision of $0.5 \mathrm{ppbv}$ (parts per billion by volume) for $10 \mathrm{~s}$ averages (Liu et al., 2017; Provencal et al., 2005). Black carbon was measured as refractory BC (rBC) using a single particle soot photometer (SP2; Schwarz et al., 2006; Stephens et al., 2003) calibrated with Fullerene soot. The SP2 measurement of $\mathrm{rBC}$ mass is estimated to have an uncertainty of $25 \%$ at the provided $1 \mathrm{~s}$ resolution. A high-resolution time-of-flight aerosol mass spectrometer (HR-ToF-AMS; Aerodyne Research Inc.), operated in highsensitivity $\mathrm{V}$ mode, was used to measure organic aerosol (OA) mass with an estimated accuracy of $50 \%$ at $1 \mathrm{~s}$ time resolution.

Aerosol light scattering $\left(\sigma_{\mathrm{sp}}\right)$ at 450,550 , and $700 \mathrm{~nm}$ was measured on board the P-3 at low $(<40 \%)$ RH with a TSI (model 3563) nephelometer, with the corrections of Anderson and Ogren (1998) applied. In 2018, two TSI nephelometers were operated, with one periodically measuring the submicron aerosol only. When both were measuring the total aerosol, reported $\sigma_{\mathrm{sp}}$ is the average of the two. In 2018, the $450 \mathrm{~nm}$ channel on the nephelometer was not working, so SAE data are not available for that year.

As discussed below, most models report aerosol optical properties at ambient RH. Relative humidity profiles and aerosol hygroscopic growth factors inform whether this could be a significant source of differences between the modeled and observed aerosol optical properties and so are shown here. The observed ambient RH was calculated based on dew point measured using an Edgetech 137 Vigilant hygrometer. Hygroscopic growth factors for $530 \mathrm{~nm}$ light scattering were 
quantified during ORACLES, using a pair of Radiance Research nephelometers, run at low $(<40 \%) \mathrm{RH}$ and approximately $85 \% \mathrm{RH}$, respectively. However, there were instrumental issues that resulted in significant data gaps in 2016 and 2018 and instrumental problems across the full 2017 campaign. This complicates correcting to humidified scattering values for the statistical comparisons with the models. As such, here we use these data only to estimate the effect of humidification on scattering, based on aerosol characteristics aggregated across all observations (not just those in the comparison transects) within each field season.

Dry aerosol light absorption $\left(\sigma_{\mathrm{ap}}\right)$ at 470,530 , and $660 \mathrm{~nm}$ was calculated using measurements from one (2017 and 2018) or two (2016) three-wavelength Radiance Research particle soot absorption photometers (PSAPs). For 2016, the values from the two PSAPs are averaged; for 2017 and 2018 only one of the PSAPs consistently measured the total ambient aerosol absorption, so only data from that PSAP was used. Filter-based absorption measurements, such as the PSAP, are known to have loading-based artifacts that produce a positive bias that requires correction (e.g., Bond et al., 1999; Virkkula, 2010). Early versions of the PSAP instrument measured $\sigma_{\mathrm{ap}}$ at only one wavelength $(530 \mathrm{~nm})$, so correction factors at this wavelength are better understood than at 470 and $660 \mathrm{~nm}$, where they are untested for accuracy. Here, two sets of correction factors have been applied to the PSAP dat, namely the wavelength-averaged and the wavelength-specific corrections, which are both described in Virkkula (2010). These correction factors are very similar at $530 \mathrm{~nm}$ but yield different values of $\sigma_{\mathrm{ap}}$ at 470 and $660 \mathrm{~nm}$. They, therefore, yield different values of derived absorption Ångström exponent but nearly identical $530 \mathrm{~nm}$ SSA.

Scattering at the 450,550 , and $700 \mathrm{~nm}$ wavelengths $(\lambda)$ is used to calculate a $\operatorname{linear}$ fit to $\log \left(\sigma_{\mathrm{sp}}\right)$ versus $\log (\lambda)$, yielding the scattering Ångström exponent (SAE). The absorption Ångström exponent (AAE) is analogously calculated from $\sigma_{\text {ap }}$ at 470,530 , and $660 \mathrm{~nm}$ for, as noted above, $\sigma_{\text {ap }}$ derived using the two sets of Virkkula (2010) correction factors. The observed values of $\sigma_{\mathrm{ep}}$ and SSA included here are at $530 \mathrm{~nm}$ for low RH aerosol. They are calculated by adjusting the measured low RH $550 \mathrm{~nm} \sigma_{\mathrm{sp}}$ with the above-calculated SAE. This adjusted $\sigma_{\mathrm{sp}}$ is then summed with the $530 \mathrm{~nm} \sigma_{\mathrm{ap}}$ to obtain $\sigma_{\mathrm{ep}}$, and SSA is calculated as the ratio of $530 \mathrm{~nm} \sigma_{\mathrm{sp}}$ to $530 \mathrm{~nm} \sigma_{\mathrm{ep}}$. SAE and SSA are calculated only when $\sigma_{\mathrm{ep}}$ is greater than $10 \mathrm{Mm}^{-1}$, and AAE is only calculated when $\sigma_{\mathrm{ap}}$ is greater than $5 \mathrm{Mm}^{-1}$ in order to avoid including data dominated by noise.

All of the above measurements were made from the P3 aircraft. Data from the airborne second-generation High Spectral Resolution Lidar version 2 (HSRL-2) that was flown on the ER-2 aircraft in 2016 and the P-3 in 2017 and 2018 are also included in the comparison. The HSRL-2 is a remote sensing instrument, so retrieved values of $\sigma_{\mathrm{ep}}$ are at ambient $\mathrm{RH}$ and, therefore, are more directly comparable to the modeled values. The HSRL-2 independently detects backscatter from aerosols and molecules using the spectral distribution of the returned signal, thereby retrieving $\sigma_{\text {ep }}$ without having to make assumptions about the backscatter-to-extinction ratio of the aerosol (Shipley et al., 1983; Hair et al., 2008; Burton et al., 2018). The HSRL-2 retrieves $\sigma_{\text {ep }}$ at 355 and $532 \mathrm{~nm}$ with $315 \mathrm{~m}$ vertical resolution; here, we use the $532 \mathrm{~nm}$ data only for comparison to modeled $550 \mathrm{~nm} \sigma_{\mathrm{ep}}$.

\subsection{Observed cloud properties}

From the standpoint of aerosol forcing, the clouds of most interest in the SE Atlantic are stratocumulus and cumulus (warm and low) clouds in the boundary layer, as these clouds are most prevalent in the region and underlie the aerosol plume, so they are a strong controlling factor on the direct aerosol radiative effect sign and magnitude. As such, here we compare the warm, low cloud $(<2.5 \mathrm{~km}, T>273 \mathrm{~K})$ fraction $\left(\mathrm{CF}_{\mathrm{warm}}\right)$ from models to that retrieved in several satellite products.

Cloud optical thickness for these clouds $\left(\mathrm{COT}_{\text {warm }}\right)$ is approximately log-normally distributed (e.g., Fig. S1 in the Supplement), so for $\mathrm{COT}_{\text {warm }}$ we compare the geometric mean of all values within the comparison grid boxes. This statistic was selected as being the most physically meaningful, since it more closely represents the cloud optical thickness and, therefore, cloud impact on scene albedo for heterogeneous scenes.

$\mathrm{CF}_{\text {warm }}$ and $\mathrm{COT}_{\text {warm }}$ are derived for several retrieval products and are compared to each other and to the observations. As described later (Sect. 4.4), the SEVIRI-LaRC (Langley Research Center) values of $\mathrm{CF}_{\text {warm }}$ (Sect. 3.2.3) and the MODIS-ACAERO (above-cloud aerosol) values of $\mathrm{COT}_{\text {warm }}$ (Sect. 3.2.2) are used as the benchmark for the comparison to the modeled values.

\subsubsection{MODIS standard cloud products}

The Collection 6 MODIS Level 3 (L3) daily cloud products (Platnick et al., 2015a) from both the Aqua (MYD08) and Terra (MOD08) satellites are used to calculate average warm cloud fractions $\left(\mathrm{CF}_{\mathrm{warm}}\right)$. These $\mathrm{L} 3$ products are statistical aggregations at $1^{\circ} \times 1^{\circ}$ resolution (latitude $\times$ longitude) of the MODIS Level 2 (L2) pixel-level cloud retrievals (Platnick et al., 2015b, 2017). Since Aqua and Terra are polarorbiting satellites, their cloud retrieval statistics from the ORACLES comparison grid boxes are from, on average, 10:20 LT (local time; Terra) and 13:40 LT (Aqua). Herein we refer to these as the MODIS standard retrieved cloud properties.

The L3 MODIS variables used for $\mathrm{CF}_{\text {warm }}$
are
Cloud_Retrieval_Fraction_Liquid Cloud_Retrieval_Fraction_PCL_Liquid, with the latter allowing for inclusion of partly cloudy pixels. Data are excluded from statistics if the retrieved cloud top height is greater than $2.5 \mathrm{~km}$ in order to include only low warm 
clouds. These variables only include the Level 2 pixel population that is identified as liquid phase or overcast and that has successful cloud optical property retrievals, allowing classification as liquid clouds. As such, $\mathrm{CF}_{\text {warm }}$ may be smaller than the actual warm cloud fraction, depending on the rate of cloud optical property retrieval failure (see, e.g., Cho et al., 2015) and the prevalence of broken clouds and cloud edges in a retrieval pixel. For the selected comparison transects - and for this region in general - the fraction of mid-level and high clouds is low. For example, in 2016, warm, low clouds comprise, on average, $93 \%$ or more of the clouds in the diagonal and meridional 1 transect grid boxes and the four easternmost zonal transect grid boxes. In the seven westernmost zonal grid boxes, $>99 \%$ of the clouds are warm clouds. An exception is the grid boxes closer to the African coastline, where mid-level clouds, in particular, can be more frequent. This is consistent with the fact that most mid-level and high clouds in the region originate over the continent (Adebiyi et al., 2020), a phenomenon we observed directly during the field campaigns.

\subsubsection{MODIS-ACAERO cloud products}

Retrievals of cloud properties from satellite-imager-based observations can be affected by the presence of aerosol above the clouds, particularly when that aerosol is lightabsorbing (Haywood et al., 2004; Coddington et al., 2010; Meyer et al., 2013). While retrieved CF is not significantly impacted, the retrieved COT will be. If not accounted for, the attenuation of cloud-reflected solar radiation due to aerosol absorption can be interpreted by satellite imager cloud retrieval algorithms as higher effective radii and as a lower COT. Therefore, in addition to the MODIS standard cloud retrievals, we calculate cloud statistics using the L2 (1 km resolution) MOD06/MYD06 ACAERO retrievals from MODIS that use the Meyer et al. (2015) approach, which accounts for the effects of the absorbing aerosol layer above low clouds and has been shown to produce COT values that compare better to aircraft-based observations than the MODIS standard product (Chang et al., 2021). These retrievals, referred to here as MODIS-ACAERO, simultaneously retrieve the above-cloud aerosol optical properties and the unbiased cloud optical properties and are used as the reference for observed $\mathrm{COT}_{\text {warm. }}$. (Specifically, the Cloud_Optical_Thickness_ModAbsAero parameter is used). The MODIS-ACAERO-retrieved $\mathrm{CF}_{\text {warm }}$ is also included, which differs from the MODIS standard definition in its use of cloud-top height (CTH) as an additional filter (specifically, $\mathrm{CTH}<4 \mathrm{~km}$; thus mid-level clouds are excluded). Otherwise, as with the MODIS standard retrievals, these are averages from the MODIS instruments on the Terra and Aqua satellites.

\subsubsection{SEVIRI-LaRC cloud products}

Warm clouds over the SE Atlantic have a significant diurnal cycle, particularly in cloud fraction (Rozendaal et al., 1995; Wood et al., 2002; Painemal et al., 2015). A question arises as to whether the MODIS retrievals, which make observations only twice daily, are representative of the daytime averages. The Spinning Enhanced Visible and Infrared Imager (SEVIRI) on the geostationary satellite Meteosat-10 views the SE Atlantic region at all times of the day. We use the cloud fraction retrieved from SEVIRI for three purposes. First, we calculate the average daytime $\mathrm{CF}_{\text {warm }}$ in each comparison grid box to test the modeled average daytime $\mathrm{CF}_{\text {warm }}$. Second, we calculate the difference in the average daytime $\mathrm{CF}_{\text {warm }}$ and the average of $\mathrm{CF}_{\text {warm }}$ at 10:30 and 13:30 UTC only, as an estimate for how different $\mathrm{CF}_{\text {warm }}$ from the MODIS Terra and Aqua retrievals might be from an actually full daytime average of $\mathrm{CF}_{\mathrm{warm}}$. Third, as described below, we use the diurnal cycle in $\mathrm{CF}_{\text {warm }}$ to infer the diurnal cycle in $\mathrm{COT}_{\text {warm }}$ and, therefore, the representativeness of the MODIS-ACAERO Terra and Aqua COT warm $_{\text {to }}$ the daytime average.

Here, the SEVIRI retrievals described by Minnis et al. (2008, 2011a, b) and Painemal et al. (2015) are used and are referred to as the SEVIRI NASA Langley Research Center (LaRC) retrievals. Warm cloud fractions are derived at $0.25^{\circ}$ grid resolution from pixel-level $(3 \mathrm{~km})$ retrievals by counting pixels with a liquid cloud phase and the effective cloud-top temperature $T_{\text {cldtop }}>273.2 \mathrm{~K}$. Retrievals are provided every $30 \mathrm{~min}$. We limit our analysis to daytime samples with solar zenith angles (SZAs) of less than $75^{\circ}$ to minimize retrieval uncertainties in the day-night transition.

In this region, cloud cover tends to be at a maximum in the early morning, then either decreases throughout the day or decreases until mid- to late afternoon, and then increases again (Fig. S2; Painemal et al., 2015). The average of $\mathrm{CF}_{\text {warm }}$ at 10:30 and 13:30 UTC is generally lower than, but within, $5 \%$ of the daytime average (Table S2). The exception is at the northern end of the meridional 1 and meridional 2 transects, when the 10:30 and 13:30 UTC average is up to $14 \%$ below the daytime average. While the 10:30 and 13:30 UTC average $\mathrm{CF}_{\text {warm }}$ is lower than the daytime average, it does represent $\mathrm{CF}_{\text {warm }}$ midday well, when solar flux (and, therefore, radiative forcing) is at a maximum.

An additional question is whether the $\mathrm{COT}_{\text {warm }}$ values from the 10:30 and 13:30 UTC MODIS-ACAERO retrievals are representative of the daytime average. The SEVIRILaRC retrievals do not simultaneously provide aerosol optical depth and cloud products, and inferred $\mathrm{COT}_{\text {warm }}$ could be biased if there is a high AOD layer above the clouds. To approximate the diurnal cycle in $\mathrm{COT}_{\text {warm }}$, an empirical fit to $\mathrm{COT}_{\text {warm }}$ versus $\mathrm{CF}_{\text {warm }}$ from the MODIS-ACAERO dataset from all 3 field campaign years and comparison transects was used to approximate the difference between the 10:30 and 13:30 UTC average $\mathrm{COT}_{\text {warm }}$ and the average of $\mathrm{COT}_{\text {warm }}$ 
across the full daytime. The resulting fit (Fig. S3) is as follows:

$\mathrm{COT}_{\text {warm,fit }}=1.663 \times e^{1.982 \cdot \mathrm{CF}_{\text {warm }}}$.

$\mathrm{COT}_{\text {warm }}$, like $\mathrm{CF}_{\text {warm }}$, is slightly lower - typically by less than 0.5 - for the 10:30 and 13:30 UTC average than for the full daytime average when calculated using the approximation in Eq. (1) (Table S3). At the northern end of the 2016 meridional 1 and 2017 meridional 2 transects, the difference is closer to 1.0. For a SZA of $30^{\circ}$, a decrease in $\mathrm{COT}_{\text {warm }}$ from 10.0, which is typical of clouds in this region (see Sect. 4.4), to 9.0 reduces cloud albedo by only 0.02 , from 0.46 to 0.44 (see Sect. 5). The influence on scene albedo, which is the variable of interest for DARE, will be even smaller any time when $\mathrm{CF}_{\text {warm }}$ is less than 1.0. As such, the $\mathrm{COT}_{\text {warm }}$ values from MODIS appear to represent the daytime average, within the context of their role in determining aerosol direct radiative effects, very well.

\subsection{Modeled aerosol and cloud fields}

Data for all 3 ORACLES years are available for the WRFCAM5 and GEOS models; UM-UKCA and ALADIN provided comparison data for the 2016 and 2017 ORACLES field campaign periods only. Statistics for all variables listed in Sect. 2.1 are provided for the WRF-CAM5 model. Statistics are not provided for RH from GEOS, for CO from UMUKCA, or for CO, RH, and AAE for ALADIN.

All models report aerosol optical properties at ambient $\mathrm{RH}$, in contrast to the observed optical properties which are at low RH. The UM-UKCA model also reports dry aerosol optical properties. In addition, all models report extinction and SSA at $550 \mathrm{~nm}$, whereas the observed values are at $530 \mathrm{~nm}$. Finally, the modeled AAE and SAE are calculated from 400 to $600 \mathrm{~nm}$, whereas the observed AAE is calculated using $\sigma_{\mathrm{ap}}$ at the three wavelengths of 470,530 , and $660 \mathrm{~nm}$ and the SAE using $\sigma_{\mathrm{sp}}$ at 450,550 , and $700 \mathrm{~nm}$.

The reported model $\mathrm{CF}_{\text {warm }}$ values are the mean of the grid box 2D warm, low cloud fractions, i.e., the fraction of the grid box covered by cloud as viewed from above, and not the fraction of the 3D grid box filled by cloud. Modeled $\mathrm{CF}_{\text {warm }}$ values exclude mid- and high-altitude clouds and include all low-lying warm clouds. This $2 \mathrm{D} \mathrm{CF}$ is roughly equivalent to what would be observed via satellite and is the relevant quantity when interested in short-wave radiative forcing. For all models, 3D cloud fractions are converted to 2D warm, low cloud fractions $\left(\mathrm{CF}_{\text {warm }}\right)$ by assuming a maximum horizontal overlap in clouds at different altitudes within the same model column. As with the observed mean $\mathrm{COT}_{\text {warm }}$ values, the model mean $\mathrm{COT}_{\text {warm }}$ for each grid box is the geometric mean (Sect. 3.2), with one exception, namely for the ALADIN model, where the geometric mean $\mathrm{COT}_{\text {warm }}$ statistic was not calculated, so the median $\mathrm{COT}_{\text {warm }}$ is used instead.

Details on each model are given in Sect. 9.2 of Shinozuka et al. (2020), with brief descriptions given here. WRF-CAM5 is the regional Weather Research and Forecasting model with chemistry (WRF-Chem) coupled with the Community Atmosphere Model v.5 (CAM5) physics (Ma et al., 2014) with updated aerosol activation parameterizations (Zhang et al., $2015 \mathrm{a}, \mathrm{b})$. Here, the model is run at $36 \mathrm{~km}$ horizontal resolution and with 74 vertical layers varying in resolution from 10 to $500 \mathrm{~m}$, with a higher resolution at lower altitudes. Aerosol mass and number are tracked, and aerosol optical properties are calculated with Mie code, assuming an internally mixed aerosol with three aerosol modes (Aitken, accumulation, and coarse). Cloud formation is driven by the shallow convection scheme of Bretherton and Park (2009) and deep convection by the Zhang and McFarlane (1995) scheme with interactive aerosols. Smoke emissions are initialized daily from the Quick Fire Emissions Dataset version 2 (QFED2; Darmenov and Da Silva, 2015), which provides emissions on a daily basis. Smoke is emitted directly into the boundary layer without using any plume injection parameterization. The model is initialized every $5 \mathrm{~d}$ using the National Centers for Environmental Prediction National Centers for Environmental Prediction Final Operational Global Analysis (NCEP FNL) and CAMS reanalysis and runs for $7 \mathrm{~d}$, with the first $2 \mathrm{~d}$ of the run used for spin-up. Data are output at a $3 \mathrm{~h}$ time resolution and aggregated for statistics.

The GEOS (Goddard Earth Observing System v. 5) global model (Molod et al., 2015; Rienecker et al., 2008), often referenced as GEOS-FP (GEOS forward processing), is the forecast system of NASA's Global Modeling and Assimilation Office. It is run in near-real time at approx. $25 \mathrm{~km}$ horizontal resolution $\left(0.25^{\circ}\right.$ in latitude, $0.3125^{\circ}$ in longitude) and 72 vertical layers (of which 25 layers are between the surface and $400 \mathrm{hPa}$ ). The model is initialized every $12 \mathrm{~h}$, with aerosol fields saved every $3 \mathrm{~h}$ and cloud fields hourly. The model is initialized using the Modern-Era Retrospective analysis for Research and Applications, version 2 (MERRA-2), reanalysis product, so it includes an assimilation of observed AOD data. This nudging towards observed AOD should improve this model's simulated $\sigma_{\text {ep }}$ values relative to a free-running model. Like WRF-CAM5, GEOS also uses QFED2 biomass burning emissions and injects the emissions at the surface. It prognostically predicts $\mathrm{CO}$, aerosol component masses, and ambient RH aerosol optical properties using GOCART (Goddard Chemistry Aerosol Radiation and Transport; Chin et al., 2002; Colarco et al., 2010). It assumes that aerosols are externally mixed in modes of fixed mean diameter and standard deviation. Optical properties are computed for each aerosol species included in GOCART and as a function of RH (Randles et al., 2017; Colarco et al., 2014). GEOS assimilates AOD observations from remote sensing every $3 \mathrm{~h}$ (Albayrak et al., 2013). Organic aerosol (OA) concentration is not provided explicitly by GEOS but organic carbon $(\mathrm{OC})$ is. The ratio $\mathrm{OA} / \mathrm{OC}=1.4$ is used to obtain the reported OA concentrations. Both hydrophilic and hydrophobic BC and OC are simulated; the masses reported here are from the sum of the hydrophilic and hydrophobic 
components. Clouds are simulated by the convective parameterization.

The UM-UKCA is a global model that forecasts aerosols and clouds and is run here with a configuration modified from that used in Gordon et al. (2018), which also focused on the SE Atlantic. The model resolution varies with latitude (N216 resolution), with approximately $60 \mathrm{~km} \times 90 \mathrm{~km}$ resolution at the Equator. It has 70 vertical levels between the surface and $80 \mathrm{~km}$ altitude, with a decreasing vertical resolution such that the grid spacing at $1.5 \mathrm{~km}$ altitude is approximately $200 \mathrm{~m}$. It is nudged to horizontal wind fields (not to temperature) from ERA-Interim reanalyses, with nudging starting at $1700 \mathrm{~m}$ above the surface and ramping up to its full strength at $2150 \mathrm{~m}$ altitude. The reanalysis files are read every $6 \mathrm{~h}$, which is also the relaxation time for the nudging. The model is run continuously forward from the initialization used by Gordon et al. (2018). In contrast to WRF-CAM5 and GEOS, biomass burning emissions are updated daily using the FEER (Fire Energetics and Emissions Research) inventory (Ichoku and Ellison, 2014). Smoke aerosol is emitted into and distributed through the boundary layer, such that concentrations are highest at the surface and then taper down to zero at $3 \mathrm{~km}$ above the surface (Gordon et al., 2018). The emitted smoke has an initial log-normal size distribution, with a mode centered on $120 \mathrm{~nm}$ diameter. Sea salt emissions are based on winds, no dust emissions are included, and all other emissions are from the CMIP5 inventories. Aerosols in the model are represented in five sized modes of internally mixed aerosol. Both dry and ambient RH aerosol properties are tracked, with hygroscopicity based on Petters and Kreidenweis (2007). Convection is represented using the pc2 subgrid cloud scheme of Wilson et al. (2008) or is parameterized where it cannot be resolved.

The ALADIN model is a regional climate model developed at Météo-France/Centre National de Recherches Météorologiques (CNRM). The version (v.6) used here has a more detailed treatment specifically of biomass burning aerosols than previous versions (Mallet et al., 2019, 2020). The model has $12 \mathrm{~km}$ horizontal resolution and 91 vertical levels, with 28 located between the surface and $6 \mathrm{~km}$ altitude. Lateral boundary conditions and the initial state for the modeled region come from the ERA-Interim reanalysis (Dee et al., 2011). The model includes TACTIC (Tropospheric Aerosols for Climate In CNRM; Nabat et al., 2020) which includes sea salt, desert dust, sulfates, and black and organic carbon separated in 12 aerosol size bins. All emissions come from the CMIP6 emissions inventory (van Marle et al., 2017), which uses the Global Fire Emissions Database (GFED) for biomass burning emissions. This inventory has realistic biomass burning emissions only through 2014, so these runs were done using constant year 2014 emissions. Furthermore, while the BC emissions from GFED are used, ALADIN uses a fixed particulate organic matter (POM) to organic carbon (OC) ratio, based on Formenti et al. (2003), so secondary organic aerosol formation is not accounted for.
The radiative properties of liquid clouds are calculated in the short wave using the Slingo and Schrecker (1982) parameterizations. The atmospheric physics has recently been revisited, as described in detail in Roehrig et al. (2020). For the model runs used here, the first indirect effect was not simulated, and the cloud droplet effective radius was held fixed at $10 \mu \mathrm{m}$.

\section{Results}

The representativeness of the sampled aerosol properties to that of the entire field campaign period within each deployment year are discussed in Sect. 4.1. Biases in modeled extensive properties ( $\mathrm{CO}, \mathrm{BC}$, and $\mathrm{OA}$ concentrations and $\left.\sigma_{\mathrm{ep}}\right)$ are then discussed in Sect. 4.2, in aerosol intensive properties (SSA, SAE, and AAE) in Sect. 4.3, and in clouds $\left(\mathrm{CF}_{\text {warm }}\right.$ and $\mathrm{COT}_{\text {warm }}$ ) in Sect. 4.4.

\subsection{Representativeness of observations}

As discussed above, a goal of flying along the routine track was to acquire data representative of the observation period rather than, e.g., targeting high-concentration plumes. With limited flight hours and in situ sampling from the P-3 at specific altitudes on each flight track, the number of minutes spent in many of the grid boxes and altitude bins was of the order of $1-2 \mathrm{~h}$ in total over the approximately month-long campaign in each year; for some grid boxes and altitudes, it was $<20 \mathrm{~min}$ (Fig. 2). The amount of data collected is particularly limited at the far reach of the comparison transects, i.e., the northwesternmost and northernmost grid boxes in the 2016 diagonal and meridional 1 transects and the southernmost grid boxes in the 2017 and 2018 meridional 2 transect. For the zonal transect, in situ sampling was extremely limited, with significant sampling only in 2017 in the westernmost zonal grid boxes 1 and 2 (from the suitcase flights to Ascension Island; Redemann et al., 2021) and in grid box 11, which intersects with the meridional 2 routine track.

Figures 3 and 4 show the ratios of the average of $\sigma_{\text {ep }}$ in the model for those times when the aircraft was present for sampling (in situ for the P-3 and of the full column below the aircraft for the HSRL-2 on the ER-2 aircraft; i.e., sampled) to the daytime average for the full duration of the field deployment that year (climatology). Shinozuka et al. (2020) tested the representativeness of the observed column properties to the full month of the 2016 campaign period using as a metric the mean bias (MB) and the root mean squared deviation (RMSD) of CO and aerosol properties, along with their ratio (percent) to the monthly mean. They calculated MB and RMSD across grid boxes for data within broad altitude ranges, including the range of 3-6 km. Here we test for representativeness through the ratio of the means in $1 \mathrm{~km}$ deep altitude bins for each grid box (colored dots in Figs. 3 and 4). This metric is the same as $\mathrm{MB}(\%) / 100+1$. This selection was made because the RMSD gives greater weight to 
individual large deviations, and the focus of this paper is on the average bias in observed values, which will most directly scale with a mean bias in DARE. In addition to calculating the mean bias for each grid box, the transect mean bias is calculated across all grid boxes in a given comparison transect and altitude bin (open circles in Figs. 3 and 4).

Both WRF-CAM5 and GEOS indicate that $\sigma_{\text {ep }}$ at plume altitudes $(2-5 \mathrm{~km})$ along the 2016 diagonal transect is, on average, somewhat higher during the times sampled by the P-3 than it is for the monthly average (Fig. 3a, b), consistent with the findings of Shinozuka et al. (2020) in their AOD comparisons. The transect mean ratio is up to a factor of 1.5, depending on the altitude and model, with WRF-CAM5 showing larger and less variable differences than GEOS. Values of $\sigma_{\mathrm{ep}}$ at the times measured by the HSRL-2 from the ER-2 better represented the month-long average (Fig. 3c, d), with mostly moderate differences (ratios of 0.8-1.2) according to GEOS. In WRF-CAM5, the ratio of the sampled $\sigma_{\mathrm{ep}}$ to the monthlong climatology increases with altitude from 2 to $6 \mathrm{~km}$, indicating that the sampled plume may have been centered at higher altitudes than was typical for that month.

The 2016 meridional 1 transect is not a routine flight track, so sampling was on flights targeting the smoke plume and/or specific cloud fields and includes fewer observations than the diagonal transect (Fig. 2). As such, it was not expected to be as representative of the monthly average. Despite this, in the heart of the plume (2-4 km altitude), sampled values of $\sigma_{\mathrm{ep}}$ were generally within $0.9-1.2$ of the month-long climatology in both models (Fig. 3e, f). Both models also indicate that smoke concentrations sampled by the P-3 at higher altitudes $(4-6 \mathrm{~km})$ are much higher than was typical. Values of $\sigma_{\mathrm{ep}}$ from times when the HSRL-2 could make observations from the ER-2 are more consistently representative of the month-long average, with transect mean ratios in most altitude bins above $2 \mathrm{~km}$ and between 0.8 and 1.2 (Fig. $3 \mathrm{~g}$, h). As for the 2016 diagonal transect, the WRF-CAM5 simulations indicate that the sampled plumes were centered at a higher altitude than is typical for this month.

The two models give very different results regarding the representativeness of both the in situ and HSRL-2 values of $\sigma_{\text {ep }}$ to the month-long climatologies along the meridional 2 transect in both 2017 and 2018. The WRF-CAM5 model indicates that $\sigma_{\text {ep }}$ in the 2-6 km altitude range for both in situ and HSRL-2 sampling was generally $0.8-1.2$ times that of the month-long climatology and was almost always within a factor of 2 for individual grid boxes in the $2-5 \mathrm{~km}$ altitude range (Fig. 4a, c, e, g). GEOS simulations, however, show significantly higher values of $\sigma_{\mathrm{ep}}$ in the P-3 sampling average than in the month-long climatology for almost all grid boxes and altitudes. It also shows much greater variability across the different grid boxes in the sampling bias. As noted in Sect. 2.2, $\sigma_{\text {ep }}$ in GEOS had a higher relative variability than observed along the 2017 meridional 2 transect, whereas WRF-CAM5 had similar variability to that observed and, therefore, may present a better test of the representativeness of the observations.

Overall, the values of HSRL- $2 \sigma_{\text {ep }}$ sampled by the HSRL2 are more representative of the climatology than the in situ values, likely because there simply were more samples gathered by the HSRL-2. Typically, the HSRL-2 retrievals are available in full curtains from just below the aircraft flight level to either the surface or cloud top from the southbound leg. In 2016, the HSRL-2 was on the ER-2, which always flew fully above the plume, so it captured the full vertical extent of the plume. In 2017 and 2018, when it was on board the P-3, the HSRL-2 generally could capture most of the plume vertical extent during the outbound leg of routine flights along the meridional 2 transect, since they were flown at high altitude. A combination of in situ measurements and HSRL-2 measurements would then be collected on the return, the northbound leg, which was flown at a variety of altitudes. As such, there are more data from the HSRL-2 than from the in situ measurements to contribute to comparison statistics.

In 2016, the ER-2 flew along the zonal transect on several flights (Fig. 1). WRF-CAM5 and GEOS both simulate average $\sigma_{\mathrm{ep}}$ from HSRL-2 sampling times that are, on average, within $0.8-1.2$ of the month-long average in the $2-5 \mathrm{~km}$ altitude range (Fig. 5). This ratio is both more positive and more variable across grid boxes for $4-5 \mathrm{~km}$ than for $2-4 \mathrm{~km}$ or 5-6 km. This likely reflects the sampling coincidence with individual elevated plumes during the ER-2 flights.

In 2017, $\sigma_{\text {ep }}$ from both the in situ and HSRL-2 sampling times poorly represent the August average for most grid boxes and altitudes (Fig. S4), and in 2018 the P-3 did not fly along the zonal transect. For this reason, comparisons are not made of modeled and measured aerosols along the zonal transect. Clouds $\left(\mathrm{CF}_{\text {warm }}\right.$ and $\left.\mathrm{COT}_{\text {warm }}\right)$ were measured by satellite on all field campaign days, so comparisons of these fields along the zonal transect are included for all 3 years.

Tests of the representativeness of $\sigma_{\mathrm{ep}}$ measured from the aircraft addresses sampling biases in the concentration of the aerosol. In the context of DARE calculations, an additional question is whether the optical properties of the sampled aerosol are representative. Aerosol SSA in particular is a strong controlling factor for the sign and magnitude of DARE. In the WRF-CAM5 model, SSA of the aerosol in the 2-6 km altitude range at the times when there are in situ measurements from the P-3 are generally within 0.01 of the month-long average for that campaign year (not shown). SSA deviations from the average were a bit larger in the GEOS model in some grid boxes at these altitudes. In particular, in the meridional 2 transect, the aerosol measured in the two southernmost grid boxes in 2017 has an anomalously low SSA (by about 0.03-0.04), and in 2018, the SSA for 4-5 km is similarly anomalously high. These two grid boxes were the most undersampled in the meridional 2 transect, since they were the farthest from the deployment base. As will be seen below, the observed SSA varied more than the WRF-CAM5- 

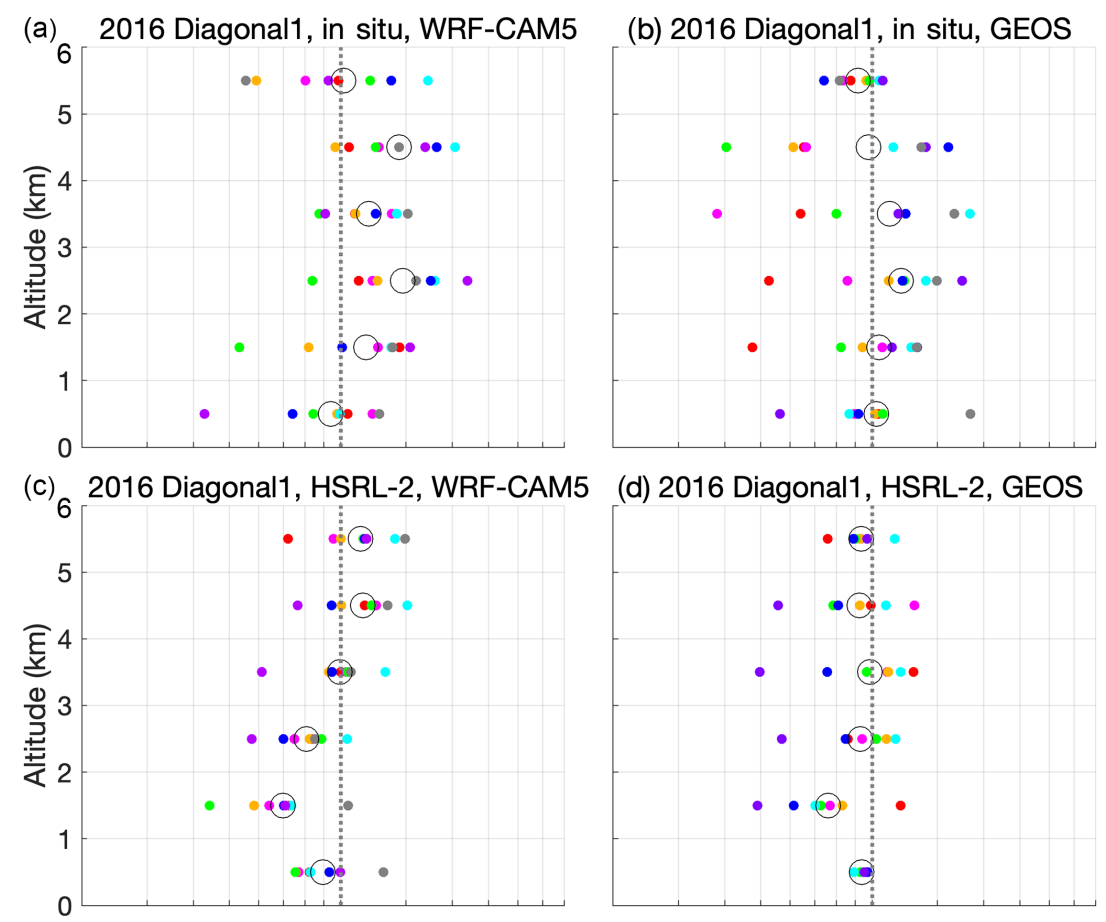

(d) 2016 Diagonal1, HSRL-2, GEOS
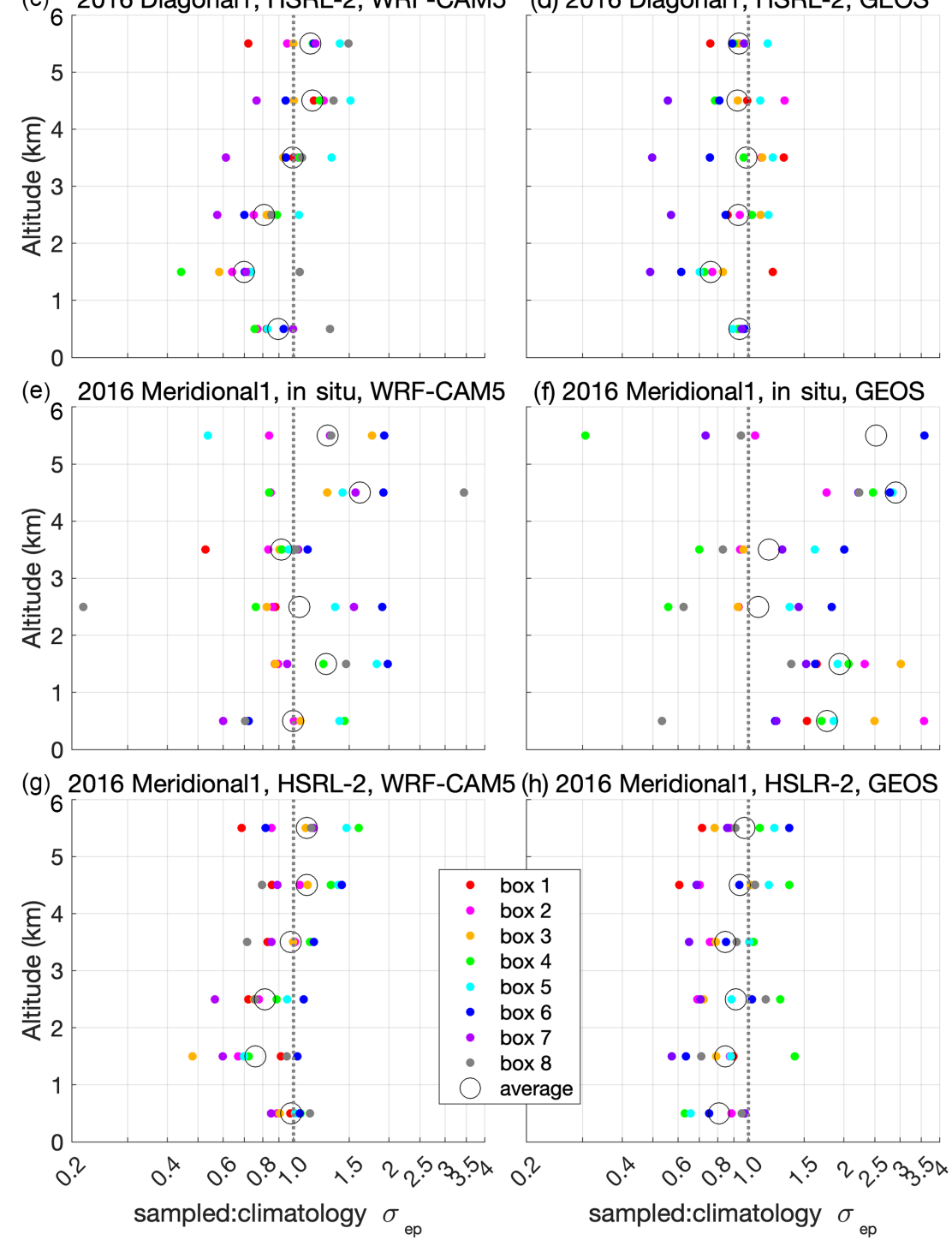

Figure 3. The ratio in the mean of $\sigma_{\mathrm{ep}}$ modeled by WRF-CAM5 (a, $\left.\mathbf{c}, \mathbf{e}, \mathbf{g}\right)$ and GEOS $(\mathbf{b}, \mathbf{d}, \mathbf{f}, \mathbf{h})$ for only those times when observed

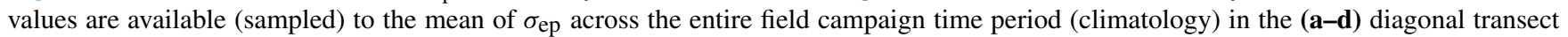
in September 2016 and the (e-h) meridional 1 transect in September 2016. The representativeness of both the in situ (a, b, e, f) and HSRL-2 $(\mathbf{c}, \mathbf{d}, \mathbf{g}, \mathbf{h})$ observations of $\sigma_{\mathrm{ep}}$ are shown. The color dots show the means within individual comparison grid boxes; open circles are the mean across all grid boxes in that transect. Note that, in panel (f), there is a single grid box data point that is off scale (sampled : climatology $\left.\sigma_{\mathrm{ep}}>4\right)$. 

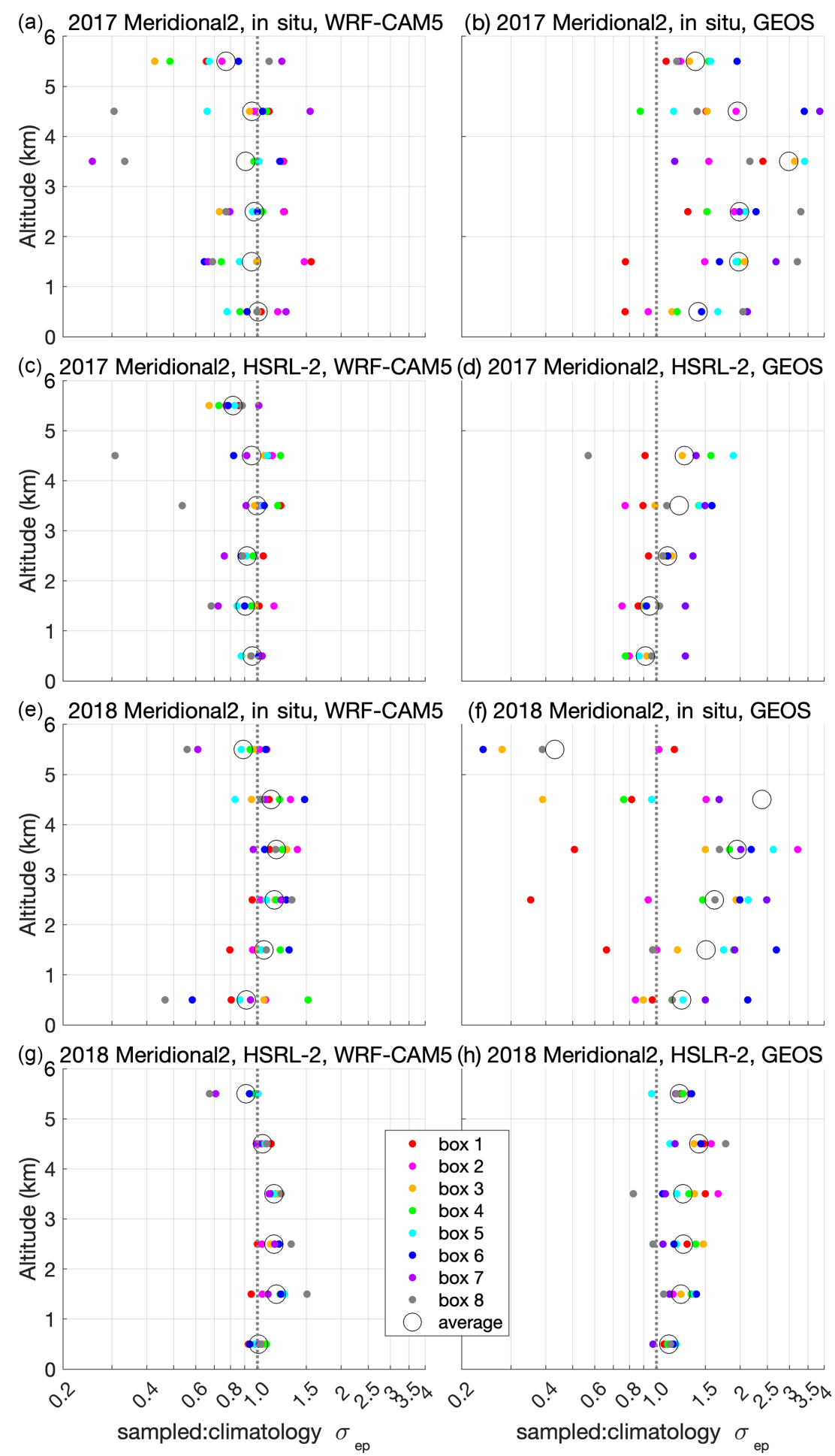

Figure 4. As in Fig. 3 but showing the representativeness of sampled $\sigma_{\mathrm{ep}}$ values to the month-long average of $\sigma_{\mathrm{ep}}$ across the 2017 meridional 2 and 2018 meridional 2 transects. 


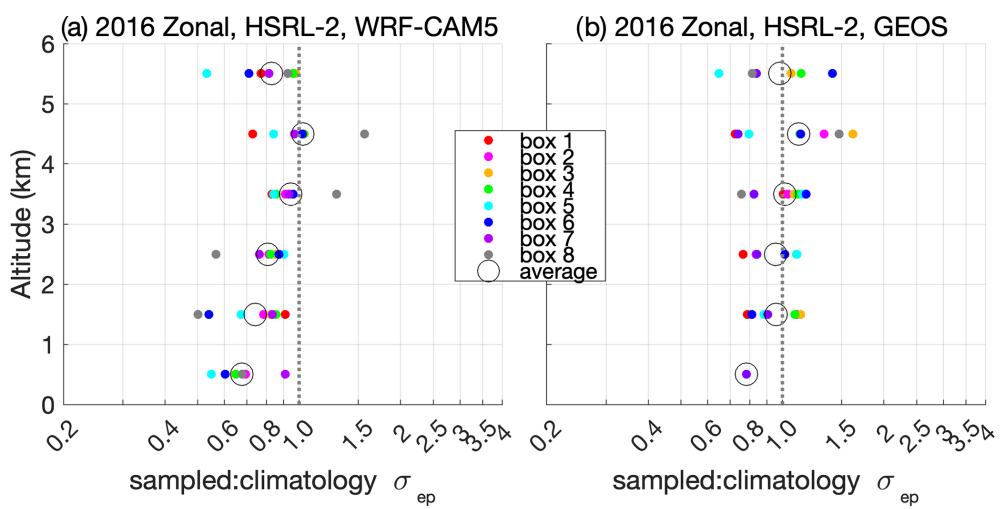

Figure 5. As in Fig. 3 but for the 2016 zonal transect and for the HSRL-2 retrievals of $\sigma_{\text {ep }}$ only.

modeled SSA, but less than the GEOS-modeled SSA, so the apparent representativeness of the sampled aerosol SSA may be a reflection of an inherent invariance in SSA in the models rather than an indication of the actual representativeness of the sampled aerosol optical properties.

\subsection{Biases in plume extensive properties}

Biomass burning smoke from the African continent is advected over the SE Atlantic largely in the free troposphere, and this is reflected in the observed profiles of $\sigma_{\mathrm{ep}}$ across the comparison transects (Figs. 6-9). This continental air mass carries water vapor with it (Pistone et al., 2021), though RH in the plume is still generally less than $60 \%$ in September 2016 and August 2017 and less than $70 \%$ in October 2018, except in the two northernmost grid boxes of the meridional 2 transect in 2018 (Figs. 10 and 11). The impact of humidification on $\sigma_{\mathrm{ep}}$ and on this comparison is discussed in Sect. 4.2.3.

Analogous figures showing profiles of the other extensive variables can be found in the Supplement (see Figs. S5 for $\mathrm{CO}, \mathrm{S} 6$ for $\mathrm{BC}$, and $\mathrm{S} 7$ for $\mathrm{OA}$ ). In the sections below, the modeled-to-observed ratios of these parameters are discussed; these should be viewed in the context of the smoke plume distribution (Figs. 6-9), since large biases in the core of the smoke plume have much greater impact than large biases where concentrations are low.

\subsubsection{Carbon monoxide (CO)}

Carbon monoxide does not lead to climate forcing, but it is an excellent and relatively inert tracer of biomass burning emissions and so is discussed here. WRF-CAM5-modeled CO at plume altitudes $(2-5 \mathrm{~km})$ is typically around $70 \%$ to $80 \%$ of that observed, with a slightly greater low bias in 2018 (Table 1 and Fig. S5). GEOS also has a low bias in $\mathrm{CO}$ at plume altitudes, but the biases are somewhat smaller and were more variable than for WRF-CAM5. In 2016 and 2017, the GEOS $\mathrm{CO}$ concentrations are increasingly biased low going from $2 \mathrm{~km}$ to $5 \mathrm{~km}$ altitude. In 2018, the GEOS biases are more consistent (0.6-0.8; Table 1) across almost all altitudes and grid boxes. The GEOS-modeled plume extends to lower altitudes than observed (Fig. S5), so that, for the 1-2 km altitude bin, the overall low bias in modeled CO is effectively offset by the contribution of the lower part of the modeled plume. Near the surface $(0-1 \mathrm{~km}), \mathrm{CO}$ in both WRF-CAM5 and GEOS is biased as low. CO was not reported for the UMUKCA and ALADIN models. The biases in WRF-CAM5 and GEOS suggest underestimates in CO emissions, or possibly in the efficiency of transport of the biomass burning plume over the SE Atlantic from the burning source regions, since $\mathrm{CO}$ is not affected by scavenging processes. An earlier evaluation, by Das et al. (2017), of GEOS simulations of the SE Atlantic biomass burning plume compared to CloudAerosol Lidar with Orthogonal Polarization (CALIOP) lidar profiles indicated that, for that model, transport biases are the more likely explanation.

\subsubsection{Aerosol $\mathrm{BC}$ and $\mathrm{OA}$ masses}

During ORACLES, the aerosol components $\mathrm{BC}$ and OA were measured in situ and were reported for the WRFCAM5, GEOS, and UM-UKCA models. In addition to emissions and transport processes, accurate simulation of aerosol concentrations requires simulating loss processes, including dry and wet deposition and any in-atmosphere production or loss. During the biomass burning season (July-October), south of $\sim 2-3^{\circ} \mathrm{S}$ latitude in the SE Atlantic, there are few clouds with tops above $2 \mathrm{~km}$, with small drop sizes further discouraging the wet scavenging of aerosols from the free troposphere (Adebiyi et al., 2020). For the 2016 diagonal comparison grid boxes, and for all but the northernmost two to three meridional 2 grid boxes in 2017 and 2018, almost all wet scavenging occurs in moist convection over the central African continent (Ryoo et al., 2021). Once over the ocean, wet deposition likely plays essentially no role in driving aerosol gradients in latitude and longitude above the marine boundary layer across our comparison transects, except possibly in meridional 2 grid boxes $1-3$ (located between $0.5^{\circ} \mathrm{N}$ 

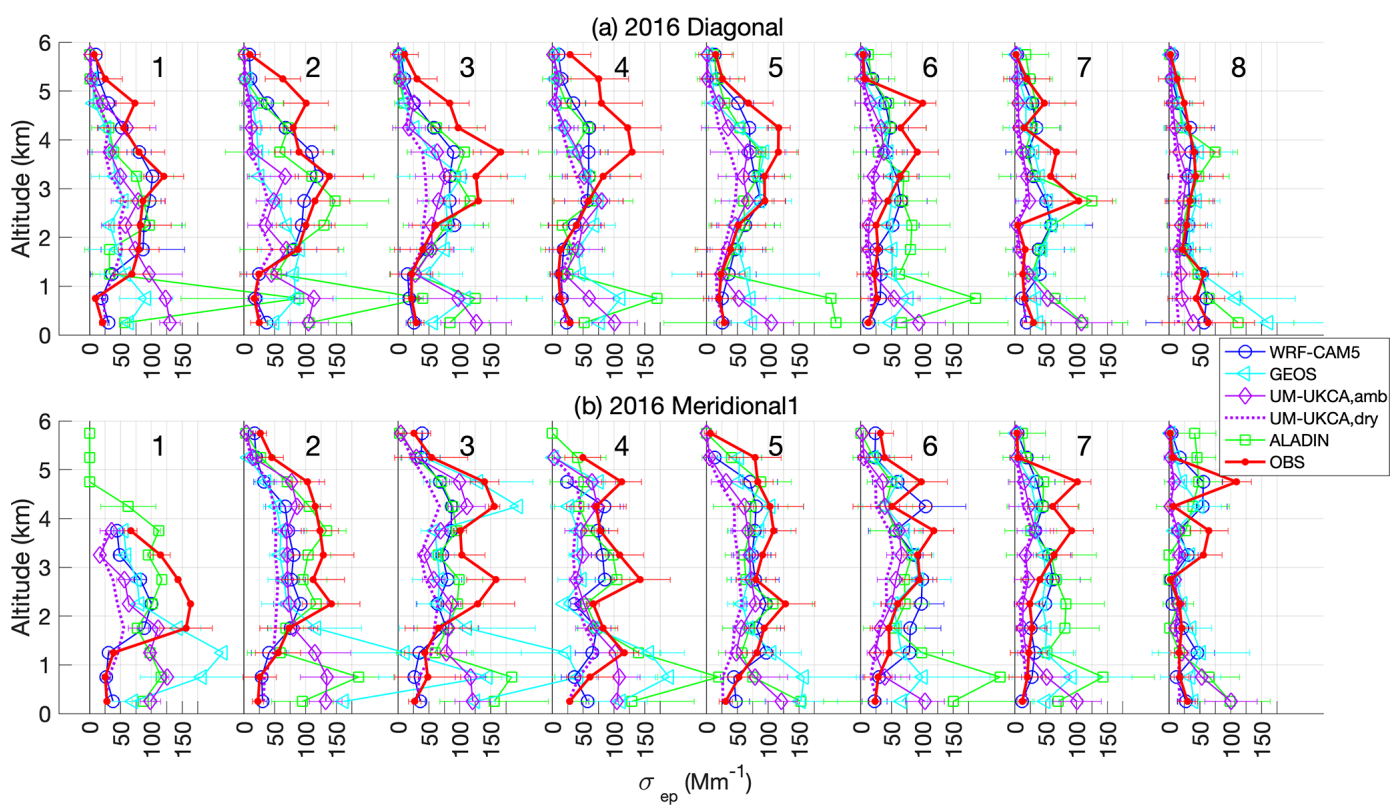

Figure 6. Profiles of $\sigma_{\mathrm{ep}}$, as observed in situ from the P-3 aircraft (low RH; $530 \mathrm{~nm}$ ), and modeled (ambient RH and, for UM-UKCA only, dry; $550 \mathrm{~nm}$ ) for (a) the 2016 diagonal transect and (b) 2016 meridional 1 transect. All values are means and standard deviations calculated across only those times and locations when in situ measurements were made. Grid boxes are numbered as in Fig. 1.

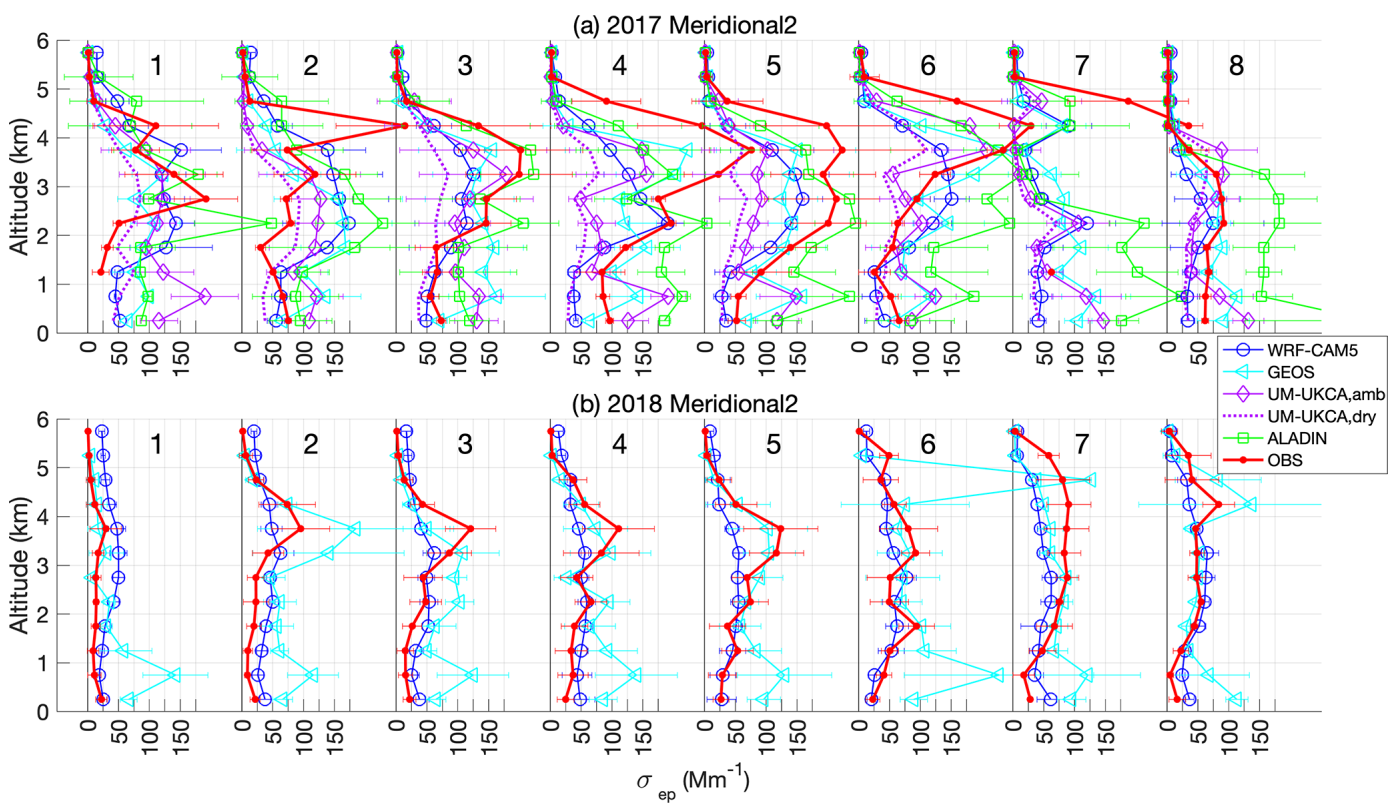

Figure 7. As in Fig. 4 but for the (a) 2017 and (b) 2018 meridional 2 transect.

and $5.5^{\circ} \mathrm{S}$ ). Fall speeds for accumulation-mode aerosols are, at most, a few meters per week; given that the biomass burning smoke is largely advected over the ocean at altitudes $>2 \mathrm{~km}$, dry scavenging rates will also be negligible. The vertical position of the plume and how it changes with transport is, therefore, dominated by the overall atmospheric convection and subsidence.
$\mathrm{BC}$ and $\mathrm{OA}$ are the primary constituents of biomass burning aerosol, so their distribution is a direct measure of the smoke plume intensity and location. On average, the observed core of the plume is centered at higher altitudes moving towards the edges of the plume (i.e., the southern end of the meridional 1 transect and the southeastern end of the diagonal transect in 2016 and the northern end of the meridional 2 transect in 2017 and 2018), and it covers a broader 

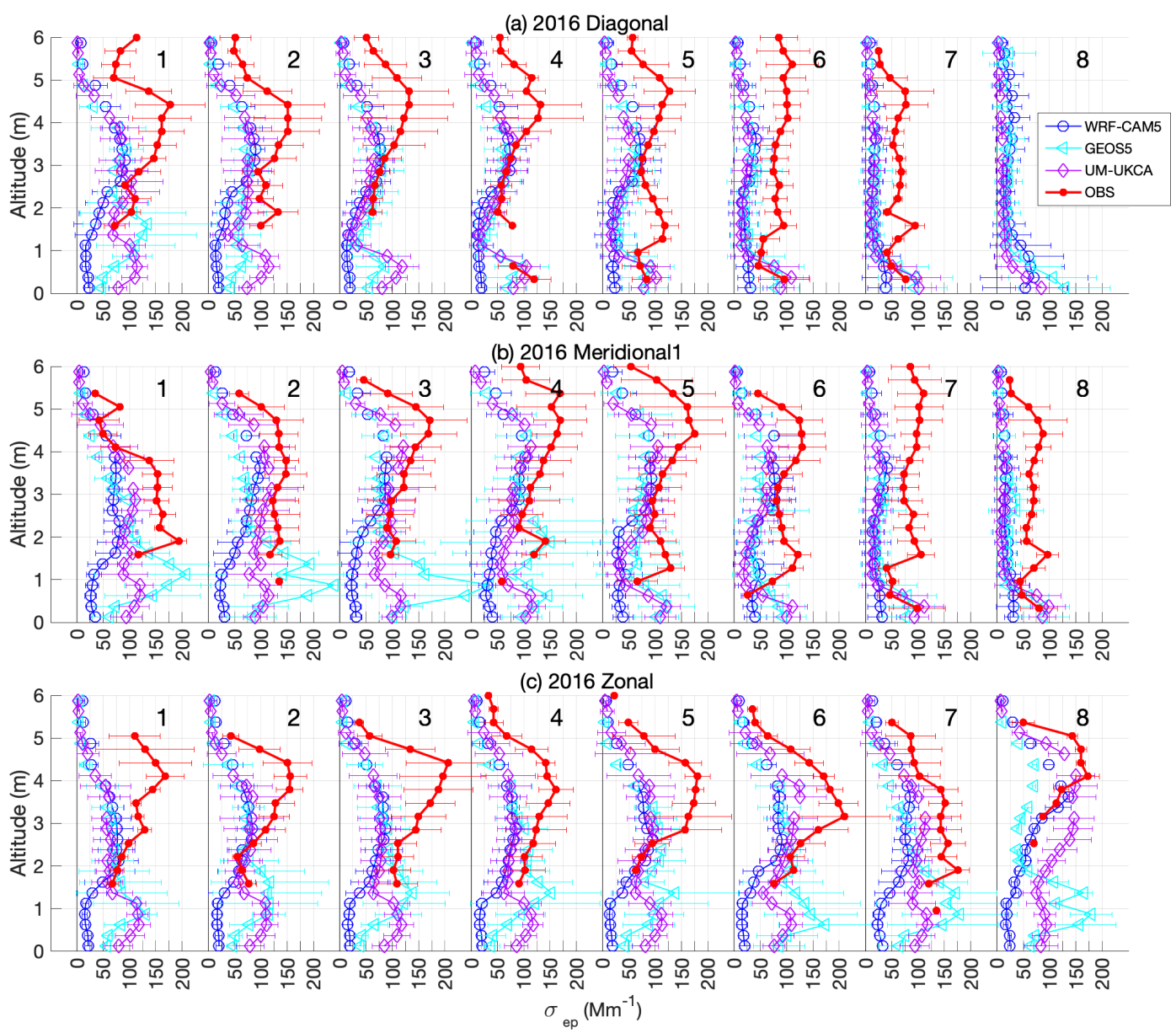

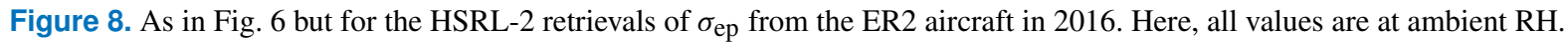
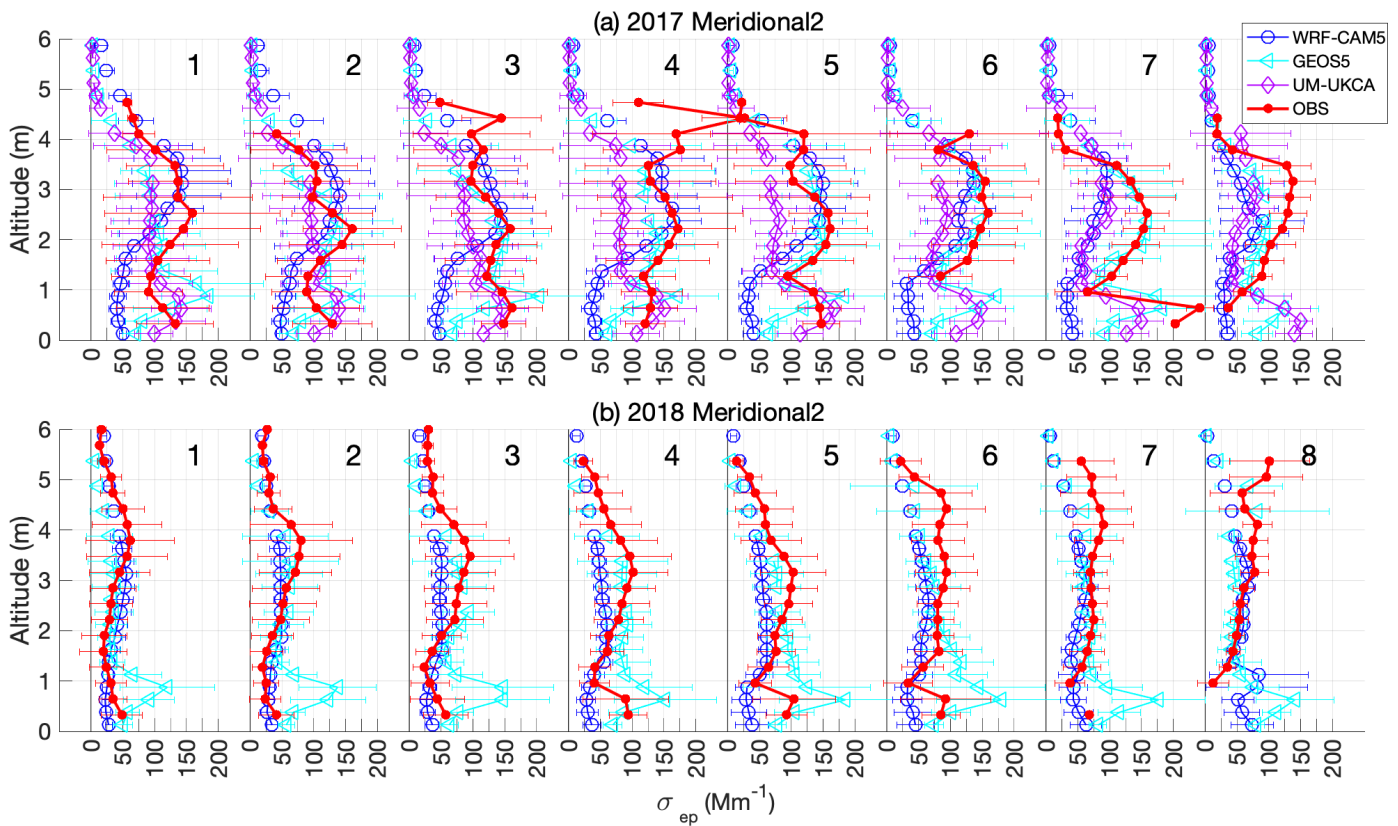

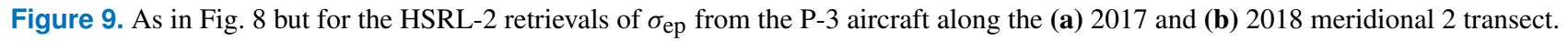



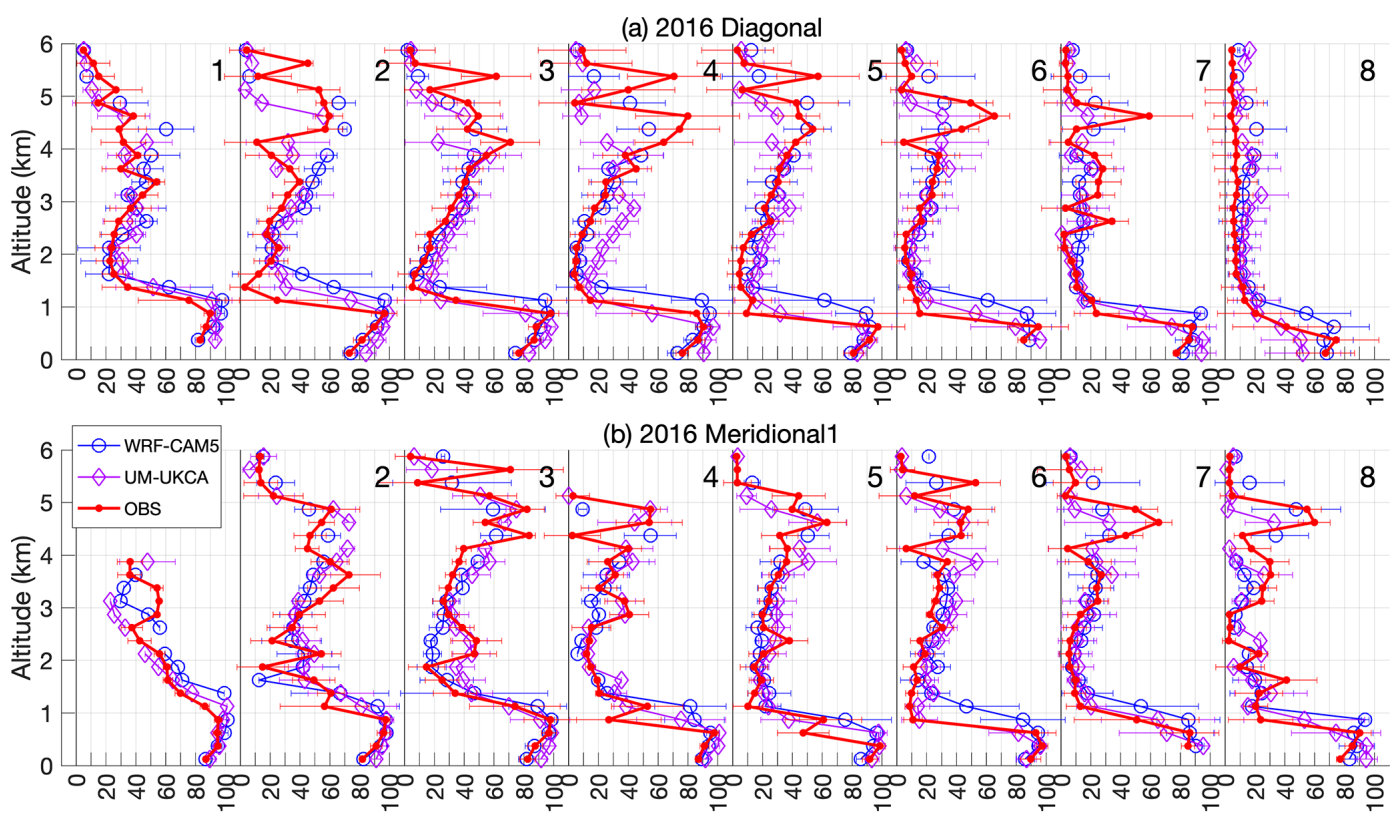

Relative Humidity (\%)

Figure 10. As in Fig. 6 but for RH and at $250 \mathrm{~m}$ vertical resolution rather than $500 \mathrm{~m}$ vertical resolution.
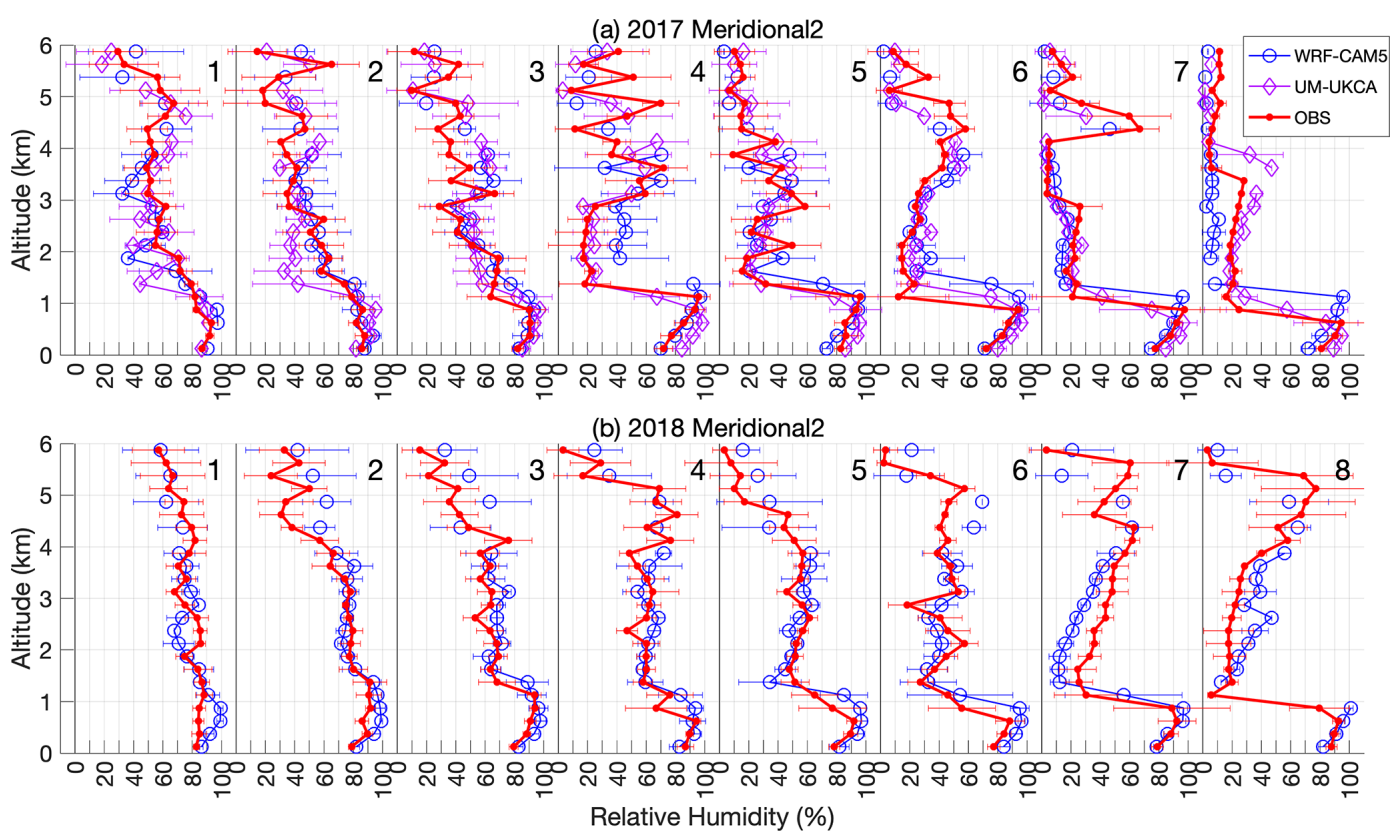

Figure 11. As in Fig. 10 but for RH along the (a) 2017 and (b) 2018 meridional 2 transect.

vertical extent towards the geographic center of the plume (Figs. 6-9, S6, and S7). In 2016 in particular, this tendency is not captured by any of the models, which have a vertically broader plume across all grid boxes and, in the case of GEOS and UM-UKCA especially, place the plume core at too low an altitude, though the plume top height is nonetheless captured properly in some cases (Shinozuka et al., 2020).
This overly vertical diffuse plume in WRF-CAM5 is consistent with underestimates in $\mathrm{BC}$ concentrations in the core of the plume (3-4 km altitude in 2016 and $2018 ; 3.5-5 \mathrm{~km}$ in 2017; Figs. 12 and 13), overestimates above this, and smaller biases for the $2-3 \mathrm{~km}$ altitude bin. The pattern of bias is similar for GEOS, except that it does a better job of reproducing BC concentrations aloft at the southern end of the 2016 meridional 1 transect (Fig. 12) and has greater high biases at 
Table 1. Median across each comparison transect of modeled-to-observed ratios for extensive parameters averaged within $1 \mathrm{~km}$ deep altitude bins. Shown are median biases for CO concentrations, BC mass, OA mass, and $\sigma_{\mathrm{ep}}$ as measured in situ from the P-3 aircraft. Observed values of $\sigma_{\mathrm{ep}}$ are at $530 \mathrm{~nm}$ and for low $\mathrm{RH}(<40 \%)$ aerosol, whereas modeled values are at $550 \mathrm{~nm}$ and ambient RH, except for UM-UKCA, which reports $\sigma_{\mathrm{ep}}$ for both the dry and ambient $\mathrm{RH}$ aerosol.

\begin{tabular}{|c|c|c|c|c|c|c|c|c|c|c|c|c|c|c|c|c|c|}
\hline & \multicolumn{4}{|c|}{ WRF-CAM5 } & \multicolumn{4}{|c|}{ GEOS } & \multicolumn{6}{|c|}{ UM-UKCA } & \multicolumn{3}{|c|}{ ALADIN } \\
\hline & 2016 & 2016 & 2017 & 2018 & 2016 & 2016 & 2017 & 2018 & \multirow{2}{*}{\multicolumn{2}{|c|}{$\begin{array}{l}2016 \\
\text { Diag }\end{array}$}} & \multirow{2}{*}{\multicolumn{2}{|c|}{$\begin{array}{l}2016 \\
\text { Mer1 }\end{array}$}} & \multicolumn{2}{|c|}{2017} & 2016 & 2016 & 2017 \\
\hline & Diag & Mer1 & Mer2 & Mer2 & Diag & Mer1 & Mer2 & Mer2 & & & & & & & Diag & Mer1 & Mer2 \\
\hline \multicolumn{18}{|c|}{ Carbon monoxide (CO) } \\
\hline $5-6 \mathrm{~km}$ & 0.60 & 0.80 & 0.72 & 0.74 & 0.76 & 0.80 & 1.00 & 0.82 & & & & & & & & & \\
\hline $4-5 \mathrm{~km}$ & 0.70 & 0.82 & 0.60 & 0.69 & 0.65 & 0.87 & 0.73 & 0.76 & & & & & & & & & \\
\hline $3-4 \mathrm{~km}$ & 0.74 & 0.72 & 0.87 & 0.65 & 0.72 & 0.91 & 0.89 & 0.66 & & & & & & & & & \\
\hline $2-3 \mathrm{~km}$ & 0.81 & 0.72 & 0.72 & 0.68 & 1.05 & 0.90 & 0.89 & 0.77 & & & & & & & & & \\
\hline $1-2 \mathrm{~km}$ & 0.76 & 0.68 & 0.68 & 0.68 & 1.01 & 1.02 & 1.12 & 0.77 & & & & & & & & & \\
\hline $0-1 \mathrm{~km}$ & 0.83 & 0.70 & 0.80 & 0.83 & 0.85 & 0.93 & 0.73 & 0.85 & & & & & & & & & \\
\hline \multicolumn{18}{|c|}{ Black carbon (BC) mass } \\
\hline $5-6 \mathrm{~km}$ & 1.09 & 5.01 & 3.30 & 12.59 & 1.21 & 2.15 & 4.16 & 1.84 & & 59 & & & & & & & \\
\hline $4-5 \mathrm{~km}$ & 0.84 & 1.21 & 0.47 & 1.20 & 0.50 & 1.28 & 0.50 & 1.40 & & 39 & & & & & & & \\
\hline $3-4 \mathrm{~km}$ & 0.82 & 0.84 & 0.83 & 0.79 & 0.85 & 0.93 & 1.11 & 1.25 & & 55 & & & & & & & \\
\hline $2-3 \mathrm{~km}$ & 1.04 & 0.90 & 0.97 & 1.28 & 1.79 & 0.90 & 1.11 & 1.81 & & 86 & & & & & & & \\
\hline $1-2 \mathrm{~km}$ & 0.89 & 0.79 & 0.95 & 0.90 & 2.60 & 2.57 & 2.22 & 1.87 & & 05 & & & & 23 & & & \\
\hline $0-1 \mathrm{~km}$ & 1.68 & 0.88 & 1.17 & 1.03 & 3.48 & 3.09 & 1.06 & 4.82 & & 77 & & & & & & & \\
\hline \multicolumn{18}{|c|}{ Organic aerosol (OA) mass } \\
\hline $5-6 \mathrm{~km}$ & 0.71 & 2.50 & 10.08 & 14.56 & 0.81 & 2.37 & 7.02 & 2.80 & & 37 & & & & & & & \\
\hline $4-5 \mathrm{~km}$ & 0.71 & 1.25 & 2.28 & 1.58 & 0.60 & 1.82 & 3.59 & 2.86 & & 51 & & & & 32 & & & \\
\hline $3-4 \mathrm{~km}$ & 0.84 & 0.77 & 1.24 & 1.36 & 1.37 & 1.33 & 2.69 & 3.39 & & 68 & & & & 17 & & & \\
\hline $2-3 \mathrm{~km}$ & 1.09 & 0.89 & 1.23 & 2.61 & 3.31 & 1.58 & 2.28 & 6.49 & & 98 & & & & 39 & & & \\
\hline $1-2 \mathrm{~km}$ & 0.96 & 0.89 & 0.92 & 4.46 & 4.48 & 4.38 & 3.05 & 14.63 & & 46 & & & & 20 & & & \\
\hline $0-1 \mathrm{~km}$ & 1.35 & 0.79 & 2.02 & 6.40 & 6.71 & 7.29 & 1.92 & 45.33 & & 00 & & & & 31 & & & \\
\hline \multicolumn{18}{|c|}{ Aerosol light extinction $\left(\sigma_{\mathrm{ep}}\right)$} \\
\hline & & & & & & & & & Dry & $\mathrm{Amb}$ & Dry & Amb & Dry & Amb & & & \\
\hline $5-6 \mathrm{~km}$ & 0.88 & 0.89 & 3.30 & 7.12 & 0.29 & 0.68 & 1.71 & 0.80 & 0.09 & 0.12 & 0.18 & 0.24 & 0.57 & 0.73 & 0.34 & 0.35 & 0.76 \\
\hline $4-5 \mathrm{~km}$ & 0.64 & 0.70 & 0.49 & 0.83 & 0.32 & 0.69 & 0.28 & 0.87 & 0.18 & 0.27 & 0.37 & 0.57 & 0.24 & 0.41 & 0.52 & 0.65 & 0.90 \\
\hline $3-4 \mathrm{~km}$ & 0.70 & 0.66 & 0.63 & 0.57 & 0.57 & 0.57 & 0.72 & 0.89 & 0.31 & 0.44 & 0.40 & 0.54 & 0.40 & 0.69 & 0.70 & 0.74 & 1.24 \\
\hline $2-3 \mathrm{~km}$ & 1.08 & 0.77 & 0.90 & 1.16 & 1.11 & 0.59 & 0.92 & 1.25 & 0.52 & 0.69 & 0.43 & 0.56 & 0.54 & 0.73 & 1.09 & 0.80 & 2.00 \\
\hline $1-2 \mathrm{~km}$ & 1.13 & 1.01 & 0.92 & 1.34 & 2.03 & 2.24 & 1.64 & 1.89 & 0.72 & 1.14 & 0.69 & 0.85 & 0.74 & 1.23 & 1.41 & 1.17 & 2.80 \\
\hline $0-1 \mathrm{~km}$ & 1.10 & 1.18 & 0.59 & 1.63 & 3.46 & 4.16 & 1.62 & 5.34 & 0.97 & 4.22 & 0.89 & 3.34 & 0.51 & 1.81 & 6.81 & 4.66 & 2.32 \\
\hline
\end{tabular}

the bottom of the plume (2-3 km altitude bin). UM-UKCA $\mathrm{BC}$ in the 2016 diagonal transect in the $3-5 \mathrm{~km}$ altitude range is about half that measured; in the 2016 meridional 1 and 2017 meridional 2 transects, biases in modeled BC are smaller (generally $0.70-0.85$ at plume altitudes; Figs. 12 and 13; Table 1). In 2016, as with GEOS, the fact that the plume is too low in altitude results in large negative biases at the highest altitude, but there is a low bias below this that decreases from 5 to $2 \mathrm{~km}$ altitude. Both GEOS and UM-UKCA overestimate the amount of BC (i.e., biomass smoke) that mixes into the marine boundary layer, with consequences for derived forcing through aerosol-cloud interactions.

In several of the transects, above $5 \mathrm{~km}$ the observed $\mathrm{BC}$ and OA concentrations effectively go to zero (Figs. S6 and S7), whereas, for all models, the aerosol concentrations taper off more slowly, possibly due to coarse vertical resolution at these heights (e.g., WRF-CAM5 resolution is $\sim 500 \mathrm{~m}$ at
$6 \mathrm{~km})$. This produces very high modeled-to-observed ratios for the $5-6 \mathrm{~km}$ altitude bin. However, this bias will have little effect on column aerosol mass and, therefore, aerosol forcing because concentrations are so low. More consequential is the high bias in modeled $\mathrm{BC}$ and $\mathrm{OA}$ in the $2-3 \mathrm{~km}$ altitude bin. This high bias is particularly pronounced for GEOS for the 2016 comparison transects. The tendency of GEOS to place aerosol too low in altitude can also be seen in the large high bias in boundary layer $(\sim 0-2 \mathrm{~km}) \mathrm{BC}$ and OA concentrations (Figs. 12 and 13), as reported for the 2016 campaign by Shinozuka et al. (2016); as in UM-UKCA, this would lead to an overestimate in modeled forcing through aerosol-cloud interactions.

The marine environment can be a source of OA, but is only a small component of accumulation mode aerosol in the subtropics (Heald et al., 2008; Shank et al., 2012; Twohy et al., 2013), and in the models included here the ocean is not a 


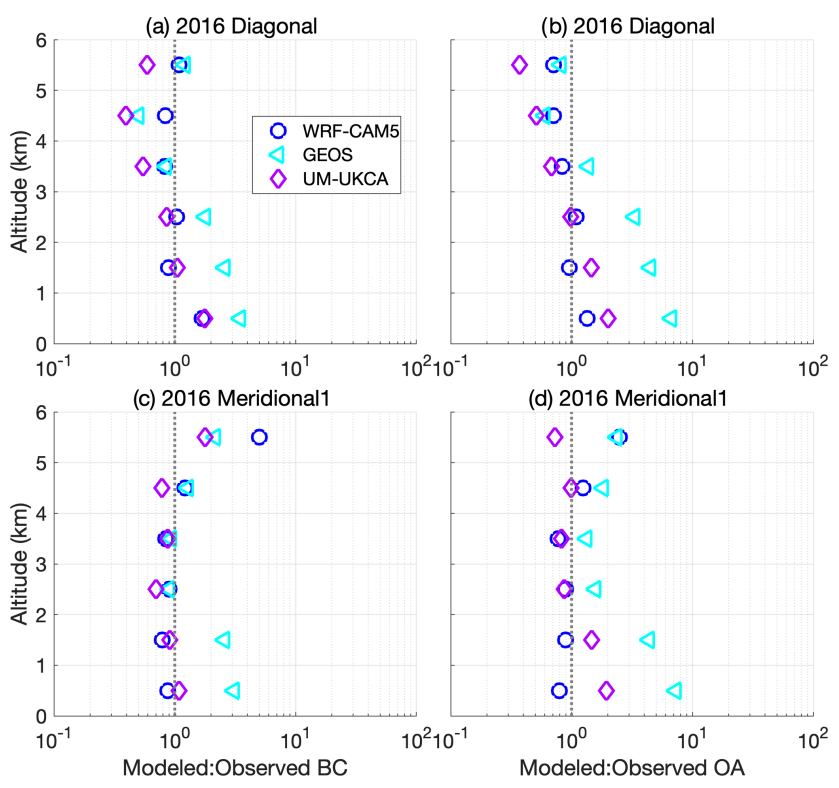

Figure 12. Mean ratio of modeled-to-observed BC mass (a, c) and OA mass (b, d) across all eight grid boxes along the 2016 diagonal $(\mathbf{a}, \mathbf{b})$ and meridional $1(\mathbf{c}, \mathbf{d})$ comparison transects. The ratios for individual grid boxes, along with these means, can be seen in the Supplement (Fig. S8 for WRF-CAM5, Fig. S10 for GEOS, and Fig. S12 for UM-UKCA).

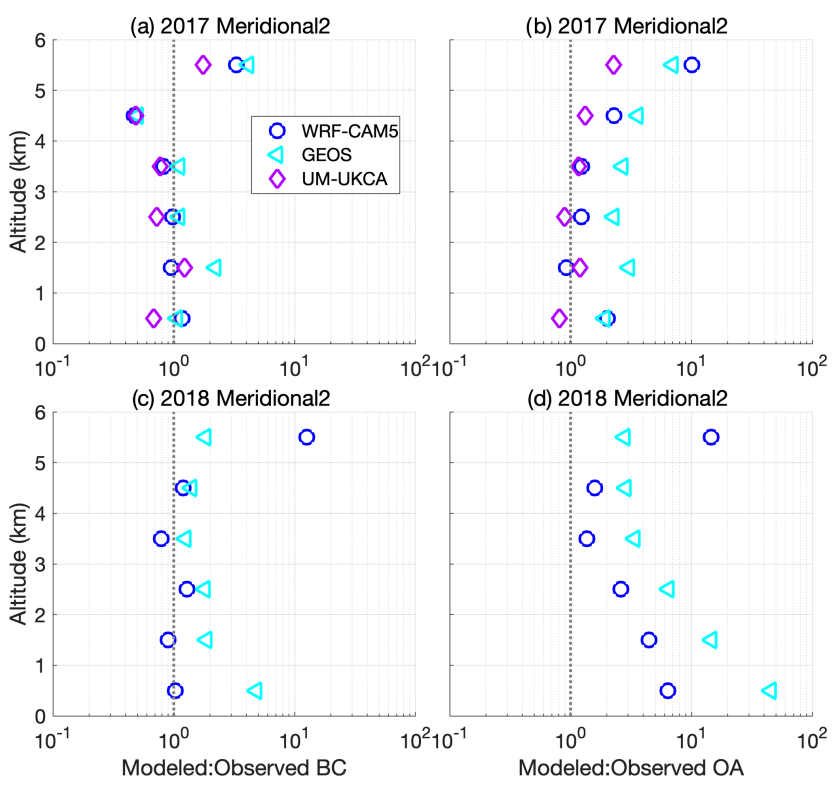

Figure 13. As in Fig. 12 but for the 2017 and 2018 meridional 2 comparison transect. The ratios for individual grid boxes, along with these means, are given in the Supplement (Fig. S9 for WRFCAM5, Fig. S11 for GEOS, and Fig. S13 for UM-UKCA).

source of OA. Additionally, there is no marine source for $\mathrm{BC}$. Thus, the high bias in $\mathrm{OA}$ and $\mathrm{BC}$ concentrations below $2 \mathrm{~km}$ in the UM-UKCA and GEOS simulations is a clear indication the model is mixing too much biomass burning smoke into the boundary layer and, therefore, into low marine clouds.

\subsubsection{Light extinction}

The comparison between modeled and observed $\sigma_{\mathrm{ep}}$ is complicated by the fact that $\sigma_{\mathrm{ep}}$ from the in situ measurements is at low RH (typically $<40 \%$ ), whereas the models report $\sigma_{\text {ep }}$ at ambient RH. An exception is the UM-UKCA model, which provides both dry and ambient $\mathrm{RH} \sigma_{\mathrm{ep}}$. The disparity between low RH and ambient $\mathrm{RH} \sigma_{\text {ep }}$ is expected to be large in the boundary layer, where $\mathrm{RH}$ is generally above $75 \%$ $80 \%$. Sea salt can be a significant component of boundary layer aerosol and, in addition to being very hygroscopic (Tang et al., 1997; Niedermeier et al., 2008), much of it is in the aerosol coarse mode, which would have been undersampled by the P-3 aircraft aerosol inlet. Given these issues, the fact that the smoke resides largely above the boundary layer (e.g., Das et al., 2017), and that the focus of this analysis is on comparisons relevant to the direct aerosol radiative effect by biomass burning aerosol, our discussion will focus on the comparison of $\sigma_{\mathrm{ep}}$ at altitudes above $2 \mathrm{~km}$.

The effect of humidification on the biomass burning aerosol light scattering is estimated using in situ measurements of low $(<40 \%)$ and high $(\sim 85 \%)$ RH $530 \mathrm{~nm}$ light scattering made on the P-3 aircraft in 2016 and 2018. Instrumental problems in 2017 preclude estimates for that year. The growth of light scattering is parameterized by fitting an exponential function to the measured low and high $\mathrm{RH}$ values of $\sigma_{\mathrm{sp}}$ versus the $\mathrm{RH}$ of the measurements, using the exponent gamma $(\gamma)$ as the metric for hygroscopicity (e.g., Kasten, 1969; Burgos et al., 2019). Using all data within a given campaign year, $\gamma$ in the plume averages $0.62 \pm 0.05$ in 2016 and $0.68 \pm 0.05$ in 2018. This is quite a bit higher than $\gamma$ for biomass burning smoke from previous measurements (e.g., Kotchenruther and Hobbs, 1998; Titos et al., 2016). Evaluating the hygroscopicity measurements is beyond the scope of this paper, but the estimates presented here should be viewed with this in mind. The derived values of $\gamma$ are used directly to calculate the approximate scale factor, $f(\mathrm{RH})$, to convert the low RH measured values of $\sigma_{\mathrm{sp}}$ to ambient $\mathrm{RH} \sigma_{\mathrm{sp}}$. Values of $f(\mathrm{RH})$ are calculated for the mean $\pm 1 \sigma$ observed ambient RH in each comparison transect grid box within $250 \mathrm{~m}$ resolution altitude bins from 2 to $6 \mathrm{~km}$ (Fig. S14). For 2017, the value of $\gamma$ from 2018 (0.68) is used in this calculation since the comparisons in these 2 years both cover the same meridional 2 transect.

Shinozuka et al. (2020) estimated that, for September 2016, $f(\mathrm{RH})$ was less than 1.2 for $90 \%$ of the free troposphere aerosol measurements across the campaign. Estimates for the comparison grid boxes included here are consistent with this (Fig. S14) but also show that $f(\mathrm{RH})$ for the 2016 diagonal grid boxes $3-6$ in the $4-5.5 \mathrm{~km}$ altitude range were often higher, with means of $1.30 \pm 0.14,1.46 \pm 0.19$, $1.30 \pm 0.10$, and $1.26 \pm 0.21$ for grid boxes $3,4,5$, and 6 , re- 


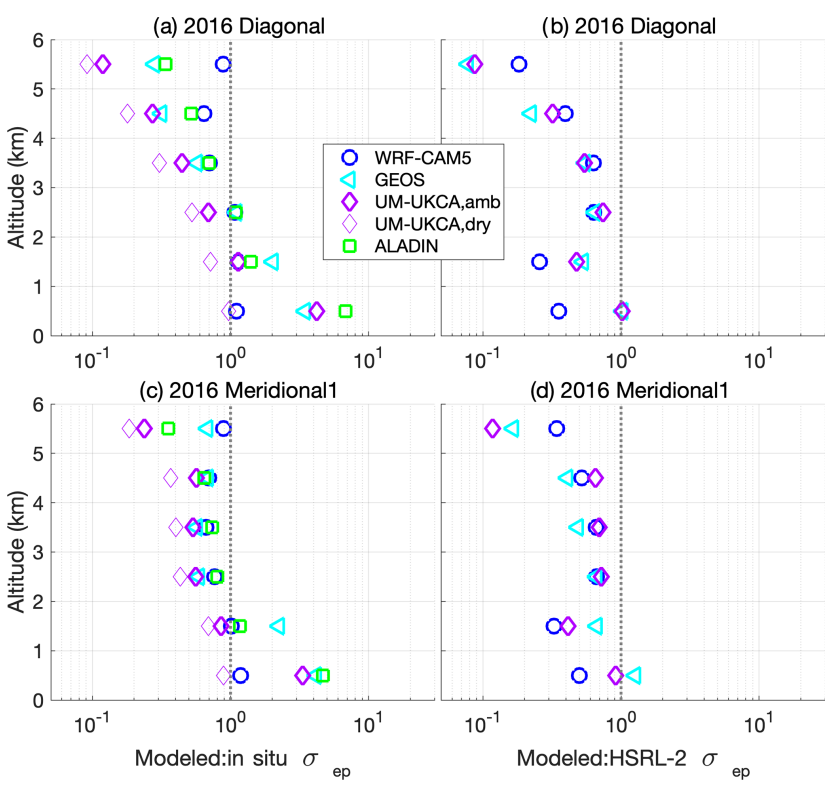

Figure 14. Mean ratio of modeled-to-in-situ low RH (a, c) and HSRL-2 ambient RH (b, d) mid-visible $\sigma_{\text {ep }}$ across all grid boxes for the 2016 diagonal (a, b) and meridional 1 (c, d) comparison transects. Comparisons to both dry and ambient $\mathrm{RH} \sigma_{\mathrm{ep}}$ are shown for the UM-UKCA model; for all other models, the comparison is to ambient $\mathrm{RH} \sigma_{\mathrm{ep}}$. The ratios for individual grid boxes, along with these means, are given in the Supplement (Fig. S15 for WRFCAM5, Fig. S17 for GEOS, Fig. S19 for UM-UKCA, and Fig. S21 for ALADIN).

spectively. Grid boxes farther north in the 2016 meridional 1 transect were also more humid, with $f(\mathrm{RH})$ for grid boxes 1,2 , and 3 of $1.36 \pm 0.14,1.39 \pm 0.14$, and $1.44 \pm 0.51$, respectively, in the $2-5 \mathrm{~km}$ altitude range. If $\gamma$ is actually lower than derived here - e.g., closer to a value of $\sim 0.3$, as measured in the year 2000 SAFARI campaign in southwestern Africa (Titos et al., 2016) - then the $f(\mathrm{RH})$ values applied here would be about $30 \%$ too large $(\sim 1.5$ vs. $\sim 1.2$ for $\gamma$ of 0.65 vs. 0.3 for an ambient RH of $60 \%$ ).

In both 2016 and 2017, RH at plume altitudes was generally $<60 \%$ (Figs. 10 and 11). In 2017, RH in the plume tended to decrease from the north (grid box 1) to the south (grid box 8) across the meridional 2 transect. The humidification factor $f(\mathrm{RH})$ is accordingly estimated to decrease from typical values of 1.3-1.5 towards the northern end of the transect to 1.0-1.2 at the southern end (Fig. S14). In 2017, $f(\mathrm{RH})$ is again slightly higher at $4-5 \mathrm{~km}$ altitude, and the humidity and $f(\mathrm{RH})$ more variable than in the lower part of the plume. This is consistent with the fact that mid-level clouds were intermittently observed within and upwind of this transect.

In October 2018, the RH in the plume was greater than in September 2016 or August 2017 (Fig. 11 vs. Fig. 10) because convection was shifted further south and was carried over the SE Atlantic by the southern African easterly jet (Ryoo et al., 2021). It was still generally $60 \%$ or lower in meridional 2 grid boxes $6-8$, with $f(\mathrm{RH})$ usually $<1.3$. North of this, in grid boxes $3-5, \mathrm{RH}$ at $2-4 \mathrm{~km}$ was closer to $60 \%$, so $f(\mathrm{RH})$ is more typically 1.3-1.5. In grid boxes 1 and 2 , RH was closer to $80 \%$ in the free troposphere. For these grid boxes, $f(\mathrm{RH})$ was almost always greater than 1.5 and could exceed a factor of 2 (Fig. S14).

This analysis estimates the effect of humidification on light scattering only and not on light absorption. Since scattering dominates extinction, $f(\mathrm{RH})$ for $\sigma_{\mathrm{sp}}$ nonetheless provides a good estimate of the impact of humidification on $\sigma_{\mathrm{ep}}$. Based on this analysis, the in situ, low RH values of $\sigma_{\text {ep }}$ are expected to typically be $20 \%-50 \%$ lower than the modeled and HSRL-2-measured ambient RH values of $\sigma_{\mathrm{ep}}$, with everything else being equal. Instead, the modeled values of ambient $\mathrm{RH} \sigma_{\mathrm{ep}}$ in the plume are generally lower than both the dry in situ values and the ambient RH HSRL-2 values.

\section{WRF-CAM5}

As for $\mathrm{OA}$ and $\mathrm{BC}$, the observed $\sigma_{\mathrm{ep}}$ profiles are at a higher altitude and less vertically diffuse than in the models (Figs. 6-9). This produces a similar pattern to the biases in BC, OA, and $\sigma_{\mathrm{ep}}$. The in situ measurements of $\sigma_{\mathrm{ep}}$, in particular, increase more rapidly with altitude at the bottom of the plume and decrease more rapidly with altitude at the top of the plume than does the WRF-CAM5-modeled extinction. This is most pronounced in the grid boxes with higher concentration and/or more well-defined plumes (e.g., Fig. 6a). In addition, the observed plume is centered at a higher altitude than in the models. This leads to underestimates in modeled $\sigma_{\text {ep }}$ in WRF-CAM5, relative to in situ values, in the core of the plume (3-4 km altitude) of about 30\%-35\% in 2016, $10 \%$ in 2017, and $15 \%$ in 2018 (Table 1; Figs. 14 and 15). Below and above the core of the plume (the 2$3 \mathrm{~km}$ and $4-5 \mathrm{~km}$ bins), the modeled-to-in situ-observed ratio in $\sigma_{\text {ep }}$ is closer to 1.0. In 2017 and 2018, WRF-CAM5modeled extinction at $5-6 \mathrm{~km}$ is more than 4 times (2017) and 9 times (2018) greater than that observed in situ (Fig. 15), but this is because $\sigma_{\text {ep }}$ is measured to be near zero above $5 \mathrm{~km}$ in most grid boxes.

Biases in the model, when compared to $\sigma_{\text {ep }}$ from HSRL-2, follow a similar but less consistent pattern (Figs. 14 and 15; Table 2). Again, the measurements show a plume core that is centered at a higher altitude and is less vertically diffuse than in the models, especially in 2016 (Fig. 8). The model mean low bias referenced to the HSRL-2 measurements is generally greater than the mean low bias compared to in situ observed $\sigma_{\text {ep }}$ (compare Tables 1 and 2), consistent with the former being at ambient RH and the latter dry $\sigma_{\text {ep }}$. Except in the 2018 meridional 2 transect, WRF-CAM5 $\sigma_{\text {ep }}$ is generally $30 \%-40 \%$ lower than measured by HSRL-2 (Table 2).

Notable in comparing Figs. 6 and 8 is that, in 2016, when the HSRL-2 was on board the ER2 and so had retrievals to $>6 \mathrm{~km}$ altitude, the top of the plume extends to higher altitudes than covered by the in situ measurements. In the latter, 
Table 2. As in Table 1 but for retrieved values of $\sigma_{\text {ep }}$ only from the HSRL-2 lidar on board the ER-2 aircraft in 2016 and the P-3 aircraft in 2017 and 2018. Both modeled and observed values are at ambient RH. The modeled values are 550 nm, and the HSRL-2 values are at $532 \mathrm{~nm}$.

\begin{tabular}{|c|c|c|c|c|c|c|c|c|c|c|c|c|c|c|}
\hline & \multicolumn{5}{|c|}{ WRF-CAM5 } & \multicolumn{5}{|c|}{ GEOS } & \multicolumn{4}{|c|}{ UM-UKCA } \\
\hline & 2016 & 2016 & 2016 & 2017 & 2018 & 2016 & 2016 & 2016 & 2017 & 2018 & 2016 & 2016 & 2016 & 2017 \\
\hline & Diag & Mer1 & Zon & Mer2 & Mer2 & Diag & Mer1 & Zon & Mer2 & Mer2 & Diag & Mer1 & Zon & Mer2 \\
\hline \multicolumn{15}{|c|}{ Aerosol light extinction $\left(\sigma_{\mathrm{ep}}\right)$} \\
\hline $5-6 \mathrm{~km}$ & 0.18 & 0.34 & 0.41 & - & 0.82 & 0.08 & 0.17 & 0.17 & - & 0.24 & 0.09 & 0.12 & 0.21 & - \\
\hline $4-5 \mathrm{~km}$ & 0.40 & 0.52 & 0.34 & 0.76 & 0.61 & 0.22 & 0.41 & 0.25 & 0.57 & 0.50 & 0.32 & 0.65 & 0.45 & 0.39 \\
\hline $3-4 \mathrm{~km}$ & 0.63 & 0.66 & 0.52 & 1.06 & 0.60 & 0.55 & 0.49 & 0.48 & 0.78 & 0.79 & 0.54 & 0.70 & 0.54 & 0.77 \\
\hline $2-3 \mathrm{~km}$ & 0.64 & 0.66 & 0.71 & 0.86 & 0.79 & 0.65 & 0.67 & 0.79 & 0.93 & 1.00 & 0.74 & 0.72 & 0.76 & 0.60 \\
\hline $1-2 \mathrm{~km}$ & 0.26 & 0.33 & 0.64 & 0.57 & 1.17 & 0.53 & 0.67 & 1.12 & 0.94 & 1.57 & 0.48 & 0.41 & 0.83 & 0.62 \\
\hline $0-1 \mathrm{~km}$ & 0.35 & 0.50 & 0.19 & 0.31 & 0.82 & 1.03 & 1.27 & 1.33 & 0.87 & 2.07 & 1.02 & 0.92 & 0.85 & 1.10 \\
\hline
\end{tabular}

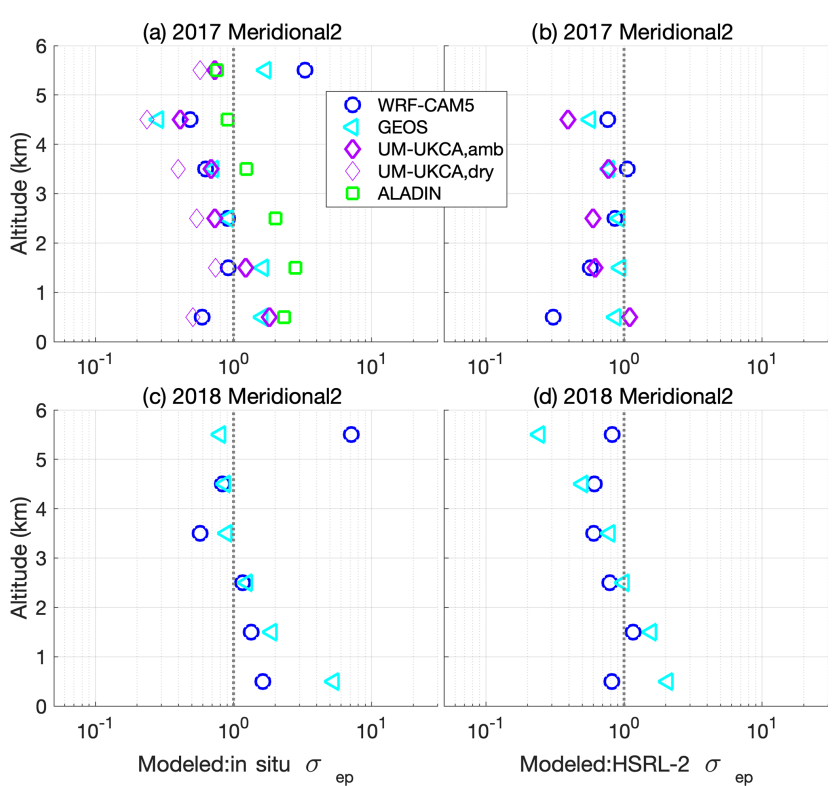

Figure 15. As in Fig. 14 but for the (a, b) 2017 and (c, d) 2018 meridional 2 comparison transects. The ratios for individual grid boxes, along with these means, are given in the Supplement (Fig. S16 for WRF-CAM5, Fig. S18 for GEOS, Fig. S20 for UMUKCA, and Fig. S21 for ALADIN).

$\sigma_{\text {ep }}$ drops to near zero above $6 \mathrm{~km}$ in most comparison grid boxes; in the HSRL-2 retrievals, $\sigma_{\mathrm{ep}}$ above $5.5 \mathrm{~km}$ is usually still $>50 \mathrm{Mm}^{-1}$. The in situ and HSRL-2 measurements were not coincident, so this difference could simply reflect different sampling, but the consistency of this feature across multiple comparison transects makes this seem unlikely. Relative humidity often increased above about $4 \mathrm{~km}$ (Fig. 6), with humidification often amplifying $\sigma_{\mathrm{ep}}$ by a factor of 1.5 or more (Fig. S14). While this cannot fully account for the very large difference in $\sigma_{\mathrm{ep}}$ in the models versus that observed in situ, or all of the difference between the plume-top behavior be- tween the in situ and HSRL-2 measurements, humidification differences could be contributing.

The net effect of these altitude-dependent biases in $\sigma_{\mathrm{ep}}$ is that WRF-CAM5 underestimates plume AOD, with Shinozuka et al. (2020) calculating a low bias of 10\%-30\% in AOD for the 2016 campaign. Here, the modeled ambient $\mathrm{RH} \sigma_{\mathrm{ep}}$ is typically $70 \%-80 \%$ of the in-situ-measured dry $\sigma_{\mathrm{ep}}$ (with considerable variability). Accounting for the difference in humidity of the in situ measurements (i.e., scaling in situ $\sigma_{\text {ep }}$ by $1.2-1.5$ ) would make the WRF-CAM5 $\sigma_{\text {ep }}$ in the plume to only about $50 \%-70 \%$ of the observed average. This is not far from the observed ratios of WRF-CAM5 to HSRL-2 observed ambient RH $\sigma_{\text {ep }}$ (Table 2).

\section{GEOS}

Biases in GEOS-modeled $\sigma_{\text {ep }}$ profiles have a strong vertical gradient in most comparison transects, with generally positive biases below about $2 \mathrm{~km}$; above this, the model has a low bias that becomes greater with altitude (Figs. 14 and 15; Table 1). The low bias in GEOS $\sigma_{\text {ep }}$ is smaller for August 2017 than for September 2016 and smaller again for October 2018. (Tables 1 and 2). In 2017, the bias also has a less consistent dependence on altitude (Fig. 15). In 2018, the higher ambient $\mathrm{RH}$ (Fig. 11) could be compensating for some of the low bias in dry aerosol $\sigma_{\mathrm{ep}}$.

Overall, it is clear that GEOS underestimates $\sigma_{\text {ep }}$ in the plume and centers the plume at too low an altitude (Figs. 69 ), with a net impact of underestimating the above-cloud AOD. This is consistent with the finding of a greater low bias in AOD from GEOS $(30 \%-50 \%)$ than from WRF-CAM5 (10\%-30\%) in Shinozuka et al. (2020). As for WRF-CAM5, accounting for humidification in the in situ observations would increase the estimated bias in GEOS to greater than a factor of 2. This is somewhat surprising, given that GEOS assimilates satellite-retrieved AOD every $3 \mathrm{~h}$ (Albayrak et al., 2013). 


\section{ALADIN}

Statistics from the ALADIN model are not available for comparison to the HSRL-2-retrieved $\sigma_{\mathrm{ep}}$, so comparisons are made to in situ $\sigma_{\text {ep }}$ only. For both 2016 transects, ALADINmodeled $\sigma_{\mathrm{ep}}$ is underestimated at the core of the plume, and the modeled plume is too vertically diffuse (Fig. 6). Also apparent is that the model increasingly places the plume at too low an altitude (Figs. 14 and 15), with the plume notably too low at the northwestern end of the diagonal transect (Fig. 6), consistent with too much subsidence in the model with aerosol transport (Das et al., 2017). In the 2016 diagonal transect, this produces a low bias in modeled $\sigma_{\text {ep }}$ that increases with altitude from 3 to $5 \mathrm{~km}$ and high biases below $3 \mathrm{~km}$ (Fig. 14a; Table 1), which is much the same as for the GEOS model.

In 2017, biases in ALADIN-simulated $\sigma_{\text {ep }}$ along the meridional 2 transect again have an altitude dependence, indicating a plume that is displaced too low in altitude, but in this case producing high biases below $4 \mathrm{~km}$ altitude (Fig. 15a). There is, in particular, a tendency for the model to overestimate $\sigma_{\mathrm{ep}}$ at the northern end of this transect and underestimate it at the southern end (Fig. S21), very possibly due to humidification amplifying $\sigma_{\text {ep }}$ by about a factor of 2 for the northern grid boxes but only by a factor of $\sim 1.1-1.4$ at the southern end (Fig. S14).

Notably, the ALADIN simulations were run using fixed 2014 GFED emissions. Central and southern African biomass burning emissions in 2014 were not particularly different from the 2001-2013 climatological average (Kaiser and Van der Werf, 2015). While not a direct measure of emissions, AOD over the SE Atlantic was lower in both September 2016 and August 2017 than the 2003-2018 average (Redemann et al., 2021), consistent with lower emissions in these months and years than on average. If the ALADIN simulations had used the emissions for the observed months, modeled $\sigma_{\text {ep }}$ may have been smaller, with greater low biases in 2016 and greater high biases (below $4 \mathrm{~km}$ ) in comparison to the observations.

\section{UM-UKCA}

For the UM-UKCA model, dry as well as ambient RH $\sigma_{\text {ep }}$ values were reported, allowing for a more robust comparison to the measured low $\mathrm{RH} \sigma_{\text {ep }}$ and a rough comparison of observed versus modeled humidification factors. At all altitudes above $2 \mathrm{~km}$, the model underpredicts dry aerosol $\sigma_{\text {ep }}$ significantly across all comparison transects in 2016 and 2017 (Figs. 14 and 15; Table 1). This low bias increases systematically with altitude from 2 to $5 \mathrm{~km}$. The grid box mean dry $\sigma_{\text {ep }}$ is typically a factor of 2 to 3 lower in the model in the 3-4 and $4-5 \mathrm{~km}$ altitude bins than observed in situ. The altitude dependence of the model biases again results from the modeled plume being too vertically diffuse and the plume core too low in altitude.
Even with humidification added, the UM-UKCA-modeled extinction is lower than the observed dry $\sigma_{\mathrm{ep}}$, despite the fact that the model aerosol appears to be too hygroscopic. In 2016 , modeled $\sigma_{\text {ep }}$ in the $2-5 \mathrm{~km}$ altitude range is a factor of 1.4 higher at ambient RH than for the dry aerosol; for 2017 , it is a factor of 1.5 higher. These humidification factors are somewhat higher than expected from our analysis from the in situ observations, where $f(\mathrm{RH})$ at these altitudes averaged 1.2 in both 2016 and 2017 (Fig. S14). The significant contribution of humidification to $\sigma_{\mathrm{ep}}$ also manifests in the fact that the modeled ambient $\mathrm{RH} \sigma_{\text {ep }}$ is typically $0.55-0.75$ of that observed from the HSRL-2, and the simulated dry values of $\sigma_{\text {ep }}$ are typically $0.2-0.5$ of that observed in situ (Figs. 14 and 15; Tables 1 and 2).

The UM-UKCA low biases in dry $\sigma_{\text {ep }}$ are much greater than the model low biases in $\mathrm{OA}$ and $\mathrm{BC}$, indicating that the model has a low bias in biomass burning aerosol mass extinction efficiency and mass. There could also be simply less total aerosol mass (e.g., of components other than OA and $\mathrm{BC}$, such as sulfate) in the UM-UKCA model than in reality.

\subsection{Biases in aerosol intensive optical properties}

Model biases in aerosol constituent component masses (BC and $\mathrm{OA}$ ) and $\sigma_{\mathrm{ep}}$ can arise from a combination of biases in the emissions, transport, deposition, and (for OA) in-atmosphere production and loss from the aerosol phase of the biomass plume aerosol, which will clearly affect the magnitude of the calculated direct aerosol radiative effect. As noted earlier, the aerosol intensive optical properties, in particular the SSA, will also affect the sign of the aerosol DARE. The SAE connects the aerosol mass and extinction through the aerosol size, which is directly related to its aerosol mass scattering efficiency. The SAE and AAE, combined with mid-visible $\sigma_{\text {ep }}$, give the wavelength-dependence of SSA (Russell et al., 2010).

\subsubsection{Single scatter albedo (SSA)}

Observed and modeled SSAs differ in two respects, namely in their absolute value and in their variation with altitude. In September 2016, the observed SSA increases with altitude within the biomass burning plume along both the diagonal and meridional 1 transects (Fig. 16), generally increasing from $0.82-0.84$ at the bottom of the plume to $0.86-0.88$ at the plume top. In August 2017, SSA spanned a similar range as in 2016 (Fig. 17), but there is no significant gradient in SSA with altitude in the northern four meridional 2 grid boxes and only a slight indication of an increase in SSA with altitude towards the southern half of the plume. There is also no vertical gradient in SSA in the northernmost three meridional 2 grid boxes in October 2018, and SSA is overall higher than in September 2016 and August 2017.

A vertical gradient is apparent in the southern five meridional 2 grid boxes in 2018, where SSA increases from 0.86- 



Figure 16. Profiles of SSA as observed (at low RH and $530 \mathrm{~nm}$ ) and modeled (at ambient RH and also, for UM-UKCA, dry, at $550 \mathrm{~nm}$ ) for the 2016 (a) diagonal and (b) meridional 1 transects.

0.89 at plume bottom to $0.90-0.92$ at plume top. Notably, grid boxes 4-7 are located well within the biomass plume, whereas the northern end of this transect was often outside of or on the edges of the plume. The vertical gradient in SSA has been associated with a gradient in aerosol composition (Redemann et al., 2021). Accounting for this gradient is important in determining the direct aerosol radiative effect because it is the extinction-weighted column SSA, combined with below-plume albedo, which dictates the sign of the direct forcing.

WRF-CAM5 produces little to no associated gradient in SSA with altitude (Figs. 16 and 17), showing increases in SSA only at the very top of the plume in some comparison grid boxes. Within the plume, modeled SSA encompasses quite a small range, which is almost always $0.82-0.84$ in the September 2016 transects and the August 2017 transect (Fig. 15). This difference in vertical gradient explains why Shinozuka et al. (2020) find greater low biases in the 3-6 km altitude column SSA than in the lower free troposphere column SSA. As in the observations, in October 2018 the WRFCAM5 SSA is slightly higher than in the other years, generally $0.84-0.86$. WRF-CAM5 does not consider OA and BC aging, and primary OA hygroscopicity is low $(0.1)$, which is consistent with the small range in SSA.

GEOS, similarly, has little gradient in SSA with altitude within the plume, and, where it does, the tendency is for SSA to decrease with altitude, particularly towards the plume top. Here it diverges from the observed, increasing dry aerosol SSA. Mean plume SSA values, on average, are similar in GEOS and WRF-CAM5, but SSA is about twice as variable in GEOS. This larger range in SSA does not show any appar- ent spatial pattern, other than having somewhat higher SSA in the northernmost meridional 2 grid box in both 2017 and 2018. This grid box tended to be either on the northern edge or out of the main biomass burning plume. Aging of OC in GEOS could be creating more hygroscopic aerosol with time, which, in turn, would increase the variability in ambient SSA through differences in water uptake.

In the UM-UKCA simulations, SSA decreases significantly towards the top of the plume in some comparison grid boxes. In most cases this is true for both the dry and ambient RH aerosol SSA, so this appears to be driven by a change in aerosol composition or size but not by, e.g., a decrease in scattering due to a decrease in RH. The UM-UKCA ambient RH SSA values are within 0.02 of the values measured in situ at most altitudes in the plume (Fig. 14), but the dry aerosol SSA from UM-UKCA is significantly lower (typically $0.77-0.83$ ) than both the modeled ambient RH values (typically $0.84-0.88$ ) and the dry in situ values (Figs. 16 and 17). This difference between the SSA of the dry and ambient $\mathrm{RH}$ aerosol results from the significant increase in extinction with RH (Sect. 4.3.2).

ALADIN is the only model of the four where the SSA (which is at ambient RH) has a similar gradient with altitude in the plume to that observed. SSA in ALADIN includes a dependence on aerosol aging and RH (Mallet et al., 2019), and thus, it is not clear if this altitude dependence in SSA is a response to higher RH towards the top of the plume or if it would still be present under dry conditions. ALADINmodeled SSA is also consistently higher than that observed.

The observed values of SSA are available only at low RH since $\sigma_{\text {ap }}$ was measured only at low RH, and only the UM- 


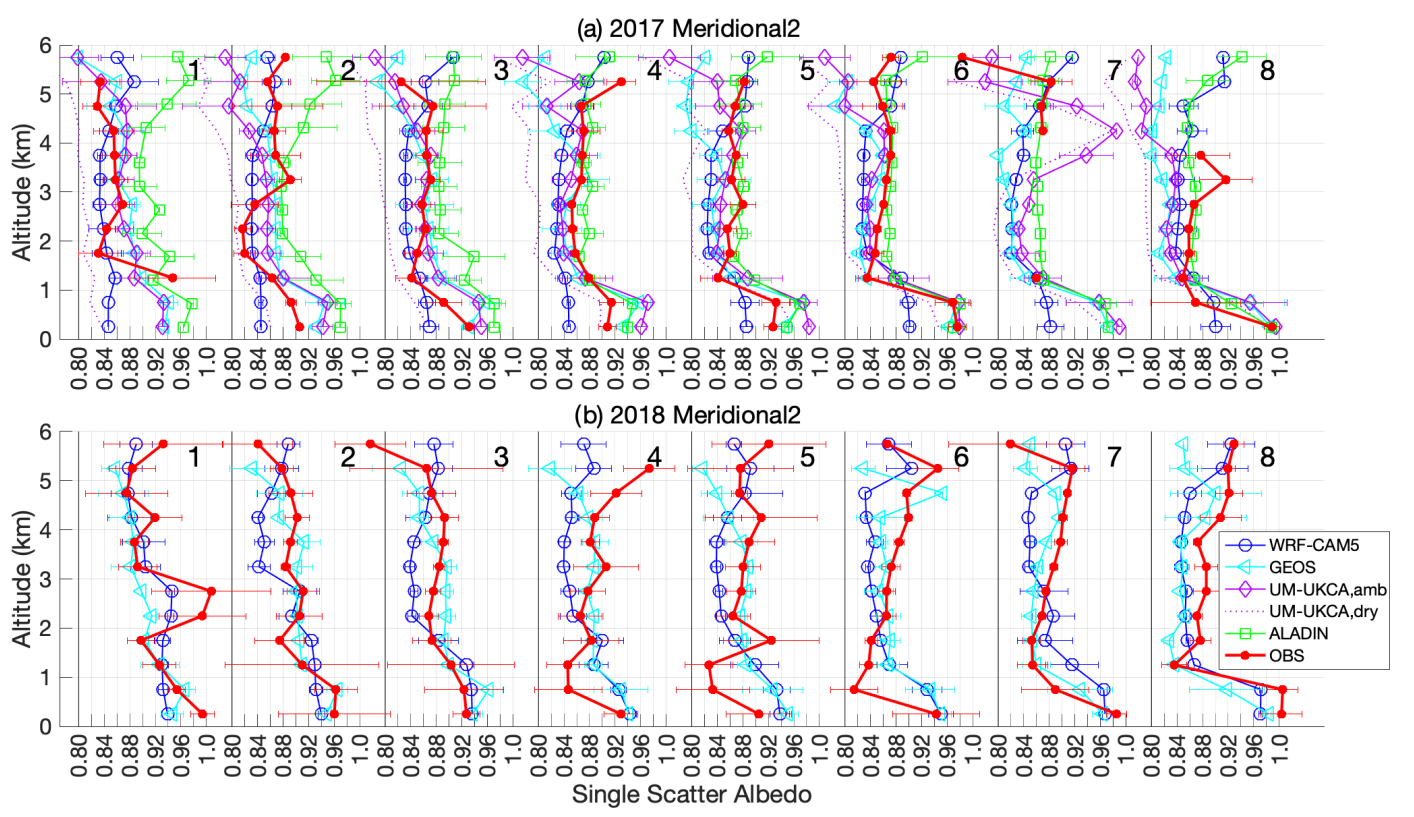

Figure 17. As in Fig. 16 but for the (a) 2017 and (b) 2018 meridional 2 transects.

UKCA model provided both dry and ambient RH values of SSA. This makes it difficult to determine how much humidification differences are contributing to the differences between the observed and modeled SSA. The models include the effect of humidification on SSA by accounting for the impact of water on the aerosol indices of refraction (WRFCAM5, GEOS, and UM-UKCA) or by parameterizing the effect of RH on SSA (ALADIN; Mallet et al., 2017, 2019). In all four models, the result is an increase in SSA with humidification. In reality, it is likely that humidification affects both scattering and absorption. However, the former has been well quantified observationally, whereas the latter has not and is therefore highly uncertain (e.g., Bond et al., 2013; Zhou et al., 2020).

The modeled ambient RH SSA at plume altitudes is generally lower than the observed dry aerosol SSA in both the WRF-CAM5 and GEOS models (Fig. 18). Thus, the dry aerosol SSA in these models has an even greater low bias than indicated by Figs. 14-16; whether it is as large as the low bias in the UM-UKCA dry SSA depends on the relative effects of humidity on scattering and absorption in the models. Humidity in the plume was somewhat higher in August 2017, and, in particular, October 2018 than in September 2016 (Fig. 11 versus Fig. 10), thus increasing modeled SSA and moving the modeled (ambient $\mathrm{RH}$ ) and observed (dry) SSA values in closer alignment on average. In contrast, for the two 2016 transects, the ALADIN ambient RH SSA is almost always higher than the observed dry SSA, with typical differences of 0.02-0.04. Adjustment of the ALADIN (ambient $\mathrm{RH}$ ) values to low RH (as in the observations) should bring the two into better agreement, though perhaps not for all transects. The differences are smaller in the 2017 merid- ional 2 transect, particularly towards the south, despite the higher ambient RH.

Aerosol SSA is determined largely by aerosol composition which, for biomass burning aerosol, is dominated by organic aerosol (e.g., see Fig. 14 of Redemann et al., 2021). Black carbon is highly absorbing, so the mass fraction of BC in particular drives SSA. As discussed below (Sect. 6), the relative biases in $\mathrm{OA}$ and $\mathrm{BC}$ indicate that the models have a higher $\mathrm{OA}: \mathrm{BC}$ ratio than observed. For given indices of refraction for these components, a higher $\mathrm{OA}$ : $\mathrm{BC}$ ratio would increase SSA in the models (since they do not include organic aerosol brown carbon absorption). Thus, the model OA : BC ratio does not explain the low bias in SSA in the WRF-CAM5 and GEOS models. Biases in model aerosol component indices of refraction, photochemical whitening (Carter et al., 2021), incorrect representation of the impacts of internal mixing on indices of refraction, and the influence of aerosol components other than $\mathrm{BC}$ and $\mathrm{OA}$ could all be contributing to the observed modeled biases in SSA.

An earlier study using data from the ORACLES 2016 field season compared SSA derived from the in situ measurements used here and from three remote sensing instruments (Pistone et al., 2019). These were a spectral radiometer (SSFR) in combination with Sun-photometer-derived AOD, a hyperspectral Sun photometer and sky radiometer (4STAR) in combination with SSFR-derived scene albedo, and an imaging polarimeter (Airborne Multi-angle Spectro Polarimetric Imager - AirMSPI). The SSFR and 4STAR instruments were deployed on the NASA P-3 aircraft along with the in situ instruments; the AirMSPI instrument was mounted on the NASA ER-2 high-altitude aircraft which overflew the P-3 at least once on coincident flight days (see Pistone et 


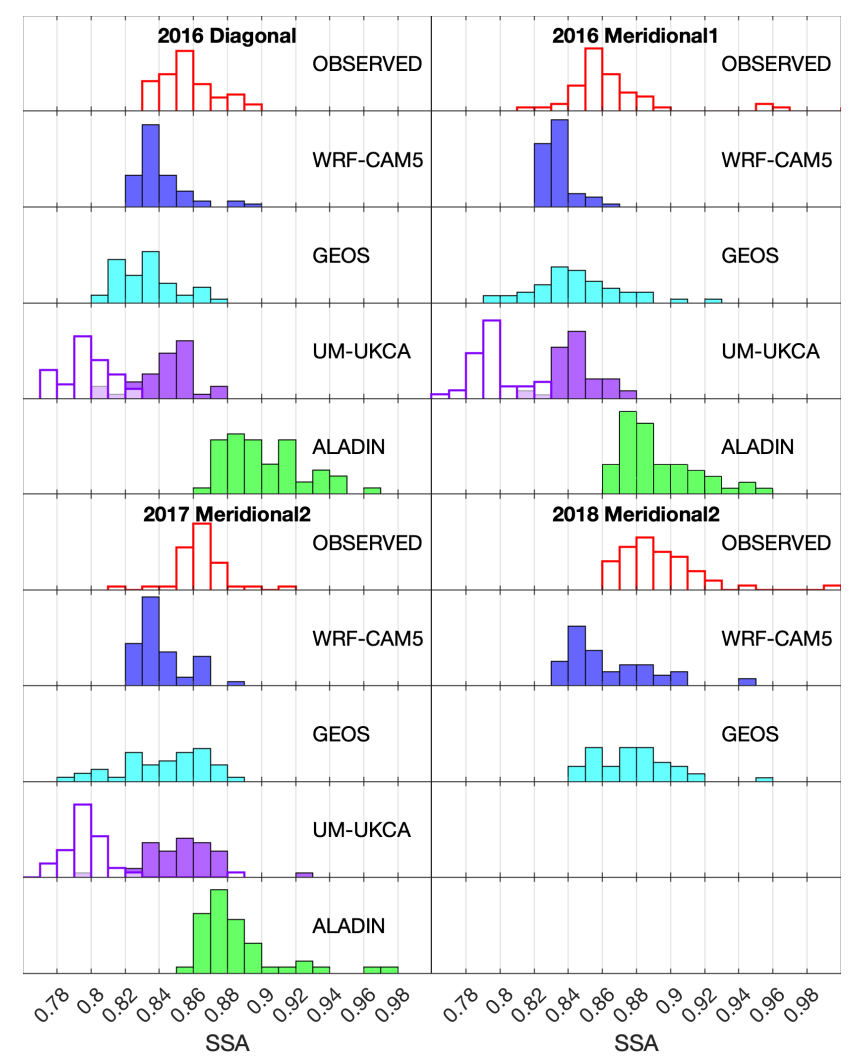

Figure 18. Histograms of SSA from the $2-5 \mathrm{~km}$ altitude range only, as measured in situ from the P-3 and as modeled using WRFCAM5, GEOS-5, UM-UKCA, and ALADIN for all samples along the comparison transects. For the UM-UKCA model, values are shown for both ambient RH aerosol (filled bars) and dry aerosol (unfilled bars); the observed values are available only for the dry aerosol (unfilled bars).

al., 2019, for more detail). The remote sensing instruments, like the models, all derive SSA at ambient RH. At $530 \mathrm{~nm}$, the average distribution of SSA from the in situ instruments was higher than the 4STAR SSA by (on average) $0.01-0.02$ (with 10-90 percentile ranges of 0.07 in each) but was generally lower than the AirMSPI SSA, with differences of 0.03 , with less variability overall (0.03 in 10-90 percentiles) compared with the P-3 instruments. The spread in differences was likely in part due to the full campaign measurements not being coincident in either time or space due to the varying measurement techniques. Direct comparison to the SSFR was made in one case study only, and for that case, the SSFR $530 \mathrm{~nm}$ SSA was $<0.01$ lower than the in situ SSA (within the instrument uncertainty ranges). These results indicate it is unlikely that SSA from the in situ instruments is significantly biased high. It also supports the idea that humidification is not significantly influencing SSA over the SE Atlantic, since the in situ values are at low RH, and the remote sensing values are at ambient RH. They also imply that the impact of humidification on SSA in the UM-UKCA model (Fig. 18) is too large (consistent with $f(\mathrm{RH})$ being too large; see the subsection on ALADIN), though it is difficult to make a robust conclusion based on this one observational comparison.

\subsubsection{Scattering Ångström exponent (SAE)}

Whereas SSA varies primarily with aerosol composition, SAE varies primarily with aerosol size. For aerosol smaller than approximately $1000 \mathrm{~nm}$ in dry diameter - i.e., as for aerosol in the SE Atlantic biomass burning plume (Shinozuka et al., 2020) - SAE becomes smaller as aerosol size increases (Schuster et al., 2006). The observed SAE is quite consistently 1.7-1.9 within the plume, with very little vertical variation or difference across the 2 campaign years (2016 and 2017) where observations are available (Figs. 19 and 20). WRF-CAM5-simulated SAE deviates the furthest from the observed values, with values in the plume generally 0.9 1.3 , which is consistent with the larger aerosol size in WRFCAM5 than in reality (see Fig. 4 in Shinozuka et al., 2020). GEOS and UM-UKCA both reproduce the observed SAE quite well, with the exception of a few grid boxes. The GEOS SAE values are typically $0.1-0.2$ smaller than observed in the 2016 meridional 1 grid boxes $1-3$ and above about $4 \mathrm{~km}$ at the northern end of the 2017 meridional 2 transect. Both the dry and ambient RH UM-UKCA values of SAE generally agree well with the observed SAE, which consistent with the UM-UKCA aerosol being only slightly larger than observed.

Both GEOS and UM-UKCA simulate vertical gradients but of opposite sign - in SAE, and a gradient is not present in the observations. The ALADIN model also has a lesspronounced decrease in SAE towards the top of the plume, and it simulates SAE values that are typically $0.02-0.04$ higher than what are observed in almost all grid boxes and plume altitudes. This is consistent with the aerosol in ALADIN being smaller than the observed aerosol, but the model uses a bulk bin scheme, so a mean aerosol size is not available for comparison. The GEOS and ALADIN models do include the effect of aging on aerosol hygroscopicity, possibly driving the modeled gradients in SAE.

The very small difference between the UM-UKCA simulated dry and ambient RH aerosol SAE values are surprising, given the large between difference dry and ambient RHsimulated $\sigma_{\text {ep }}$ (see the subsection on UM-UKCA) and SSA (Figs. 16-18). The relative changes in $\sigma_{\mathrm{ep}}$ and SSA with humidification in this model are consistent with the change in SSA being driven by an increase in light scattering alone, e.g., an increase in $\sigma_{\mathrm{sp}}$ of a factor of 1.45 - which is the mean $f(\mathrm{RH})$ for $\sigma_{\text {ep }}$ in the UM-UKCA model in the 2016 transects (see the subsection of ALADIN) - would produce a change in SSA from 0.80 to 0.85 , which is consistent with the increase in SSA with humidification in the model (Fig. 18). This implies significant aerosol growth with humidification, which should be reflected in the SAE. Resolving this apparent inconsistency would require work outside of the scope 

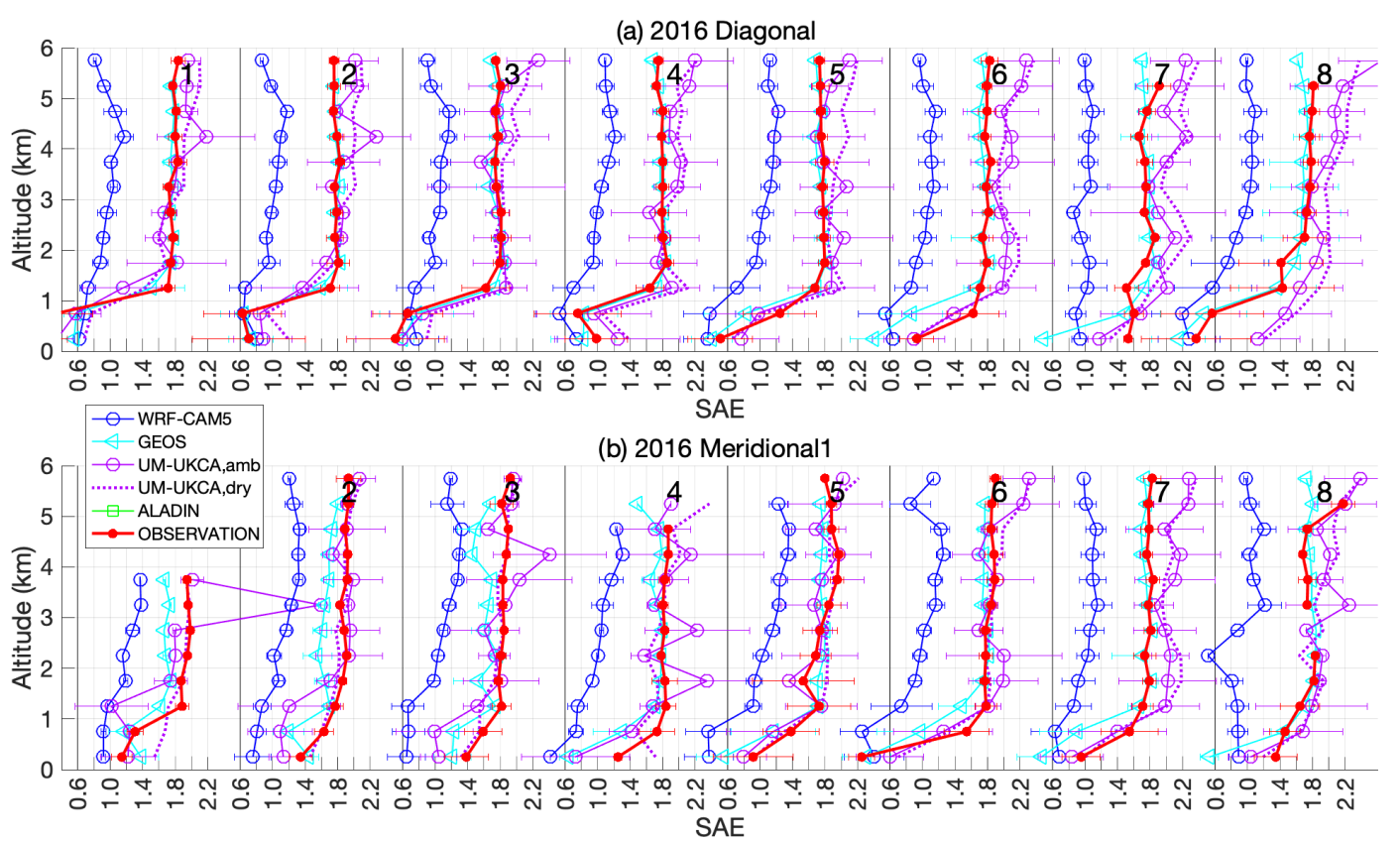

Figure 19. As in Fig. 16 but for the scattering Ångström exponent (SAE).
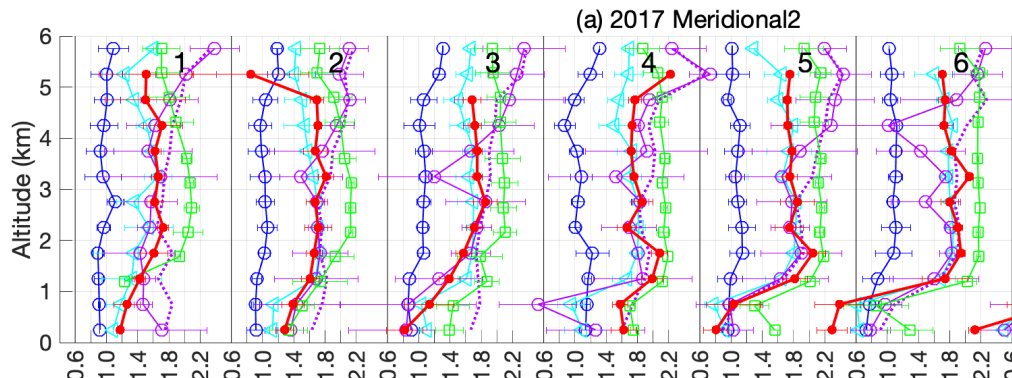

(a) 2017 Meridional2

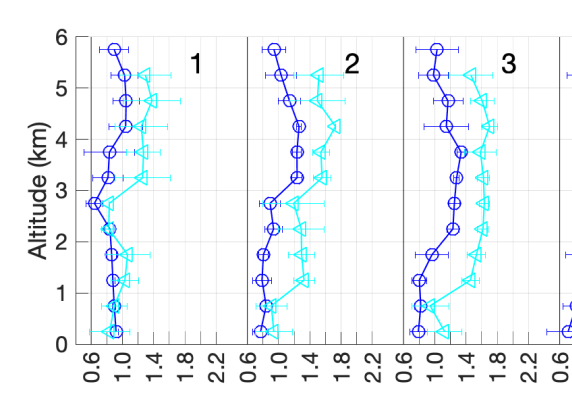

(b) 2018 Meridional2
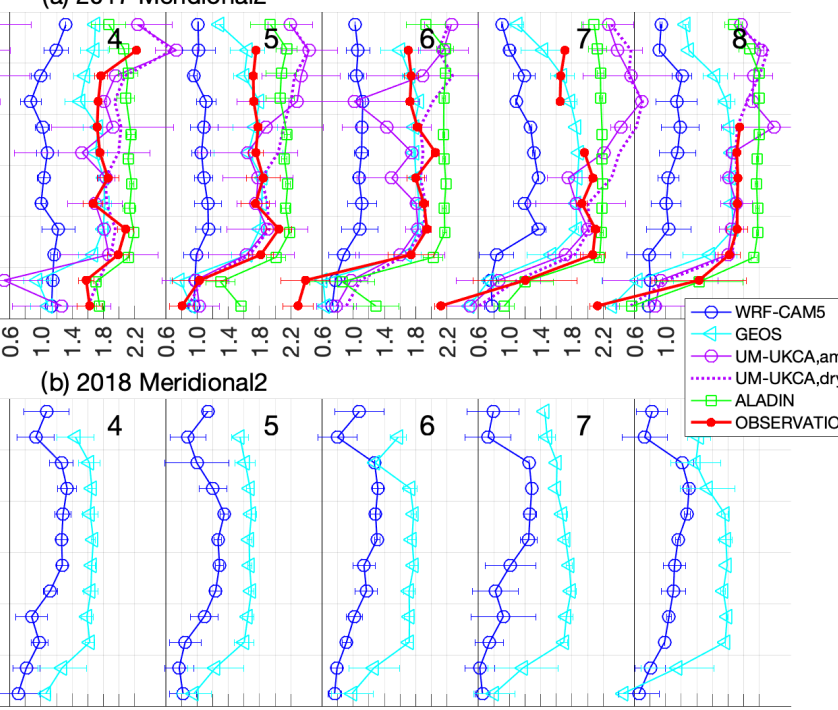

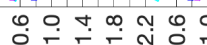

$4-$ GEOS ....... UM-UKCA,dry
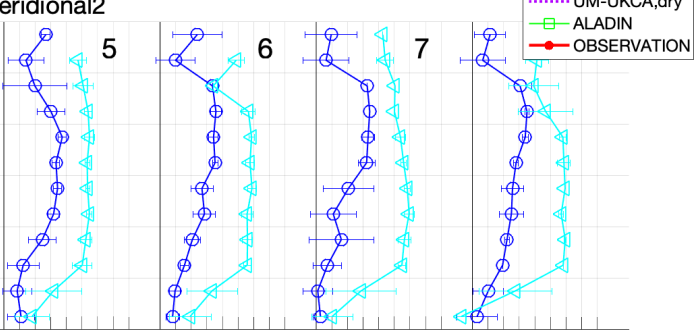

SAE

Figure 20. As in Fig. 17 but for the scattering Ångström exponent (SAE).

of this paper that considers more carefully the simulated size distribution and size-dependent composition of the aerosol.

\subsubsection{Absorption Ångström exponent (AAE)}

As noted above, the in situ PSAP measurements of $\sigma_{\text {ap }}$ at 530,460 , and $660 \mathrm{~nm}$ are processed using two sets of correction factors, namely wavelength averaged and wavelength specific (Virkkula, 2010). The two are nearly identical at
$530 \mathrm{~nm}$ but differ at 460 and $660 \mathrm{~nm}$ and so produce quite different values of the absorption Ångström exponent, both versions of which are shown in Figs. 21 and 22. In the 2$5.5 \mathrm{~km}$ altitude range, the wavelength-independent correction factors yield AAE values of $1.2 \pm 0.1$ in 2016 and $1.1 \pm 0.2$ in 2017 and 2018. AAE at these same altitudes calculated with the wavelength-specific correction factors are about $0.3-0.4$ higher, with average values of $1.5 \pm 0.1$ in 2016 and $1.5 \pm 0.2$ in 2017 and 2018. 

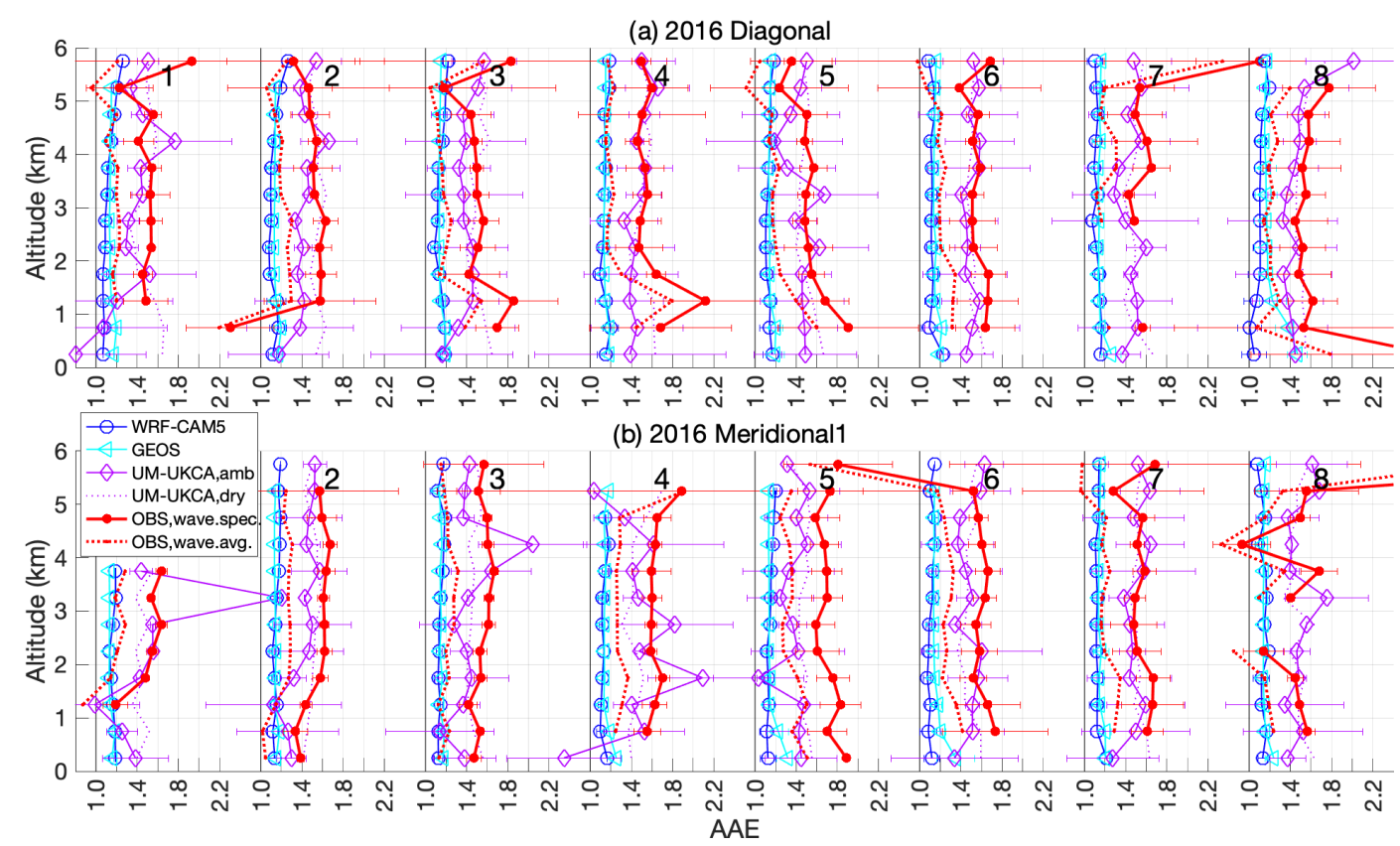

Figure 21. As in Fig. 16 but for the absorption Ångström exponent (AAE). Observed values of AAE are given for both the wavelengthspecific and wavelength-averaged correction factors.

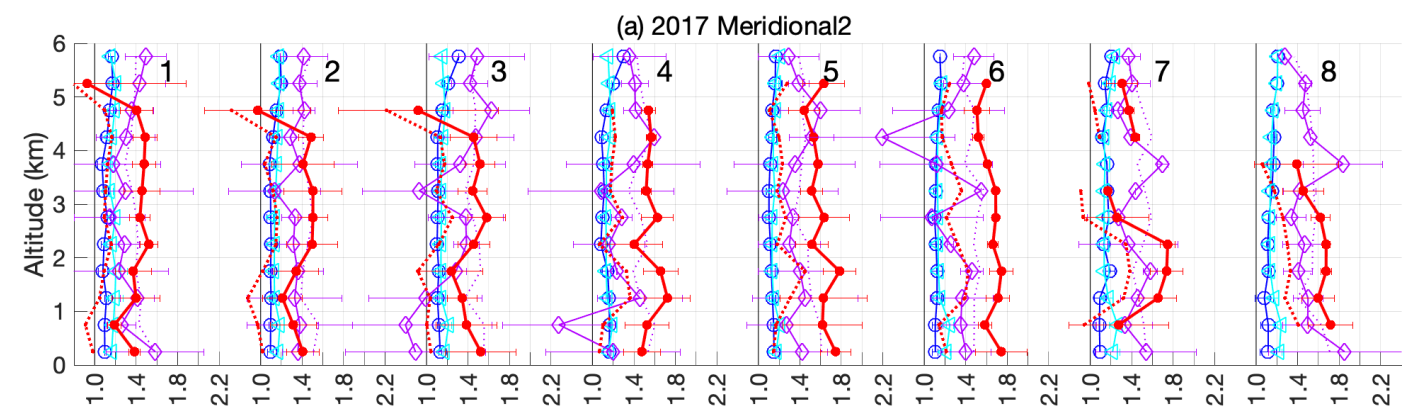

(b) 2018 Meridional2

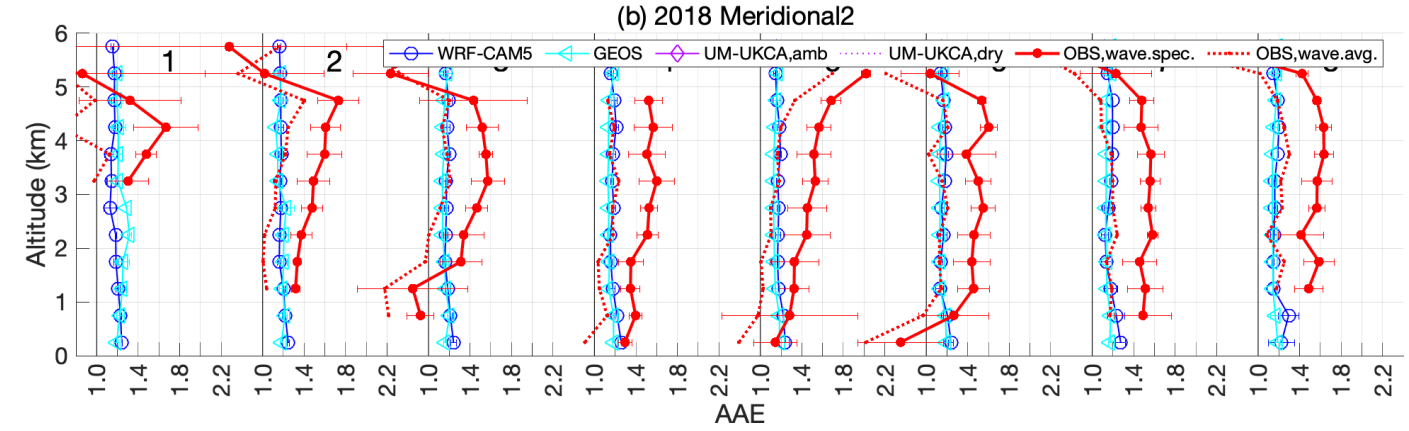

Figure 22. As in Fig. 17 but for the absorption Ångström exponent (AAE).

The Pistone et al. (2019) comparison of spectral SSA across different instruments during ORACLES 2016 used SSA calculated from $\sigma_{\mathrm{ap}}$ using the wavelength-averaged correction factor. Using the wavelength-specific correction factors produces higher $470 \mathrm{~nm}$ absorption, with the result that SSA is lower at both 470 and $660 \mathrm{~nm}$ than at $530 \mathrm{~nm}$ (Pistone et al., 2019). In contrast, SSA derived from absorption using the wavelength-averaged correction factors decreases with wavelength. The latter agrees better with the shape of the spectral SSA from the remote sensing instruments, indicating the lower values of AAE (derived from $\sigma_{\mathrm{ap}}$ values using the wavelength-averaged correction) are more likely to be correct. Values of AAE close to 1 are consistent with the absorption being dominated by black carbon (Bergstrom 
et al., 2007; Bond et al., 2013), so if these lower values are correct, then there is likely little brown carbon absorption, as also indicated by other recent studies of biomass smoke in the SE Atlantic (Chylek et al., 2019; Denjean et al., 2020; Taylor et al., 2020). These four models simulate both black and organic carbon, but the organic carbon is not light-absorbing, so AAE values are expected to be near 1 . They do include the impacts of the addition of water on the aerosol indices of refraction and aerosol size, which can drive variations in AAE from black carbon alone (i.e., of about 0.8-1.4; Liu et al., 2018).

AAE from the WRF-CAM5 and GEOS models are significantly lower than the in situ wavelength-specific values and are slightly, but not significantly, lower than the wavelengthindependent values (Figs. 21 and 22). In both models, AAE in the 2-5.5 km altitude range is 1.1 in 2016 and 2017 and 1.2 in 2018, with standard deviations of $<0.05$. The UM-UKCA AAE values vary from the observed values but, on average, are in good agreement with the in situ AAE derived using the wavelength-specific correction factors.

\subsection{Biases in cloud fraction and cloud optical thickness}

Observed cloud properties are retrieved from satellite observations and are available from every day of the three field campaign periods and for the zonal transect as well as for the diagonal, meridional 1, and meridional 2 transects. Mean $\mathrm{CF}_{\text {warm }}$ and geometric mean $\mathrm{COT}_{\text {warm }}$ from the satellite retrievals are compared to model averages across all daytime hours (Figs. 23-25). We treat the SEVIRI-LaRC retrievals as the benchmark for $\mathrm{CF}_{\text {warm }}$, since these measurements cover the daytime hours, and the MODIS-ACAERO retrievals are treated as our benchmark for $\mathrm{COT}_{\text {warm }}$, since they account for the effects of absorbing aerosol above the clouds, while acknowledging that any satellite retrievals of clouds may be subject to systematic biases. In cumulus cloud regions in particular, 3D radiative effects and subpixel clear-sky contamination may bias the retrieved values of $\mathrm{COT}_{\text {warm }}$ to be low (e.g., Marshak et al., 2006; Kato et al., 2006; Painemal et al., 2013), whereas the coarse pixel resolution relative to the cloud size could yield an overestimation of $\mathrm{CF}_{\text {warm }}$ (e.g., Zhao and Di Girolamo, 2006).

The observed $\mathrm{CF}_{\text {warm }}$ from all three satellite data products is quite high $(>60 \%-70 \%)$ across almost all comparison transect grid boxes, except at the southeastern end of the diagonal transect in 2016 (Fig. 23). Differences in the observation times of the MODIS and SEVIRI instruments are expected, on average, to lead to $\mathrm{CF}_{\mathrm{warm}}$ values that are about $1 \%-10 \%$ lower for the two MODIS products (Sect. 3.2.3 and Table S2), but in our statistics, $\mathrm{CF}_{\text {warm }}$ from MODIS standard and MODIS-ACAERO are not always lower than from SEVIRI-LaRC (Figs. 23-25). Differences in the spatial resolution ( $3 \mathrm{~km}$ for SEVIRI; $1 \mathrm{~km}$ for MODIS), in the algorithms used for identifying warm clouds, and in the aggregation of statistics (e.g., the L2 datasets for MODIS-
ACAERO versus the L3 dataset for MODIS standard) could also be producing differences in derived $\mathrm{CF}_{\mathrm{warm}}$. Notably, the uncertainty in the true $\mathrm{CF}_{\text {warm }}$, as expressed through the differences between the satellite products, is much lower than the differences between $\mathrm{CF}_{\text {warm }}$ from the observational datasets and the models.

$\mathrm{CF}_{\text {warm }}$ in WRF-CAM5 is higher than in all three observational datasets (Figs. 23-25). This is particularly the case in regions of low cloud fraction, so the gradients in cloud fraction across the transects follow the tendency of the observed gradients but are much smaller in magnitude. In contrast, the GEOS and ALADIN models both significantly underestimate $\mathrm{CF}_{\text {warm }}$ in all transects and almost all grid boxes. $\mathrm{CF}_{\text {warm }}$ gradients in the ALADIN model also track the observed gradients well but at a much lower cloud fraction. The GEOS model, in addition to significantly underestimating $\mathrm{CF}_{\text {warm }}$, fails to capture the correct gradient in cloud fraction. In particular, the latitudinal gradient in the cloud fraction along the meridional 2 transect in both 2017 and 2018 is the inverse of that observed. The UM-UKCA model comes closest to the observed cloud fractions, with variable biases depending on the transect and grid box. Like WRF-CAM5, UM-UKCA biases in cloud fraction are largest where it fails to capture spatial gradients in cloud fraction, e.g., along the meridional 1 transect, at the northern end of the meridional 2 transect, and at the eastern end of the zonal transect.

In the SE Atlantic, the large-scale gradients in day-to-day cloud fraction are controlled by a number of different intertwined factors, including gradients in sea surface temperature (SST) from the Benguela current off the Namibian-Angolan coast and by lower tropospheric stability (Wood, 2012). Increases in $\mathrm{CF}_{\text {warm }}$ in the $\mathrm{SE}$ Atlantic have been shown to be correlated with increases in lower tropospheric stability (LTS), surface wind speed, and RH at $950 \mathrm{hPa}$ (Fuchs et al., 2018). Seasonally dependent factors can also affect the SE Atlantic low cloud fields. In September, the intrusion of midlatitude disturbances to lower latitudes can significant perturb the low clouds, reducing $\mathrm{CF}_{\text {warm }}$. Elevated humidity in the free troposphere in October 2018 would also help reduce cloud-top entrainment drying. In the models, failure to capture these features and the dynamics that drive one or more of these variables could be the cause of incorrect gradients in $\mathrm{CF}_{\text {warm }}$.

Differences in the representation of small-scale turbulent mixing processes and microphysics have been shown to hamper model skill in representing stratocumulus properties, even when large-scale forcings are fixed (Zhu et al., 2005; Wyant et al., 2007). Accurate prediction of cloud cover is complicated because the relative roles of different large-scale forcings varies across the region (Fuchs et al., 2018). During the 3 years of the ORACLES campaign, the SSTs were warmer than the climatological average, though this does not appear to have resulted in a significant impact on cloud fraction in the month-long averages (Ryoo et al., 2021). 


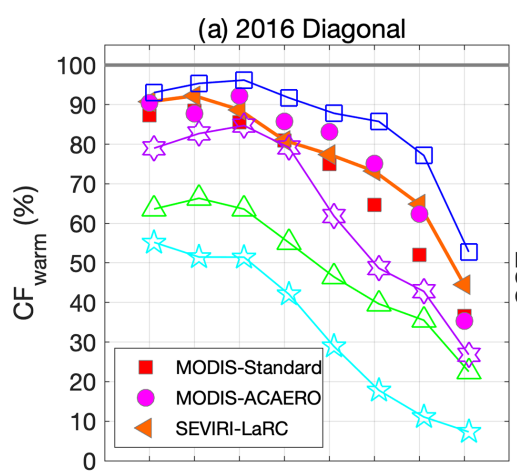

(c) 2016 Meridional1

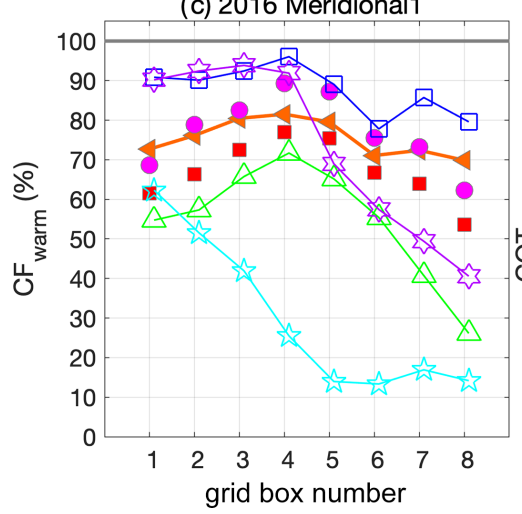

(b) 2016 Diagonal

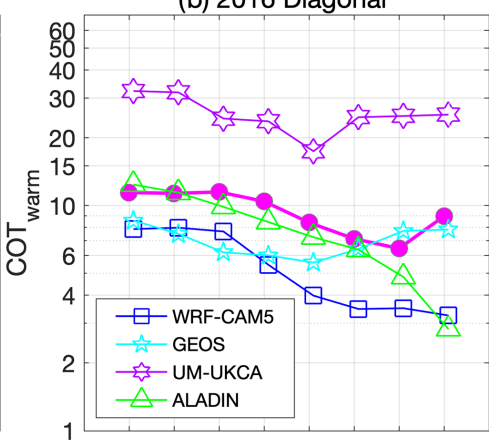

(d) 2016 Meridional1

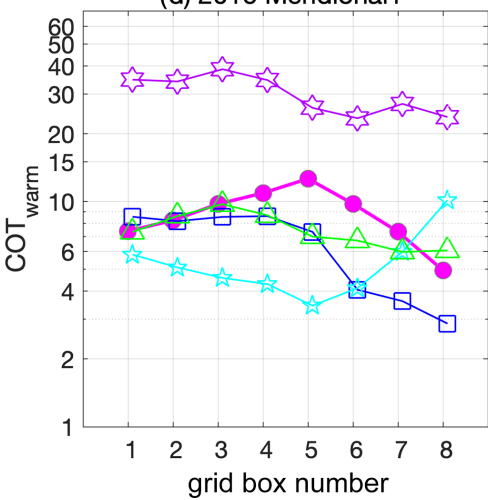

Figure 23. Average daytime mean $\mathrm{CF}_{\mathrm{warm}}(\mathbf{a}, \mathbf{c})$ and $\mathrm{COT}_{\mathrm{warm}}(\mathbf{b}, \mathbf{d})$ from satellite retrievals and from the models for the comparison grid boxes in the 2016 diagonal $(\mathbf{a}, \mathbf{b})$ and meridional 1 (c, d) transect. COT $_{\text {warm }}$ is the geometric mean, except for the ALADIN model, which shows the median. The SEVIRI-LaRC dataset is used as the reference for observed $\mathrm{CF}_{\text {warm }}$, and the MODIS-ACAERO dataset is used as the reference for observed COT $_{\text {warm }}$ in the comparison to models.

Disentangling the sources of model biases in $\mathrm{COT}_{\text {warm }}$ are even more difficult, especially since $\mathrm{COT}_{\text {warm }}$ may be affected not only by thermodynamic processes but is also very sensitive to cloud microphysical process representation (Wyant et al., 2007) and to aerosol-cloud interactions. As discussed above, the models tend to place the smoke plume at lower altitudes than observed and, therefore, to mix more of the plume into the boundary layer and low clouds than is observed. This would lead to higher aerosol loadings in the boundary layer, higher cloud droplet number concentrations, and possibly higher $\mathrm{COT}_{\text {warm }}$ (assuming cloud liquid water path is not significantly reduced in response; Twomey, 1977). An exception is for the ALADIN model $\mathrm{COT}_{\text {warm }}$, as aerosol microphysical effects on clouds were not simulated. Diagnosing the possible magnitude of this effect on $\mathrm{COT}_{\text {warm }}$ in the other models is beyond the scope of this paper.

The observed (MODIS-ACAERO) geometric mean $\mathrm{COT}_{\text {warm }}$ covers a fairly small range, of $8.3 \pm 1.8$, across all transects and years (Figs. 23-25). WRF-CAM5 COT warm values $(8.1 \pm 1.9)$ are very similar to the observed values on average but deviate from the observed values by not capturing spatial gradients. The result is that WRF-CAM5 sometimes overestimates and sometimes underestimates $\mathrm{COT}_{\text {warm. }}$ ALADIN generally reproduces the observed
$\mathrm{COT}_{\text {warm }}$ well, except at the western end of the zonal transect where $\mathrm{COT}_{\text {warm }}$ is about twice that observed. GEOS $\mathrm{COT}_{\text {warm }}$ is both too small and more spatially variable than observed (6.6 \pm 3.2$)$; like $\mathrm{CF}_{\text {warm }}$, the model also does not capture the correct spatial gradients in $\mathrm{COT}_{\text {warm }}$. UM-UKCA significantly overestimates COT $_{\text {warm }}$ across all transects, averaging $32.6 \pm 6.4$.

It has been noted that global models tend to have a "too few, too bright" bias for low-level marine clouds (Nam et al., 2012). Here, none of the four models fit this paradigm, including the two global models (GEOS and UM-UKCA). The regional WRF-CAM5 model has too many clouds, but the clouds are of about the right brightness, the regional ALADIN model has too few clouds that are generally not bright enough but are sometimes too bright, clouds in the global GEOS model are both too few and not bright enough, and the global UM-UKCA model has too many clouds that are much too bright.

In reality, it is expected that $\mathrm{COT}_{\text {warm }}$ will tend to increase with $\mathrm{CF}_{\text {warm }}$, and this is seen in the MODIS-ACAERO retrievals (Eq. 1 and Fig. S3). In contrast, the WRF-CAM5, GEOS, and ALADIN simulations show no significant change in $\mathrm{COT}_{\text {warm }}$ with $\mathrm{CF}_{\text {warm }}$, so as the cloud field develops to produce greater coverage, the clouds are not becoming op- 


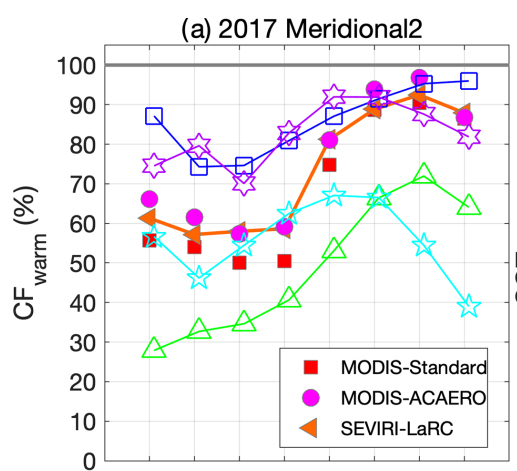

(c) 2018 Meridional2

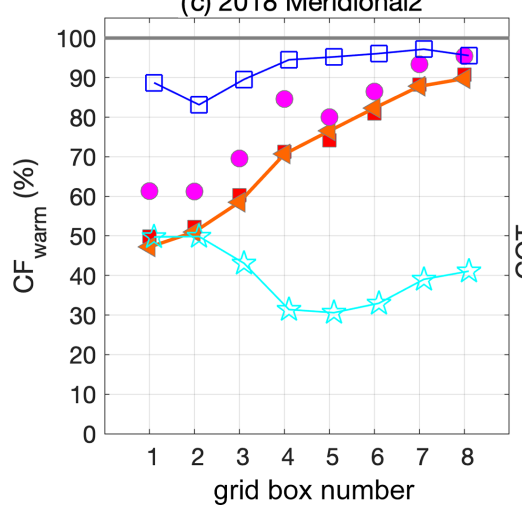

(b) 2017 Meridional2

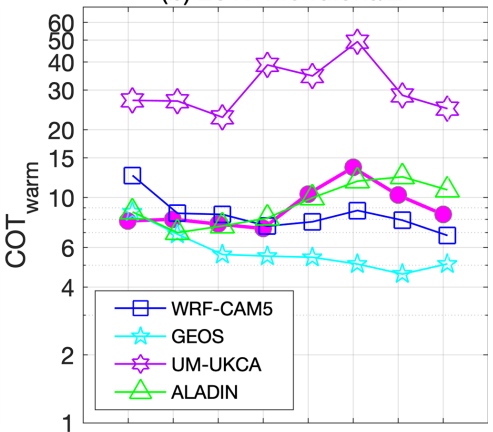

(d) 2018 Meridional2

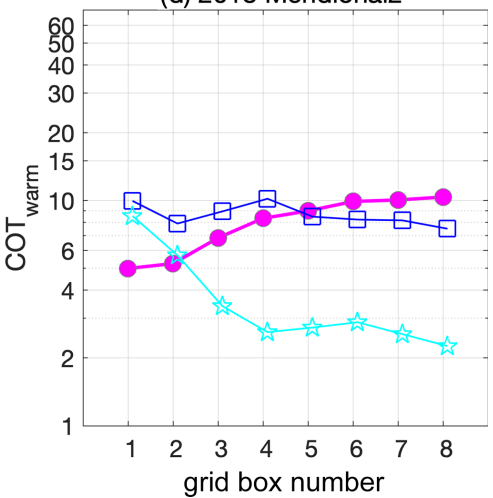

Figure 24. As in Fig. 23 but for the 2017 (a, b) and 2018 (c, d) meridional 2 transects.

tically thicker. The range in $\mathrm{CF}_{\text {warm }}$ covered by the models across the comparison transects included here is smaller than in the observations; a question is whether $\mathrm{COT}_{\text {warm }}$ would remain largely invariant for $\mathrm{CF}_{\mathrm{warm}}$ of $0-1.0$ in the models. If so, $\mathrm{COT}_{\text {warm }}$ at lower cloud fractions would be too high in WRF-CAM5 and too low in GEOS and ALADIN. In contrast, in the UM-UKCA simulations COT $_{\text {warm }}$ does increase with $\mathrm{CF}_{\text {warm }}$ at approximately the same rate as in the MODIS-ACAERO observations, but $\mathrm{COT}_{\text {warm }}$ is systematically too high (Fig. S3).

\section{Impact of aerosol and cloud biases in the direct aerosol radiative effect}

In order to quantify the net effect of model biases on the direct aerosol radiative effect (DARE), a first-order DARE estimate is calculated using the grid box mean aerosol and cloud properties for five of the comparison grid boxes. The $2016 \mathrm{di}-$ agonal grid box 3 was selected for being closer to the center of the plume while (in contrast to grid boxes 1 and 2) having more robust sampling (Figs. 1 and 2); in 2016 meridional 1 grid box 2 and 2017 and 2018 meridional 2 grid box 5 were selected for being located closer to the center of the plume meridionally; and in 2017 meridional 2 grid box 2 was selected in order to have one grid box with lower cloud fraction $(57 \%)$ since the other four selected grid boxes all have an average $\mathrm{CF}_{\text {warm }}$ of $>75 \%$.
Following Haywood and Shine (1995), DARE at the top of the atmosphere can be estimated as follows:

$$
\begin{gathered}
\mathrm{DARE} \approx-D \cdot S_{o} \cdot T_{\mathrm{at}}^{2} \cdot\left(1-A_{\mathrm{c}}\right) \cdot \mathrm{SSA} \cdot \bar{\beta} \cdot \mathrm{AOD} \\
\cdot\left(\left(1-R_{\mathrm{S}}\right)^{2}-\frac{2 R_{\mathrm{S}}}{\bar{\beta}}\left(\frac{1}{\mathrm{SSA}}-1\right)\right),
\end{gathered}
$$

where $D$ is the daylight fraction of the day, $S_{o}$ is the solar constant, $T_{\text {at }}$ is the atmospheric transmissivity (absent aerosol), $A_{\mathrm{c}}$ is cloud fraction, SSA is the single scatter albedo, $R_{\mathrm{S}}$ is the surface reflectance, $\bar{\beta}$ is the spectrally weighted aerosol hemispheric backscatter fraction, and AOD is the aerosol optical depth. This formulation assumes zero forcing in the presence of clouds (since for $A_{\mathrm{c}}=1$, DARE is equal to 0 ). The goal here is to calculate the forcing for an aerosol plume that, when clouds are present, is fully above the cloud layer and, therefore, has non-zero forcing. Equation (2) is therefore modified to the following:

$$
\begin{aligned}
& \mathrm{DARE} \approx-D \cdot S_{o} \cdot T_{\mathrm{at}}^{2} \cdot \mathrm{SSA} \cdot \bar{\beta} \cdot \mathrm{AOD} \\
& \cdot\left(\left(1-\alpha_{\mathrm{s}}\right)^{2}-\frac{2 \alpha_{\mathrm{S}}}{\bar{\beta}}\left(\frac{1}{\mathrm{SSA}}-1\right)\right),
\end{aligned}
$$

where $\alpha_{\mathrm{s}}$ is the scene albedo below the aerosol plume, and AOD is the above-cloud AOD. In this formulation, the impact of clouds on DARE is accounted for through their effect on $\alpha_{\mathrm{s}}$. This DARE estimate does not account for the fact that the cloud fields (and, therefore, $\alpha_{\mathrm{s}}$ ) might have been affected 

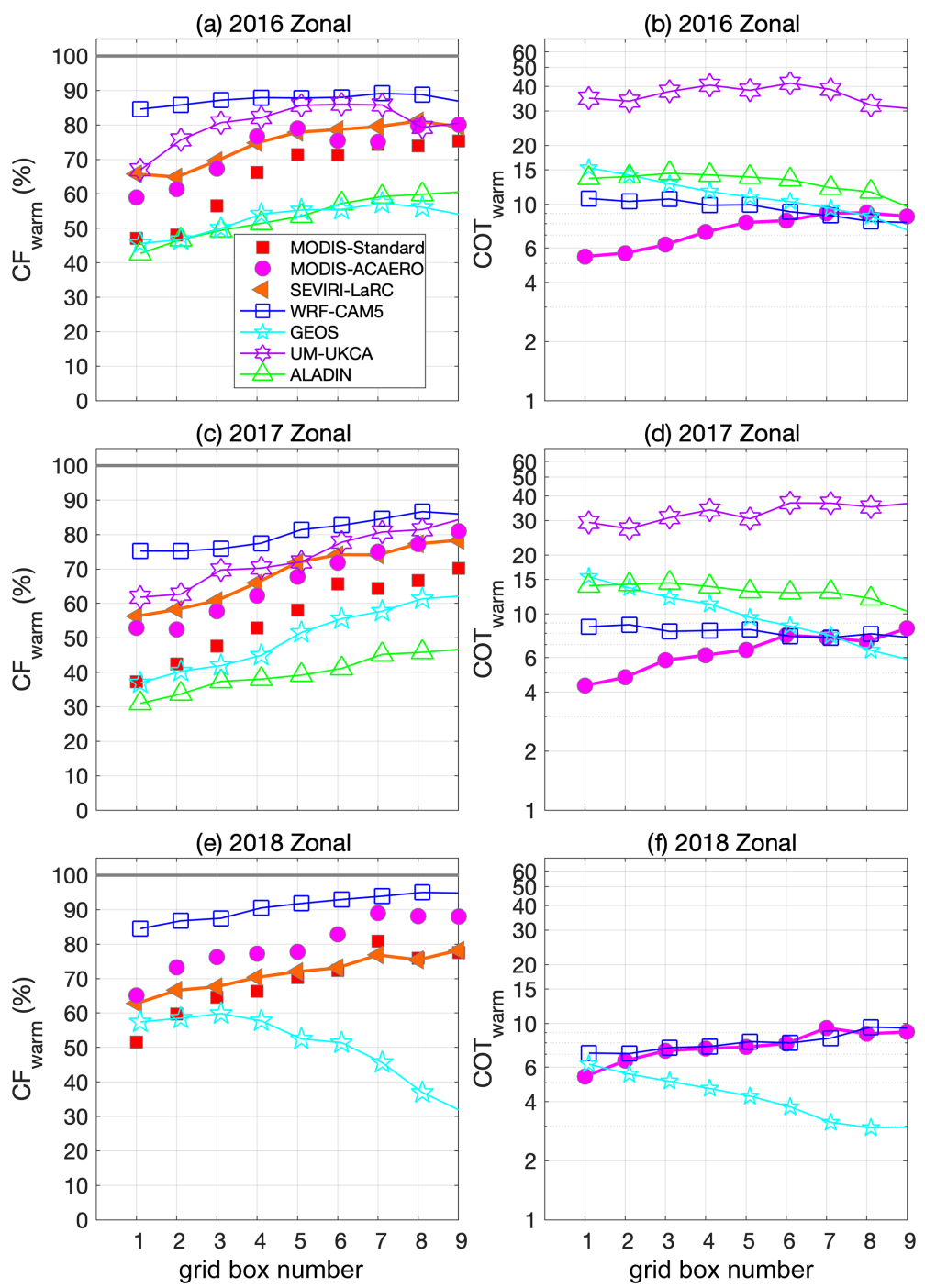

Figure 25. As in Fig. 23 but for the zonal transects in 2016 (a, b), 2017 (c, d), and 2018 (e, f).

by rapid adjustments to the smoke plume direct forcing (the semi-direct effect). Depending on the amount and altitude of heating by aerosol absorption above the clouds, this could have increased or decreased $\alpha_{\mathrm{s}}$, thereby affecting the calculation of DARE using Eq. (3).

DARE is nonlinear with $\alpha_{\mathrm{s}}$ (Eq. 3 and Cochrane et al., 2021), so here DARE is calculated separately for clear $\left(\mathrm{DARE}_{\text {clear }}\right)$ and cloudy $\left(\mathrm{DARE}_{\text {cloudy }}\right)$ skies. The grid-boxaveraged DARE $\left(\mathrm{DARE}_{\mathrm{avg}}\right)$ is the sum of the two, which are weighted by their average fractional contributions in each grid box as follows:

$$
\begin{aligned}
\operatorname{DARE}_{\text {avg }} & =\operatorname{DARE}_{\text {clear }}\left(1-\mathrm{CF}_{\text {warm }}\right) \\
& +\operatorname{DARE}_{\text {cloudy }} \mathrm{CF}_{\text {warm }} .
\end{aligned}
$$

This assumes that the aerosol is not systematically different over clear skies than over cloudy skies, as demonstrated for this region by Kacenelenbogen et al. (2019). The observed values of $\mathrm{CF}_{\text {warm }}$ used in Eq. (4) are the grid box means from the SEVIRI-LaRC retrievals.

For clear skies, $\alpha_{\mathrm{s}}$ in Eq. (3) is set to 0.07 (approximated from $\mathrm{Li}$ et al., 2006, for ocean reflectivity), and for cloudy skies, $\alpha_{\mathrm{s}}$ is the grid-box-averaged cloud albedo. The twostream approximation of Feingold et al. (2017) is used to calculate the visible cloud albedo $\alpha_{\mathrm{c}}$ as follows:

$\alpha_{\mathrm{c}}=\frac{\frac{(1-g)}{\cos \theta_{o}} \tau_{\mathrm{c}}}{2+\frac{(1-g)}{\cos \theta_{o}} \tau_{\mathrm{c}}}$,

where the asymmetry factor, $g$, is set to 0.85 (Bohren, 1980), the solar zenith angle, $\theta_{o}$, is fixed at $30^{\circ}$, and cloud optical thickness, $\tau_{\mathrm{c}}$, is set to the grid box log-mean value of $\mathrm{COT}_{\text {warm }}$ from the MODIS-ACAERO retrievals.

In Eq. (3), $D$ is fixed at 0.5 (which is correct to within 0.02 for this latitude range in all 3 months), $S_{o}$ is set to $1361 \mathrm{Wm}^{-2}$ (Kratz et al., 2020), and $T_{\text {at }}$ is set to 0.79 , based 
on Fig. 1 of Wild et al. (2019). The value $\bar{\beta}$ is calculated using Eq. (11b) of Reid et al. (1999), which parameterizes $\bar{\beta}$ as a function of $\sigma_{\mathrm{ep}}$ at $550 \mathrm{~nm}$ and the extinction Ångström exponent (EAE) across 437-669 nm (close to our wavelength span of $470-660 \mathrm{~nm}$ ) for biomass burning smoke. For the grid boxes included in this analysis, modeled $\bar{\beta}$ values varied from a low of 0.094 (in WRF-CAM5) to a high of 0.159 (in ALADIN), with observed values in the range 0.11-0.13 (Table 3). EAE, used in deriving $\bar{\beta}$, is calculated as follows:

$\mathrm{EAE}=\mathrm{SSA} \cdot \mathrm{SAE}+(1-\mathrm{SSA}) \cdot \mathrm{AAE}$.

The values of SSA, AAE, and SAE used in Eqs. (3) and (6) are extinction-weighted column values, and AOD is the integral of $\sigma_{\mathrm{ep}}$, all calculated across $1.5-5.5 \mathrm{~km}$ altitude, since this altitude range captures the vast majority of the abovecloud smoke plume in both the observations and the models.

AAE was not reported for the ALADIN model, so the observed value is used in the calculation of DARE (Table 3). In addition, in 2018 there were problems with the measurement of SAE, so the observed value in that year is set to 1.8 , since SAE in 2016 and 2017 was typically $1.7-1.9$ at plume altitudes across most comparison grid boxes. Aerosol properties for the UM-UKCA model are the ambient RH values.

Equations (3) and (4) provide a valuable tool to represent the functional dependency of DARE on aerosol and cloud properties and surface albedo. However, the resulting values (Table 3) are an approximation that does not fully account for all of the factors that influence DARE. For example, a fixed solar zenith angle $\left(30^{\circ}\right)$ is used in calculating cloud albedo, the aerosol backscatter (rather than upscatter) fraction is used in the calculation, and this formulation does not account for the effects of Sun angle on atmospheric gaseous transmission $\left(T_{\mathrm{a}}\right)$ and on aerosol scattering; spectral variations in aerosol and radiative properties are not included either. The amount of sunlight that interacts with the aerosol at a given altitude also depends on extinction by aerosol at higher altitudes, and this is not accounted for by using a fixed atmospheric transmission factor. In addition, the calculation uses month-long grid box averages for aerosol and cloud properties. DARE does not scale linearly with SSA or the subplume albedo and, therefore, with $\mathrm{CF}_{\text {warm }}$ and $\mathrm{COT}_{\text {warm }}$, so the mean DARE values presented here will differ from a mean of instantaneous DARE values.

To explore the limitations of Eq. (3), we perform full radiative transfer calculations for spectrally resolved upward and downward broadband fluxes $(100 \mathrm{~nm}$ bandwidth in the visible spectrum and $500 \mathrm{~nm}$ beyond) for cloudy and clear skies, with and without aerosol, using libRadtran (Mayer and Kylling, 2005). From these fluxes, we calculate the instantaneous DARE in cloudy and clear skies. Finally, DARE $E_{a v g}$ is calculated from the cloud fraction weighted DARE of both cloudy and clear skies, as in Eq. (4). To compare with the parameterized DARE $E_{\text {avg }}$, the instantaneous $D_{A R E_{a v g}}$ are integrated over $24 \mathrm{~h}$ to obtain the diurnally averaged DARE. Our simulations use a mid-latitude winter gas profile and correlated $k$ parameterization from Kato et al. (1999) for spectrally resolved results prior to spectral integration. The dark ocean in the simulation is treated as a Lambertian surface with a prescribed wavelength-dependent albedo. A slab aerosol layer is assumed for $2-5 \mathrm{~km}$ altitude, and the cloud layer is located at $0.7-1 \mathrm{~km}$. Spectral AOD and SSA are calculated using the EAE and AAE in Table 3.

The comparison of parameterized DARE $\mathrm{avg}_{\text {avg }}$ with the full radiative transfer calculations are shown in Fig. S22. We find a high correlation coefficient $\left(R^{2}=0.95\right)$ with relatively few outliers which are mostly confined to the DARE $\mathrm{avg}_{\text {a }}$ estimates for 2017 meridional 2 grid box 2 . We conclude that the parameterized DARE ${ }_{\text {avg }}$ estimates in Table 3 are useful for providing a first-order estimate of how biases in key aerosol and cloud properties translate to biases in DARE in this region, and we proceed by using the parameterized DARE ${ }_{\text {avg }}$ expressions to assess the contribution of each of the variables in Table 3 to a bias in derived DARE $\mathrm{avg}_{\text {avg }}$. These contributions are indicated in parentheses following the mean value of that variable; they are the ratio of DARE $_{\text {avg }}$ calculated using that model's value for the given variable only and the observed values for all other variables, to DARE $\mathrm{avg}_{\text {avg }}$ calculated using the observed variables. For example, for the 2016 diagonal grid box 3, the WRF-CAM5 low bias in SSA alone drives a $14 \%$ high bias in DARE avg $_{\text {. }}$

Notably, DARE $E_{\text {avg }}$ is positive $(>0)$ across all five grid boxes when calculated using the observed aerosol and cloud properties and the properties from the WRF-CAM5 and UMUKCA models. In contrast, it is negative in all five grid boxes using the properties simulated with ALADIN and negative for three of the five grid boxes for GEOS (Table 3). The modeled ambient RH 1.5-5.5 km AOD is lower than the observed low RH values for almost all grid boxes and models, but this does not translate directly to lower DARE. Even in those grid boxes where observed AOD is higher (see meridional 2 in both 2017 and 2018 in Table 3), DARE avg calculated from the model properties can be either larger and more positive or smaller and of the opposite sign to DARE $\mathrm{avg}_{\text {avg }}$ calculated from the observed properties. This is because biases in different variables often counteract each other.

This can be seen in the calculations for grid box 2 in the 2017 meridional 2 transect. This example stands out in that the modeled AOD is larger than observed in three of the four models (WRF-CAM5, GEOS, and ALADIN). $\mathrm{CF}_{\text {warm }}$ in this grid box is also lower than in the other four grid boxes $(0.57$ versus $>0.75$ ). In the WRF-CAM5 model, this high AOD bias combines with, in particular, a high bias in modeled $\mathrm{CF}_{\mathrm{warm}}$, and a low bias in SSA to produce DARE $\mathrm{avg}_{\text {g }}$ that is a factor of 6.6 larger than when calculated using the observed properties. In contrast, in ALADIN an AOD high bias of a similar magnitude combines with a significant low bias in $\mathrm{CF}_{\text {warm }}$ and a high bias in SSA to produce a DARE $\mathrm{avg}_{\text {avg }}$ that is 6.1 times larger than that using observed properties - but it is of the opposite sign. 


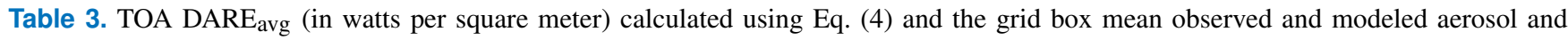
cloud properties used in the calculation for select comparison grid boxes. Also given in parentheses after each modeled variable is the ratio of DARE $E_{\text {avg calculated using that model's value for the given variable only and the observed values for all other variables to DARE }}$ avg calculated using the observed variables. The values of $\bar{\beta}, \alpha_{\mathrm{c}}$, and $\alpha_{\mathrm{S}}$ are shown in italics because they are derived from the observed and modeled parameters (see the text). In the table below, $\alpha_{\mathrm{S}}=0.07\left(1-\mathrm{CF}_{\mathrm{warm}}\right)+\alpha_{\mathrm{c}} \mathrm{CF}_{\mathrm{warm}}$ is given as a metric for the combined effect of $\mathrm{CF}_{\text {warm }}$ and $\mathrm{COT}_{\text {warm }}$ on DARE. As noted in the text, DARE is actually calculated separately for clear and cloudy skies using Eq. (3), then DARE $_{\text {avg }}$ is calculated using Eq. (4).

\begin{tabular}{|c|c|c|c|c|c|}
\hline & Observed & WRF-CAM5 & GEOS & UM-UKCA & ALADIN \\
\hline \multicolumn{6}{|c|}{2016 diagonal, grid box 3} \\
\hline AOD & 0.360 & $0.254(0.71)$ & $0.226(0.63)$ & $0.181(0.50)$ & $0.276(0.77)$ \\
\hline SSA & 0.855 & $0.841(1.14)$ & $0.851(1.04)$ & $0.842(1.13)$ & $0.892(0.64)$ \\
\hline SAE & 1.77 & $1.05(1.07)$ & $1.75(1.00)$ & $1.73(1.01)$ & $2.08(0.90)$ \\
\hline $\mathrm{AAE}$ & 1.48 & $1.12(1.01)$ & $1.13(1.01)$ & $1.38(1.00)$ & $\{1.48\}(\mathrm{NA})^{1}$ \\
\hline $\mathrm{CF}_{\text {warm }}$ & 0.88 & $0.96(1.16)$ & $0.52(0.30)$ & $0.85(0.94)$ & $0.64(0.53)$ \\
\hline $\mathrm{COT}_{\text {warm }}$ & 11.5 & $7.6(0.63)$ & $6.2(0.44)$ & $24.4(1.61)$ & $9.9(0.86)$ \\
\hline $\bar{\beta}$ & 0.120 & 0.094 & 0.112 & 0.114 & 0.158 \\
\hline$\alpha_{\mathrm{c}}$ & 0.499 & 0.397 & 0.349 & 0.678 & 0.461 \\
\hline$\alpha_{\mathrm{s}}$ & 0.448 & 0.384 & 0.215 & 0.587 & 0.320 \\
\hline DARE $_{\text {avg }}$ & 14.8 & 9.9 & 0.3 & 12.7 & -0.1 \\
\hline model/obse & ved DARE & 0.67 & 0.02 & 0.86 & -0.01 \\
\hline \multicolumn{6}{|c|}{2016 meridional 1, grid box 2} \\
\hline AOD & 0.419 & $0.257(0.62)$ & $0.236(0.56)$ & $0.259(0.62)$ & $0.375(0.90)$ \\
\hline SSA & 0.867 & $0.833(1.73)$ & $0.868(0.98)$ & $0.854(1.28)$ & $0.885(0.62)$ \\
\hline SAE & 1.89 & $1.20(1.42)$ & $1.65(1.24)$ & $1.90(0.99)$ & $2.05(0.75)$ \\
\hline AAE & 1.57 & $1.15(1.08)$ & $1.14(1.08)$ & $1.47(1.02)$ & $\{1.57\}(\mathrm{NA})^{1}$ \\
\hline $\mathrm{CF}_{\mathrm{warm}}$ & 0.76 & $0.90(1.61)$ & $0.52(-0.04)$ & $0.92(1.70)$ & $0.57(0.17)$ \\
\hline $\mathrm{COT}_{\text {warm }}$ & 8.3 & $8.2(0.99)$ & $5.1(0.01)$ & $38.7(3.77)$ & $8.6(1.10)$ \\
\hline $\bar{\beta}$ & 0.133 & 0.096 & 0.108 & 0.137 & 0.158 \\
\hline$\alpha_{\mathrm{c}}$ & 0.417 & 0.415 & 0.306 & 0.770 & 0.427 \\
\hline$\alpha_{\mathrm{S}}$ & 0.334 & 0.381 & 0.193 & 0.714 & 0.274 \\
\hline DARE $_{\text {avg }}$ & 6.2 & 10.4 & -1.1 & 21.4 & -2.4 \\
\hline model/obse & ved DARE & 1.68 & -0.18 & 3.44 & -0.39 \\
\hline \multicolumn{6}{|c|}{2017 meridional 2 , grid box 2} \\
\hline AOD & 0.292 & $0.450(1.54)$ & $0.352(1.21)$ & $0.258(0.88)$ & $0.485(1.66)$ \\
\hline SSA & 0.861 & $0.835(1.91)$ & $0.866(0.82)$ & $0.854(1.25)$ & $0.888(0.05)$ \\
\hline SAE & 1.70 & $1.02(1.56)$ & $1.67(1.05)$ & $1.72(0.96)$ & $2.06(-0.09)$ \\
\hline AAE & 1.44 & $1.1(1.10)$ & $1.14(1.09)$ & $1.34(1.03)$ & $\{1.44\}(\mathrm{NA})^{1}$ \\
\hline $\mathrm{CF}_{\mathrm{warm}}$ & 0.57 & $0.74(2.46)$ & $0.46(0.07)$ & $0.80(2.91)$ & $0.33(-1.06)$ \\
\hline $\mathrm{COT}_{\text {warm }}$ & 8.0 & $8.5(1.20)$ & $6.9(0.53)$ & $26.8(4.52)$ & $7.0(0.57)$ \\
\hline $\bar{\beta}$ & 0.114 & 0.094 & 0.109 & 0.113 & 0.160 \\
\hline$\alpha_{\mathrm{c}}$ & 0.410 & 0.425 & 0.374 & 0.699 & 0.377 \\
\hline$\alpha_{\mathrm{S}}$ & 0.264 & 0.333 & 0.210 & 0.571 & 0.170 \\
\hline DARE $_{\text {avg }}$ & 2.1 & 14.0 & -0.7 & 15.6 & -12.9 \\
\hline model/obse & ved DARE & 6.58 & -0.35 & 7.35 & -6.08 \\
\hline
\end{tabular}

${ }^{1}$ AAE was not reported for the ALADIN model, so the observed value is used in the calculation of DARE. ${ }^{2}$ SAE measurements are not available for 2018, so the average value of 1.8 from 2017 is used here. Please note that "NA" stands for not available. 
Table 3. Continued.

\begin{tabular}{lrrrrr}
\hline & Observed & WRF-CAM5 & GEOS & UM-UKCA & ALADIN \\
\hline \multicolumn{2}{l}{2017 meridional 2, grid box 5} & & & & \\
\hline AOD & 0.591 & $0.370(0.62)$ & $0.389(0.65)$ & $0.252(0.42)$ & $0.562(0.94)$ \\
SSA & 0.868 & $0.830(1.50)$ & $0.837(1.40)$ & $0.852(1.20)$ & $0.874(0.91)$ \\
SAE & 1.80 & $1.10(1.14)$ & $1.77(1.00)$ & $1.77(1.00)$ & $2.14(0.74)$ \\
AAE & 1.55 & $1.11(1.02)$ & $1.14(1.02)$ & $1.30(1.01)$ & $\{1.55\}(\mathrm{NA})$ \\
$\mathrm{CF}_{\text {warm }}$ & 0.81 & $0.87(1.15)$ & $0.67(0.62)$ & $0.92(1.28)$ & $0.53(0.24)$ \\
COT $_{\text {warm }}$ & 10.4 & $7.8(0.65)$ & $5.4(0.22)$ & $34.7(2.22)$ & $9.98(0.94)$ \\
$\beta$ & 0.122 & 0.095 & 0.114 & 0.115 & 0.171 \\
$\alpha_{\mathrm{c}}$ & 0.473 & 0.403 & 0.319 & 0.750 & 0.464 \\
$\alpha_{\mathrm{S}}$ & 0.397 & 0.360 & 0.237 & 0.696 & 0.279 \\
DARE $_{\text {avg }}$ & 16.0 & 14.0 & 3.4 & 20.7 & -3.1 \\
model/observed DARE & 0.88 & 0.21 & 1.30 & -0.22 \\
\hline
\end{tabular}

\begin{tabular}{|c|c|c|c|c|c|}
\hline \multicolumn{6}{|c|}{2018 meridional 2 , grid box 5} \\
\hline $\mathrm{AOD}$ & 0.248 & $0.165(0.67)$ & $0.261(1.06)$ & - & - \\
\hline SSA & 0.890 & $0.851(2.04)$ & $0.877(1.35)$ & - & - \\
\hline SAE & $1.8^{2}$ & $1.22(1.36)$ & $1.68(1.13)$ & - & - \\
\hline AAE & 1.45 & $1.18(1.05)$ & $1.13(1.05)$ & - & - \\
\hline $\mathrm{CF}_{\text {warm }}$ & 0.77 & $0.95(1.87)$ & $0.31(-1.21)$ & - & - \\
\hline $\mathrm{COT}_{\text {warm }}$ & 9.0 & $8.5(0.88)$ & $2.7(-1.42)$ & - & - \\
\hline $\bar{\beta}$ & 0.123 & 0.096 & 0.111 & - & - \\
\hline$\alpha_{\mathrm{c}}$ & 0.438 & 0.424 & 0.190 & - & - \\
\hline$\alpha_{\mathrm{s}}$ & 0.353 & 0.406 & 0.107 & - & - \\
\hline DARE $_{\text {avg }}$ & 3.1 & 6.4 & -5.7 & - & - \\
\hline model/ob & DARE & 2.09 & -1.85 & - & - \\
\hline
\end{tabular}

${ }^{1}$ AAE was not reported for the ALADIN model, so the observed value is used in the calculation of DARE. ${ }^{2}$ SAE measurements are not available for 2018 , so the average value of 1.8 from 2017 is used here. Please note that "NA" stands for not available.

Across the five grid boxes, biases in $\sigma_{\mathrm{ep}}$ (AOD) and $\mathrm{CF}_{\text {warm }}$ and $\mathrm{COT}_{\text {warm }}$ (through their role in determining $\alpha_{\mathrm{s}}$ ) alternately make the largest contributions to biases in

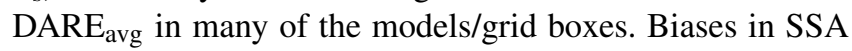
are usually the source of somewhat smaller DARE $\mathrm{Dvg}_{\mathrm{a} g}$ biases, but it is a still significant contributor across most models and grid boxes. Low biases in SAE in the WRF-CAM5 and GEOS-5 models and a high bias in SAE in the ALADIN model also can drive biases of the order of $30 \%-40 \%$ through its role in determining $\bar{\beta}$ (see Eq. 3 ).

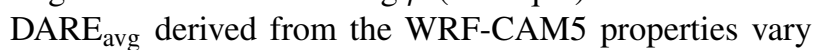
from being within about $30 \%$ of DARE $\mathrm{D}_{\mathrm{avg}}$ calculated using the observed properties in two of the five grid boxes, to having significantly high biases in the other three (factors of 1.7, 6.6, and 2.1). In these latter three cases, the consistent low bias in SSA and high bias in $\mathrm{CF}_{\text {warm more than offsets a low }}$ bias in AOD in two of the grid boxes and adds to the high bias in AOD in the third. This is not the case in 2016 diagonal grid box 3 , where SSA and $\mathrm{CF}_{\text {warm }}$ are still biased low and high, respectively, but when combined with a low bias in $\mathrm{COT}_{\text {warm }}$, the resulting DARE $\mathrm{avg}_{\text {is much close to DARE }}$ ivg from the observed properties. The excellent agreement in 2017 meridional 2 grid box 5 in DARE using the observed and WRF-CAM5 properties also results from compensating

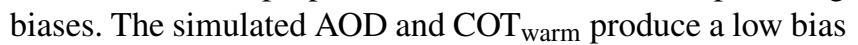
in DARE $\mathrm{Davg}_{\mathrm{a}}$, and the simulated SSA and (to a lesser degree) $\mathrm{SAE}$ and $\mathrm{CF}_{\text {warm }}$ produce a high bias in DARE $\mathrm{Dvg}_{\text {, nearly }}$ exactly offsetting each other. This shows how qualitatively consistent biases in a given model's representation of aerosol and cloud properties key to DARE can combine to produce a large range of biases in modeled DARE.

In GEOS, the extinction-weighted SSA in the plume introduces small $(<20 \%)$ low biases in DARE $\mathrm{avg}_{\mathrm{avg}}$ in three of the grid boxes and $35 \%-40 \%$ low biases in the other two. More significant for this model is larger low biases in AOD in three of the five grid boxes and systematic low biases in $\mathrm{CF}_{\text {warm, }}$, and $\mathrm{COT}_{\text {warm }}$. These result in values of DARE that are too small and, for three of the five cases, produce negative rather than positive values. As in WRF-CAM5, biases in different variables can offset each other. For example, correcting for AOD alone would produce even larger negative values of forcing for three of the five grid boxes, increasing the difference between DARE $_{\mathrm{avg}}$ from the modeled and observed properties.

In the UM-UKCA model, a high bias in $\mathrm{CF}_{\text {warm }}$ and a large high bias in $\mathrm{COT}_{\text {warm }}$ make the subplume scene albedo 
of the order of a factor of 2 too high, driving large high biases in DARE avg $_{\text {. This, combined with a small }(\sim 0.01-0.02)}$ low bias in SSA, more than compensates for the low bias in AOD to produce values of DARE $\mathrm{avg}_{\text {g }}$ that are too large in three of the four grid boxes tested and significantly so (by factors of 3.4 and 7.4) in two of the grid boxes. Correction to just the aerosol fields would produce DARE $\mathrm{avg}_{\mathrm{ag}}$ that is universally too high; correction to just the cloud fields, conversely, would produce DARE $_{\text {avg }}$ that is universally too low.

The ALADIN model consistently simulates too small $\mathrm{CF}_{\text {warm }}$ and too high SSA. These are sufficient to produce a negative direct aerosol radiative effect across all five grid boxes, which is in contrast with the positive DARE $\mathrm{avg}_{\text {avg }}$ calculated from the observed values. In the 2017 meridional 2 grid box 2, the $\mathrm{CF}_{\text {warm }}$ bias alone is sufficient to produce negative DARE. Small low biases in AOD and $\mathrm{COT}_{\text {warm }}$ and a high bias in SAE also combine to produce values of DARE $\mathrm{avg}_{\mathrm{ag}}$ that are too small (AOD and SAE) and too negative ( $\mathrm{COT}_{\text {warm }}$ ).

These findings support those of earlier studies (e.g., Chand et al., 2009; Stier et al., 2013; Zuidema et al., 2016) that emphasize the importance of accurately simulating cloud fraction in order to obtain accurate estimates of direct forcing by biomass burning aerosol over the SE Atlantic. They also highlight the importance of quantifying the relative roles of the aerosol and cloud properties that control the direct aerosol radiative effect, since the magnitude, sign, and source(s) of DARE biases can vary with the aerosol and cloud properties themselves. The limited analysis presented here makes it clear that models can have compensating biases, such that model improvements that make one key parameter more accurate could actually lead to less accurate simulated values of DARE. This first-order analysis provides a framework for a future study that employs full radiative transfer calculations that use, for example, the full 2D profiles of observed and modeled cloud properties and account for diurnal effects, and that accounts for uncertainties and variability in observed and modeled fields.

\section{Discussion and conclusions}

The WRF-CAM5 and GEOS models were used to test for representativeness of the observations of the biomass burning plume along our comparison transects, using aerosol light extinction as the metric (Sect. 4.1). This approach assumes that the models accurately represent variability in $\sigma_{\mathrm{ep}}$, even if there are biases in the mean values of $\sigma_{\mathrm{ep}}$. A first-order test indicates this is a good assumption in 2016, but that the two models had different levels of variability from each other and from the observations in 2017 and 2018 (Sect. 2.2). This is reflected in the different results from the two models when testing for representativeness. The representativeness of a given set of samples within the models also varies between years, even for the same transect (meridional 2), indicating systematic differences between the models at inter- annual timescales and/or for different locations. In addition, model invariance in the biomass burning plume aerosol intensive properties (e.g., SSA) made the models not useful for testing the representativeness of sampled aerosol intensive optical properties.

With the exception of the WRF-CAM5 model in 2018, the models simulated either comparable or higher variability $\sigma_{\mathrm{ep}}$ within the comparison transects. As such, with that one exception, they likely present a conservative estimate of the representativeness of the observations. Though there were some exceptions, sampled values of $\sigma_{\mathrm{ep}}$ in the $2-5 \mathrm{~km}$ altitude range across the diagonal (2016), meridional 1 (2016), and meridional 2 (2017 and 2018) transects were generally within $20 \%$ of the approximately month-long period of each year's campaign. This altitude range encompasses the core of the biomass burning plume in most comparison grid boxes and campaign years. The fact that the modeled plume concentrations (as measured by $\sigma_{\mathrm{ep}}$ ) at the sampled times were this close to the month-long averages is surprising given that, even with about half the ORACLES flights dedicated to routine track sampling, data were collected for, at most, only 1$2 \mathrm{~h}$ of the full approximately month-long campaign period in each year for a given grid box and $500 \mathrm{~m}$ altitude bin (Fig. 2).

Biases in the plume altitude and concentration were tested through comparisons to observed $\mathrm{CO}$ concentration, $\sigma_{\mathrm{ep}}$, and $\mathrm{BC}$ and OA concentrations across 3 campaign years covering different months (September 2016, August 2017, and October 2018) and, therefore, different parts of the African biomass burning season. Biases in $\mathrm{CO}$ for the two models that reported it (WRF-CAM5 and GEOS) suggest underestimates in emissions or possibly in the efficiency of transport of the biomass burning plume over the SE Atlantic from the burning source regions, since $\mathrm{CO}$ is not affected by scavenging processes. An earlier assessment of GEOS representation of the African biomass burning plume indicates that, for that model, transport biases are the more likely cause (Das et al., 2017). In both models, the low bias in CO was larger in October 2018, which is towards the end of the biomass burning season, than in August 2017 and September 2016. Notably, both of these models use QFED2 emissions.

In the core of the plume, low biases in BC in WRF-CAM5 and GEOS were somewhat smaller than the CO low biases. In other words, the $\mathrm{CO}: \mathrm{BC}$ ratio was somewhat lower in the models than the observations, particularly in the October 2018 meridional 2 transect and more so in the GEOS model than in WRF-CAM5. The ratio of $\mathrm{CO}: \mathrm{BC}$ in biomass burning primary emissions depends on the material being burned and the efficiency of burning (smoldering versus flaming; e.g., Reid et al., 2005), but this is set within the QFED emissions and so cannot explain these intermodel differences. Differences in anthropogenic sources could also be contributing (e.g., WRF-CAM5 uses EDGAR-HTAP while GEOS uses AeroCom Phase II), as could differences in the background CO concentrations. In October 2018, when differences between the models and the observations were largest, 
the biomass burning plume was less intense, so for that month the background and anthropogenic emissions could be more strongly influencing the $\mathrm{CO}$ and $\mathrm{BC}$ concentrations. For the biomass burning aerosol itself, given the common emissions dataset used by the two models, differences in the $\mathrm{CO}: \mathrm{BC}$ ratio between the models must be due to differences in the in-atmosphere chemistry and processing, combined with dynamics, leading to different aerosol scavenging rates. Notably, WRF-CAM5 has more sophisticated aerosol chemistry than GEOS. Greater scavenging losses in reality than in the models in the first couple of days after emission, e.g., mostly over the land, could also be contributing to the lower $\mathrm{CO}: \mathrm{BC}$ ratio in models than in the observations.

Model biases in $\mathrm{BC}$ versus in $\mathrm{OA}$, and how these biases evolve along the aerosol transport pathway, also give some insight to model processes. This is because BC is a refractory, primary aerosol; it is not produced or destroyed in the atmosphere (Bond et al., 2013). OA, on the other hand, is emitted directly as an aerosol, is being formed in the atmosphere in secondary production from gas phase constituents, and is lost in the atmosphere through evaporation back to the gas phase, photo-chemical transformation, and/or heterogenous oxidation (e.g., Hallquist et al., 2009; O'Brien and Kroll, 2019).

In most grid boxes above the boundary layer, there is a smaller low bias (or in some locations a greater high bias) in $\mathrm{OA}$ than in $\mathrm{BC}$, in the three models that report both parameters (WRF-CAM5, GEOS, and UM-UKCA). The higher $\mathrm{OA}$ : $\mathrm{BC}$ ratio in the models, as reflected in their respective relative biases, is more pronounced in 2017 and 2018 and in the GEOS model, and it tends to be lower at the core of the plume than at the plume edges. This could originate from a number of model biases, including primary emissions having too high a ratio of $\mathrm{OA}: \mathrm{BC}$, too much secondary organic aerosol (SOA) production, and/or insufficient loss of organics with aerosol aging. Again, WRF-CAM5 and GEOS both use the GFED emissions, so they should have the same $\mathrm{OA}$ : $\mathrm{BC}$ ratio in primary emissions. The UM-UKCA model, however, uses the FEER inventory, which may have a different $\mathrm{OA}$ : $\mathrm{BC}$ ratio in emissions from these fires. For OA, the in-atmosphere production and losses can be significant. Previous studies have shown that SOA can be produced rapidly - within minutes to hours - after emission (e.g., Jimenez et al., 2009; Bond et al., 2013). OA can also be produced and lost on timescales of days to $>1$ week after emission (Capes et al., 2008; Wagstrom et al., 2009; Cubison et al., 2011; Jolleys et al., 2015; Hodzic et al., 2015; Collier et al., 2016; Konovalov et al., 2019; Hodshire et al., 2019; Cappa et al., 2020).

Model-based age estimates indicate that the aerosol we sampled during ORACLES was almost always at least $2 \mathrm{~d}$ old, so our observations only inform us how the OA : BC ratio evolved starting several days after emission. Observations from ORACLES may ultimately not be able to discriminate the loss of OA through aging from differences in the OA mass in the source emissions. Regardless, processes that drive the in-atmosphere OA losses on these longer (multiday) timescales are not implemented in any of the models included here, and this could lead to higher model OA : BC ratios for aged aerosol. However, we cannot rule out too high a ratio of $\mathrm{OA}: \mathrm{BC}$ in emissions and too much secondary organic aerosol (SOA) production, although the latter is less likely as models tend to show low production of SOA compared to observations (Hodzic et al., 2016).

Biases in $\sigma_{\mathrm{ep}}$ stem from the combined biases in the aerosol component (e.g., BC and $\mathrm{OA}$ ) masses and in the mass extinction efficiency. The latter depends in part on aerosol water content, especially above $\sim 40 \%-50 \% \mathrm{RH}$. Here, the in situ observed values of $\sigma_{\mathrm{ep}}$ were made at low $(<40 \%) \mathrm{RH}$, whereas the HSRL-2 measured and modeled values were at ambient RH. All four models significantly underestimate $\sigma_{\mathrm{ep}}$, with low biases in $\sigma_{\text {ep }}$ greater than for BC or OA. Consistent with this, Shinozuka et al. (2020) calculated a proxy for the mass extinction efficiency, $\sigma_{\mathrm{ep}} /(\mathrm{OA}+\mathrm{BC})$, from the observations and models, and found it was lower in the models than the observations, including for the $3-6 \mathrm{~km}$ altitude column. For spherical particles and mid-visible wavelengths, the mass scattering efficiency increases with aerosol diameter between about 100 and $450 \mathrm{~nm}$ diameter, then decreases above about $600 \mathrm{~nm}$ (e.g., Saide et al., 2020). The SAE provides a proxy for aerosol size; assuming a monomodal size distribution, typical SAE values indicate an aerosol effective diameter of approximately $380-400 \mathrm{~nm}$ for ALADIN (SAE of 2.0-2.2), $420 \mathrm{~nm}$ for the observations and GEOS (SAE of 1.8), 400$420 \mathrm{~nm}$ for UM-UKCA (SAE of 1.8-2.0), and $700 \mathrm{~nm}$ for WRF-CAM5 (SAE of 1.0) (Schuster et al., 2006). Because the mass extinction efficiency peaks at about $500 \mathrm{~nm}$, aerosol size alone would drive it higher for the observations, GEOS, and UM-UKCA models than for ALADIN - but it should be comparable for the observations and WRF-CAM5 despite the SAE differences (see Fig. 10a of Saide et al., 2020). In this case, a more likely source of the apparent low bias in model mass extinction efficiency are the real indices of refraction used in the models for aerosol components, as the OA real refractive index used in WRF-CAM5 is 1.45 , while the literature values for biomass burning are more often in the 1.52-1.55 range (Aldhaif et al., 2018).

The $\mathrm{CO}, \mathrm{BC}, \mathrm{OA}$, and $\sigma_{\mathrm{ep}}$ comparisons all indicate that the models simulated plumes that are too vertically diffuse. Too much vertical diffusion in the models maybe responsible for, in particular, the plume top terminating at lower altitude in the in situ observations than in some of the simulations, often leading to low biases in modeled $\mathrm{CO}, \mathrm{BC}, \mathrm{OA}$, and $\sigma_{\text {ep }}$ in the $2-5 \mathrm{~km}$ altitude range and significant relative (but small absolute) high biases in the 5-6 km range in the comparisons. It is not fully clear, however, whether this is a robust result, given that the HSRL-2, like the models, measured extinction extending to higher altitudes than the in situ observations did (Sect. 4.2.3).

In the GEOS, UM-UKCA, and ALADIN models, it also appears that either the smoke is not lofted sufficiently high 
over the continent or that the subsidence is too strong in the models, particularly in 2016 but also in 2018 (for GEOS). In the WRF-CAM5 model, all biomass burning emissions are injected into the surface model layer; this smoke is lifted and mixes in the continental boundary layer, which grows to a depth of typically about 3.5-4.0 km (Labonne et al., 2007) but can reach $4.5-5.5 \mathrm{~km}$ (Ryoo et al., 2021). In the UMUKCA model, emissions are added to the boundary layer such that concentrations taper from higher values at the surface to zero at $3 \mathrm{~km}$ above the surface. Burning progresses southward through the biomass burning season, with the land surface elevation where burning is occurring shifting from $<500 \mathrm{~m}$ in the Congo Basin to $>1500 \mathrm{~m}$ in the Namibian Kalahari dryland. This increase in elevation assists the lofting of the smoke (Ryoo et al., 2021). Notably, the models underestimate the smoke plume height during the later months of the burning season when fires are sourced at higher elevations, indicating possible issues with the model representation of boundary layer development over land. It is also possible that lifting of the plume driven by subgrid scale processes (Freitas et al., 2006) and/or by aerosol self-lifting through absorption and heating (Boers et al., 2010; de Laat et al., 2012) that is not fully accounted for in the models.

The tendency for the models to have too diffuse a bottom edge of the plume and a plume that is too low in altitude will lead to greater mixing of the aerosol into clouds and, therefore, aerosol-cloud interactions. The vertical distance between the cloud top and the biomass burning plume could also affect the semi-direct forcing in this region (Adebiyi and Zuidema, 2018). Based on the altitude dependence of the model bias in aerosol concentrations, the impact of these biases is more pronounced in September 2016 and August 2017 than in October 2018.

While the magnitude of aerosol scattering and absorption over this region is largely controlled by above-cloud AOD, or vertically integrated $\sigma_{\mathrm{ep}}$, the sign of the direct effect is controlled by the aerosol SSA in the plume and by subplume albedo (here, largely controlled by $\mathrm{CF}_{\text {warm }}$ ). In the observations, SSA increases with altitude in the plume in September 2016 and October 2018 but not in August 2017. These vertical variations were not captured by any of the models (Fig. 14). Both WRF-CAM5 and GEOS do, however, have overall higher SSA in August (2018) than in September and October (2016 and 2018), as do the observations.

Co-albedo (1-SSA) differences, weighted by $\sigma_{\text {ep }}$, translate directly to differences in absorbed energy. Ambient RH SSA is lower (and co-albedo higher) than the observed dry SSA in the WRF-CAM5, GEOS, and UM-UKCA models; in ALADIN, the SSA is both higher and more variable than observed. These biases vary with altitude, with some of the largest differences in modeled and observed SSA towards the top of the plume. Large SSA biases at altitudes with very little light extinction will, however, have little impact on DARE. At altitudes where the plume is largely concentrated $(2.5-5 \mathrm{~km})$, on average, the co-albedo in the model is biased high by $\sim 5 \%-10 \%$ in UM-UKCA, $\sim 15 \%$ in GEOS-5, and $15 \%-20 \%$ in WRF-CAM5, relative to the dry observed values. ALADIN co-albedo is biased low by about $10 \%-35 \%$ on average. These biases combine with biases in $\sigma_{\text {ep }}$ to affect the atmospheric absorption and, therefore, in addition to DARE, the marine low cloud responses to atmospheric absorption above the clouds.

All of the values above are for mid-visible (530 or $550 \mathrm{~nm}$ ) SSA, but of course DARE operates over the full solar spectrum. Spectral SSA is, in turn, directly related to SAE and AAE. Thus, uncertainty in AAE translates into uncertainty in spectral SSA and, in the context of DARE, the amount of sunlight absorbed in the atmosphere. The observed values of $\sigma_{\mathrm{ap}}$ are well constrained at $530 \mathrm{~nm}$, but they are very uncertain at shorter and longer wavelengths (470 and $660 \mathrm{~nm}$ ) where the PSAP measurements have not been as robustly calibrated. For the ORACLES biomass aerosol, the two different Virkkula (2010) calibrations yield AAE values of about 1.2 (wavelength-averaged correction) and 1.5 (wavelengthspecific correction), whereas the modeled values average 1.1-1.2, with little difference across the 3 field campaign years. Notably, the lower values agree well with AAE values measured near Ascension Island during the UK CLARIFY 2017 campaign, which used a photoacoustic spectrometer to measure absorption (Taylor et al., 2020).

A question is whether this uncertainty in AAE leads to a significant uncertainty in DARE. By definition, the AAE parameterization of absorption change versus wavelength is linear in the log space, so, for higher AAE, the increase in absorption at shorter wavelengths is stronger than the decrease towards longer wavelengths. However, the downwelling solar spectrum in the troposphere peaks at $\sim 450 \mathrm{~nm}$ and drops off more rapidly at shorter wavelengths than longer wavelengths. The impact on atmospheric absorption, and therefore DARE, of differing values of AAE results from the convolution of these spectral dependencies of aerosol absorption and the downwelling solar radiation.

To quantify this effect, we calculated the 300-750 nm integrated atmospheric absorption for aerosol with AAE of 1.0, 1.2 , and 1.5 , using a fixed $550 \mathrm{~nm}$ SSA of 0.86 , a value of SAE equal to 1.8 , and a clear-sky spectral downwelling solar radiation typical of mid-latitude fall. We find that integrated absorption for AAE equal to 1.5 is only $3 \%$ greater than for AAE equal to 1.2 and only $4 \%$ greater than for AAE equal to 1.0. The offsetting effects of the spectral dependencies of AAE and solar flux allow DARE to be fairly insensitive to uncertainties in AAE. Therefore, the observed model biases in AAE - relative to either of the possible observed AAE values - will not contribute significantly to biases in modeled DARE, consistent with the findings of de Graaf et al. (2014).

In the ORACLES study region, the subplume albedo is a function of $\mathrm{CF}_{\text {warm }}$, cloud albedo $\left(\alpha_{\mathrm{c}}\right)$, and the ocean surface albedo. Because of the large difference between the cloud albedo and ocean surface albedo, $\mathrm{CF}_{\text {warm }}$ is a strong controller of the subplume albedo, with higher $\mathrm{CF}_{\text {warm }}$ driv- 
ing more positive DARE. Across our comparison transects, WRF-CAM5 tended to overestimate $\mathrm{CF}_{\text {warm }}$ and GEOS and ALADIN tended to underestimate $\mathrm{CF}_{\text {warm }}$, with the UMUKCA coming closest to reproducing the observations but still tending to be biased high (Fig. 18). GEOS and ALADIN, in particular, also had different gradients in $\mathrm{CF}_{\text {warm }}$ with latitude (meridional transects) and longitude (zonal transect) than was observed; the 2016 diagonal transect is the only comparison transect where all models largely captured the $\mathrm{CF}_{\text {warm }}$ gradient. The large difference in $\mathrm{COT}_{\text {warm }}$ between the observations, WRF-CAM5, GEOS, and ALADIN (range of 8-11) versus in UM-UKCA (range of 24-39) translates to a significantly high bias in $\alpha_{\mathrm{c}}$ in the UM-UKCA model, ranging from $40 \%$ (2016 diagonal grid box 3) to $85 \%$ (2016 meridional grid box 2; Sect. 5 and Table 3). This will combine with any high biases in $\mathrm{CF}_{\text {warm }}$ in the UM-UKCA model to produce direct aerosol radiative effects that are too positive (warming) and is sufficient to more than compensate for any small low biases in $\mathrm{CF}_{\text {warm }}$.

First-order calculations of DARE for select grid boxes in the comparison transects demonstrate how these translate into biases in aerosol radiative effects for the above-cloud aerosol (Sect. 5). Earlier studies have shown that different models simulate everything from large negative to large positive direct aerosol radiative forcing by the biomass burning aerosol over the SE Atlantic (Zuidema et al., 2016 and Stier et al., 2013). Consistent with this, DARE calculated using simulated aerosol and cloud properties for five of our comparison grid boxes spanned -12 to $20 \mathrm{Wm}^{-2}$ across the four models. In contrast, DARE calculated from the observed properties were all positive, ranging from 2 to $16 \mathrm{Wm}^{-2}$. Using this simplified calculation, we showed that, across these five grid boxes, biases in $\sigma_{\text {ep }}$ (and therefore AOD) and in $\mathrm{CF}_{\text {warm }}$ and $\mathrm{COT}_{\text {warm }}$ (through their role in determining the albedo below the aerosol plume) alternately make the largest contributions to biases in DARE in many of the models/grid boxes. SSA is a source of smaller but still significant biases in some cases, as is, in one case, the simulated SAE through its impact on the aerosol hemispheric backscatter fraction.

Calculations of how DARE is affected by biases in each of the observed aerosol and cloud properties included in this comparison study reveal that biases in different properties often produce offsetting biases in DARE. As a result, improving the model representation of just one field (e.g., AOD for GEOS or just the cloud fields for UM-UKCA) would actually increase the bias in simulated DARE. This highlights the importance of testing for and correcting biases in all simulated properties that affect DARE, which in this region includes the representation of low marine clouds. It also provides motivation for a more thorough assessment of direct aerosol radiative forcing over the SE Atlantic that accounts for the model biases identified herein.
Data availability. The P-3 and ER-2 observational data are available from the following links: https://doi.org/10.5067/Suborbital/ ORACLES/P3/2016_V3 (ORACLES Science Team, 2020a), https://doi.org/10.5067/Suborbital/ORACLES/ER2/2016_V3 (ORACLES Science Team, 2021), https://doi.org/10.5067/Suborbital/ ORACLES/P3/2017_V3 (ORACLES Science Team, 2020b), and https://doi.org/10.5067/Suborbital/ORACLES/P3/2018_V3 (ORACLES Science Team, 2020c).

The aggregated model and aerosol observational products are available at https://espo.nasa.gov/sites/default/files/box_P3ER2Models_ 2016mmdd_R8.nc (last access: 10 March 2021) (ORACLES Science Team, 2020d).

The MODIS-Standard L3 cloud products (Platnick et al., 2015a, b) are available at https://doi.org/10.5067/MODIS/MOD08_D3.006 (Terra) and https://doi.org/10.5067/MODIS/MYD08_D3.006 (Aqua). The MODIS-Standard L2 cloud products (Platnick et al., 2015c, d) are available at https://doi.org/10.5067/MODIS/MOD06_L2.006 (Terra) and https://doi.org/10.5067/MODIS/MYD06_L2.006 (Aqua).

Supplement. The supplement related to this article is available online at: https://doi.org/10.5194/acp-22-1-2022-supplement.

Author contributions. SPB, RAF, AD, SF, SGH, and JRP operated instruments during the ORACLES intensive observation periods. PES, CH, GAF, HG, MM, PN, GRC, and ADS delivered the model products. KM and DP provided and assisted with the analysis of satellite cloud products for the ORACLES intensive observation periods. YS, PES, SJD, JR, RW, and PZ formulated the modelobservation comparison. SD processed all observational data and applied statistical techniques. SJD wrote most of the first draft. JR, IC, and LG provided the full radiative transfer calculations for testing the parameterized DARE and wrote the associated text. SJD, PES, PZ, GAF, HG, MM, KM, DP, SPB, RAF, KP, RW, and JR edited the paper. JR, RW, and PZ led the efforts to acquire funding for the ORACLES mission.

Competing interests. The contact author has declared that neither they nor their co-authors have any competing interests.

Disclaimer. Publisher's note: Copernicus Publications remains neutral with regard to jurisdictional claims in published maps and institutional affiliations.

Special issue statement. This article is part of the special issue "New observations and related modelling studies of the aerosolcloud-climate system in the Southeast Atlantic and southern Africa regions (ACP/AMT inter-journal SI)". It is not associated with a conference.

Acknowledgements. All in situ aerosol data were collected as part of the ORACLES project, which is a NASA Earth Venture 
Suborbital 2 investigation (grant no. 13-EVS2-13-0028) funded by NASA's Earth Science Division and managed through the Earth System Science Pathfinder Program Office. The ORACLES team gratefully acknowledges the work by the NASA Ames Earth Science Project Office (ESPO), led by Bernadette Luna and Dan Chirica. The team is equally grateful for the tireless contributions by the NASA Wallops and NASA Johnson P-3 and ER-2 pilot and flight crews, as well as air traffic control at the Walvis Bay International Airport (Namibia) and São Tomé International Airport. Local authorities in Namibia and São Tomé played important roles as well, for which the project would like to express their gratitude.

We would like to thank the many groups and individuals involved with producing the satellite-retrieved cloud properties used in this study. For the MODIS standard cloud retrievals, the Terra and Aqua MODIS Level 3 cloud data were acquired from the Level 1 and Atmosphere Archive and Distribution System (LAADS) Distributed Active Archive Centers (DAACs), located in the Goddard Space Flight Center in Greenbelt, Maryland, USA (https://ladsweb.nascom.nasa.gov, last access: 20 April 2021).

For the SEVIRI-LaRC cloud retrievals, we acknowledge the SatCORPS team at NASA-LaRC (https://satcorps.larc.nasa.gov, last access: 5 August 2020) and include the following papers for a description of the retrievals: Minnis et al. (2008, 2011a, b) and Painemal et al. (2015).

The MODIS-ACAERO retrievals are available upon request from the author.

This publication is partially funded by the Cooperative Institute for Climate, Ocean and Ecosystem Studies (CICOES) under NOAA Cooperative Agreement NA15OAR4320063, contribution no. 2020-1126.

Financial support. This research has been supported by the National Aeronautics and Space Administration (grant no. NNX15AF96G). The WRF-CAM5 simulations were funded with Department of Energy (grant no. DOE ASR DE-SC0018272).

Review statement. This paper was edited by J. M. Haywood and reviewed by two anonymous referees.

\section{References}

Adebiyi, A. A. and Zuidema, P.: The Role of the Southern African Easterly Jet in Modifying the Southeast Atlantic Aerosol and Cloud Environments, Q. J. Roy. Meteor. Soc., 142, 1574-1589, https://doi.org/10.1002/qj.2765, 2016.

Adebiyi, A. and Zuidema, P.: Low cloud sensitivity to biomassburning aerosols and meteorology over the southeast Atlantic, J. Climate, 31, 4329-4346, https://doi.org/10.1175/JCLI-D-170406.1, 2018.

Adebiyi, A. A., Zuidema, P., Chang, I., Burton, S. P., and Cairns, B.: Mid-level clouds are frequent above the southeast Atlantic stratocumulus clouds, Atmos. Chem. Phys., 20, 11025-11043, https://doi.org/10.5194/acp-20-11025-2020, 2020.

Albayrak, A., Wei, J., Petrenko, M., Lynnes, C. S., and Levy, R. C.: Global bias adjustment for MODIS aerosol optical thickness using neural network, J. Appl. Remote Sens., 7, 073514, https://doi.org/10.1117/1.JRS.7.073514, 2013.

Aldhaif, A. M., Stahl, C., Braun, R. A., Moghaddam, M. A., Shingler, T., Crosbie, E., Sawamura, P., Dadashazar, H., Ziemba, L., Jimenez, J. L., Campuzano-Jost, P., and Sorooshian, A.: Characterization of the Real Part of Dry Aerosol Refractive Index Over North America From the Surface to 12 km, J. Geophys. Res.Atmos., 123, 8283-8300, https://doi.org/10.1029/2018jd028504, 2018.

Anderson, T. L. and Ogren, J. A.: Determining aerosol radiative properties using the TSI 3563 integrating nephelometer, Aerosol Sci. Technol., 29, 57-69, 1998.

Bergstrom, R. W., Pilewskie, P., Russell, P. B., Redemann, J., Bond, T. C., Quinn, P. K., and Sierau, B.: Spectral absorption properties of atmospheric aerosols, Atmos. Chem. Phys., 7, 5937-5943, https://doi.org/10.5194/acp-7-5937-2007, 2007.

Boers, R., deLaat, A. T., Stein Zweers, D. C., and Dirksen, R. J.: Lifting potential of solar-heated aerosol layers, Geophys. Res. Lett., 37, L24802, https://doi.org/10.1029/2010GL045171, 2010.

Bohren, C. F.: Multiple scattering of light and some of its observable consequence, Am. J. Phys., 55, 524-533, 1980.

Bond, T. C., Anderson, T. L., and Campbell, D.: Calibration and intercomparison of filter-based measurements of visible light absorption by aerosols, Aerosol Sci. Tech., 30, 582-600, 1999.

Bond, T. C., Doherty, S. J., Fahey, D. W., Forster, P. M., Berntsen, T., DeAngelo, B. J., Flanner, M. G., Ghan, S., Kärcher, B., Koch, D., Kinne, S., Kondo, Y., Quinn, P. K., Sarofim, M. C., Schultz, M. G., Schulz, M., Venkataraman, C., Zhang, H., Zhang, S., Bellouin, N., Guttikunda, S. K., Hopke, P. K., Jacobson, M. Z., Kaiser, J. W., Klimont, Z., Lohmann, U., Schwarz, J. P., Shindell, D., Storelvmo, T., Warren, S. G., and Zender, C. S.: Bounding the role of black carbon in the climate system: A scientific assessment, J. Geophys. Res.-Atmos., 118, 5380-5552, https://doi.org/10.1002/jgrd.50171, 2013.

Bretherton, C. S. and Park, S.: A New Moist Turbulence Parameterization in the Community Atmosphere Model, J. Clim., 22, 3422-3448, 2009.

Brown, H., Liu, X., Pokhrel, R., Murphy, S., Mielonen, T., Kokkola, H., Bergman, T., Myhre, G., Watson-Paris, D., Stier, P., Johnson, B., Bellouin, N., Vakkari, V., Beukes, J. P., van Zyl, P. G., Liu, S., and Chand, D.: Biomass burning aerosols in most climate models are too absorbing, Nat. Comm., 12, 277, https://doi.org/10.1038/s41467-020-20482-9, 2021.

Burgos, M. A., Andrews, E., Titos, G., Alados-Arboledas, L., Baltensperger, U., Day, D., Jefferson, A., Kalivitis, N., Mihalopoulos, N., Sherman, J., Sun, J., Weingartner, E., and Zieger, P.: A global view on the effect of water uptake on aerosol particle light scattering, Scientific Data, 6, 157, https://doi.org/10.1038/s41597-019-0158-7, 2019.

Burton, S. P., Hostetler, C. A., Cook, A. L., Hair, J. W., Seaman, S. T., Scola, S., Harper, D. B., Smith, J. A., Fenn, M. A., Ferrare, R. A., Saide, P. E., Chemyakin, E. V., and Müller, D.: Calibration of a high spectral resolution lidar using a Michelson interferometer, with data examples from ORACLES, Appl. Optics, 57, 60616075, https://doi.org/10.1364/AO.57.006061, 2018. 
Capes, G., Johnson, B., McFiggans, G., Williams, P. I., Haywood, J., and Coe, H.: Aging of biomass burning aerosols over West Africa: Aircraft measurements of chemical composition, microphysical properties, and emission ratios, J. Geophys. Res., 113, D00C15, https://doi.org/10.1029/2008jd009845, 2008.

Cappa, C. D., Lim, C. Y., Hagan, D. H., Coggon, M., Koss, A., Sekimoto, K., de Gouw, J., Onasch, T. B., Warneke, C., and Kroll, J. H.: Biomass-burning-derived particles from a wide variety of fuels - Part 2: Effects of photochemical aging on particle optical and chemical properties, Atmos. Chem. Phys., 20, 8511-8532, https://doi.org/10.5194/acp-20-8511-2020, 2020.

Carter, T. S., Heald, C. L., Cappa, C. D., Kroll, J. H., Campos, T. L., Coe, H., Cotterell, M. I. Davies, N. W., Farmer, D. K., Fox, C., Garofalo, L. A., Hu, L., Langridge, J. M., Levin, E. J. T., Murphy, S. M., Pokhrel, R. P., Shen, Y., Szpek, K, Taylor, J. W., and Wu, H.: Investigating carbonaceous aerosol and its absorption properties from fires in the western United States (WE-CAN) and southern Africa (ORACLES and CLARIFY), J. Geophys. Res.-Atmos., 126, e2021JD034984, https://doi.org/10.1029/2021JD034984, 2021.

Chand, D., Wood, R., Anderson, T. L., Satheesh, S. K., and Charlson, R. J.: Satellite-derived direct radiative effect of aerosols dependent on cloud cover, Nat. Geosci., 2, 181-184, https://doi.org/10.1038/NGEO437, 2009.

Chang, I., Gao, L., Burton, S. P., Chen, H., Diamond, M. S., Ferrare, R. A., Flynn, C. J., Kacenelenbogen, M., LeBlanc, S. E., Meyer, K. G., Pistone, K., Schmidt, S., Segal-Rozenhaimer, M., Shinozuka, Y., Wood, R., Zuidema, P., Redemann, J., and Christopher, S. A.: Spatiotemporal heterogeneity of aerosol and cloud properties over the southeast Atlantic: An observational analysis, Geophys. Res. Lett., 48, e2020GL091469, https://doi.org/10.1029/2020GL091469, 2021.

Chin, M., Ginoux, P., Kinne, S., Torres, O., Holben, B. N., Duncan, B. N., Martin, R. V., Logan, J. A., Higurashi, A., and Nakajima, T.: Tropospheric Aerosol Optical Thickness from the GOCART Model and Comparisons with Satellite and Sun Photometer Measurements, J. Atmos. Sci., 59, 461-483, 2002.

Cho, H.-M., Zhang, Z., Meyer, K., Lebsock, M., Platnick, S., Ackerman, A. S., Di Girolamo, L., C.-Labonnote, L., Cornet, C., Riedi, J., and Holz, R. E.: Frequency and causes of failed MODIS cloud property retrievals for liquid phase clouds over global oceans, J. Geophys. Res.-Atmos., 120, 4132-4154, https://doi.org/10.1002/2015JD023161, 2015.

Chylek, P., Lee, J. E., Romonosky, D. E., Gallo, F., Lou, S., Shrivastava, M., Carrico, C. M., Aiken, A. C., and Dubey, M. K.: Mie scattering captures observed optical properties of ambient biomass burning plumes assuming uniform black, brown, and organic carbon mixtures, J. Geophys. Res., 124, 11406-11427, https://doi.org/10.1029/2019jd031224, 2019.

Cochrane, S. P., Schmidt, K. S., Chen, H., Pilewskie, P., Kittelman, S., Redemann, J., LeBlanc, S., Pistone, K., Kacenelenbogen, M., Segal Rozenhaimer, M., Shinozuka, Y., Flynn, C., Dobracki, A., Zuidema, P., Howell, S., Freitag, S., and Doherty, S.: Empirically derived parameterizations of the direct aerosol radiative effect based on ORACLES aircraft observations, Atmos. Meas. Tech., 14, 567-593, https://doi.org/10.5194/amt-14-567-2021, 2021.

Coddington, O. M., Pilewskie, P., Redemann, J., Platnick, S., Russell, P. B., Schmidt, K. S., Gore, W. J., Livingston, J., Wind, G., and Vukicevic, T.: Examining the impact of over- lying aerosols on the retrieval of cloud optical properties from passive remote sensing, J. Geophys. Res., 115, D10211, https://doi.org/10.1029/2009JD012829, 2010.

Colarco, P., da Silva, A., Chin, M., and Diehl, T.: Online simulations of global aerosol distributions in the NASA GEOS-4 model and comparisons to satellite and groundbased aerosol optical depth, J. Geophys. Res., 115, D14207, https://doi.org/10.1029/2009jd012820, 2010.

Colarco, P. R., Nowottnick, E. P., Randles, C. A., Yi, B., Yang, P., Kim, K.-M., Smith, J. A., and Bardeen, C. G.: Impact of radiatively interactive dust aerosols in the NASA GEOS-5 climate model: Sensitivity to dust particle shape and refractive index, J. Geophys. Res.-Atmos., 119, 753-786, https://doi.org/10.1002/2013JD020046, 2014.

Collier, S., Zhou, S., Onasch, T. B., Jaffe, D. A., Kleinma, L., Sedlacek, A. J., Briggs, N. L., Hee, J., Fortner, E., Shilling, J. E., Worsnop, D., Yokelson, R. J., Parworth, C., Ge, X., Xu, J., Butterfield, Z., Chand, D., Dubey, M. K., Pekour, M. S., Springston, S., and Zhang, Q.: Regional Influence of Aerosol Emissions from Wildfires Driven by Combustion Efficiency: Insights from the BBOP Campaign, Environ. Sci. Technol., 50, 8613-8622, https://doi.org/10.1021/acs.est.6b01617, 2016.

Cubison, M. J., Ortega, A. M., Hayes, P. L., Farmer, D. K., Day, D., Lechner, M. J., Brune, W. H., Apel, E., Diskin, G. S., Fisher, J. A., Fuelberg, H. E., Hecobian, A., Knapp, D. J., Mikoviny, T., Riemer, D., Sachse, G. W., Sessions, W., Weber, R. J., Weinheimer, A. J., Wisthaler, A., and Jimenez, J. L.: Effects of aging on organic aerosol from open biomass burning smoke in aircraft and laboratory studies, Atmos. Chem. Phys., 11, 12049-12064, https://doi.org/10.5194/acp-11-12049-2011, 2011.

Darmenov, A. S. and da Silva, A. M.: The Quick Fire Emissions Dataset (QFED): Documentation of Versions 2.1, 2.2 and 2.4. Volume 38; Technical Report Series on Global Modeling and Data Assimilation, NASA, 212 pp., available at: https: //ntrs.nasa.gov/search.jsp?R=20180005253 (last access: 25 May 2019), 2015.

Das, S., Harshvardhan, H., Bian, H., Chin, M., Curci, G., Protonotariou, A. P., Mielonen, T., Zhang, K., Wang, H., and Liu, X.:, Biomass burning aerosol transport and vertical distribution over the South African-Atlantic region, J. Geophys. Res.-Atmos., 122, 6391-6415, https://doi.org/10.1002/2016JD026421, 2017.

Dee, D. P., Uppala, S. M., Simmons, A. J., Berrisford, P., Poli, P., Kobayashi, S., Andrae, U., Balmaseda, M. A., Balsamo, G., Bauer, P., Bechtold, P., Beljaars, A. C. M., van de Berg, L., Bidlot, J., Bormann, N., Delsol, C., Dragani, R., Fuentes, M., Geer, A. J., Haimbergere, L., Healy, S. B., Hersbach, H., Hólm, E. V., Isaksen, L., Kallberg, P., Köhler, M., Matricardi, M., McNally, A. P., Monge-Sanzf, B. M., Morcrette, J.-J., Park, B.-K., Peubey, C., de Rosnaya, P., Tavolato, C., Thépaut, J.-N., and Vitart, F.: The ERA-Interim reanalysis: configuration and performance of the data assimilation system, Q. J. Royal Met. Soc., 137, 553597, https://doi.org/10.1002/qj.828, 2011.

de Graaf, M., Bellouin, N., Tilstra, L. G., Haywood, J., and Stammes, P.: Aerosol direct radiative effect of smoke over clouds over the southeast Atlantic Ocean from 2006 to 2009, Geophys. Res. Lett., 41, 7723-7730, https://doi.org/10.1002/2014GL061103, 2014.

de Laat, A. T. J., Stein Zweers, D. C., Boers, R., and Tuinder, O. N. E.: A solar escalator: Observational evidence of the self-lifting of 
smoke and aerosols by absorption of solar radiation in the February 2009 Australian Black Saturday plume, J. Geophys. Res.Atmos., 117, D04204, https://doi.org/10.1029/2011JD017016, 2012.

Denjean, C., Brito, J., Libois, Q., Mallet, M., Bourrianne, T., Burnet, F., Dupuy, R., Flamant, C., and Knippertz, P.: Unexpected biomass burning aerosol absorption enhancement explained by black carbon mixing state, Geophys. Res. Lett, 47,e2020GL089055, https://doi.org/10.1029/2020g1089055, 2020.

Diamond, M. S., Dobracki, A., Freitag, S., Small Griswold, J. D., Heikkila, A., Howell, S. G., Kacarab, M. E., Podolske, J. R., Saide, P. E., and Wood, R.: Time-dependent entrainment of smoke presents an observational challenge for assessing aerosolcloud interactions over the southeast Atlantic Ocean, Atmos. Chem. Phys., 18, 14623-14636, https://doi.org/10.5194/acp-1814623-2018, 2018.

Feingold, G., Balsells, J., Glassmeier, F., Yamaguchi, T., Kazil, J., and McComiskey, A.: Analysis of albedo versus cloud fraction relationships in liquid water clouds using heuristic models and large eddy simulation, J. Geophys. Res.-Atmos., 122, 70867102, https://doi.org/10.1002/2017JD026467, 2017.

Formenti, P., Elbert, W., Maenhaut, W., Haywood, J., Osborne, S., and Andreae, M. O.: Inorganic and carbonaceous aerosols during the Southern African Regional Science Initiative (SAFARI 2000) experiment: Chemical characteristics, physical properties, and emission data for smoke from African biomass burning, J. Geophys. Res.-Atmos., 108, 8488, https://doi.org/10.1029/2002JD002408, 2003.

Formenti, P., D’Anna, B., Flamant, C., Mallet, M., Piketh, S. J., Schepanski, K., Waquet, F., Auriol, F., Brogniez, G., Burnet, F., Chaboureau, J.-P., Chauvigné, A., Chazette, P., Denjean, C., Desboeufs, K., Doussin, J.-F., Elguindi, N., Feuerstein, S., Gaetani, M., Giorio, C., Klopper, D., Mallet, M. D., Nabat, P., Monod, A., Solmon, F., Namwoonde, A., Chikwililwa, C., Mushi, R., Welton, E. J., and Holben, B.: The Aerosols, Radiation and Clouds in Southern Africa Field Campaign in Namibia: Overview, illustrative observations, and way forward, B. Am. Meteor. Soc., 100, 1277-1298, https://doi.org/10.1175/BAMS-D-17-0278.1, 2019.

Forster, P., Storelvmo, T., Armour, K., Collins, W., Dufresne, J. L., Frame, D. Lunt, D. J., Mauritsen, T., Palmer, M. D., Watanabe, M., Wild, M., and Zhang, H.: The Earth's Energy Budget, Climate Feedbacks, and Climate Sensitivity, in: Climate Change 2021: The Physical Science Basis. Contribution of Working Group I to the Sixth Assessment Report of the Intergovernmental Panel on Climate Change, edited by: Masson-Delmotte, V., Zhai, P., Pirani, A., Connors, S. L., Péan, C., Berger, S., Caud, N., Chen, Y., Goldfarb, L., Gomis, M. I., Huang, M., Leitzell, K., Lonnoy, E., Matthews, J. B. R., Maycock, T. K., Waterfield, T., Yelekçi, O., Yu, R., and Zhou, B., Cambridge University Press, in Press, 2021.

Freitas, S. R., Longo, K. M., and Andrea, M. O.: Impact of including the plume rise of vegetation fires in numerical simulations of associated atmospheric pollutants, Geophys. Res. Lett., 33, L17808, https://doi.org/10.1029/2006GL026608, 2006.

Fuchs, J., Cermak, J., and Andersen, H.: Building a cloud in the southeast Atlantic: understanding low-cloud controls based on satellite observations with machine learning, Atmos. Chem.
Phys., 18, 16537-16552, https://doi.org/10.5194/acp-18-165372018, 2018.

Gordon, H., Field, P. R., Abel, S. J., Dalvi, M., Grosvenor, D. P., Hill, A. A., Johnson, B. T., Miltenberger, A. K., Yoshioka, M., and Carslaw, K. S.: Large simulated radiative effects of smoke in the south-east Atlantic, Atmos. Chem. Phys., 18, 15261-15289, https://doi.org/10.5194/acp-18-15261-2018, 2018.

Gupta, S., McFarquhar, G. M., O’Brien, J. R., Delene, D. J., Poellot, M. R., Dobracki, A., Podolske, J. R., Redemann, J., LeBlanc, S. E., Segal-Rozenhaimer, M., and Pistone, K.: Impact of the variability in vertical separation between biomass burning aerosols and marine stratocumulus on cloud microphysical properties over the Southeast Atlantic, Atmos. Chem. Phys., 21, 46154635, https://doi.org/10.5194/acp-21-4615-2021, 2021.

Hair, J. W., Hostetler, C. A., Cook, A. L., Harper, D. B., Ferrare, R. A., Mack, T. L., Welch, W., Izquierdo, L. R., and Hovis, F. E.: Airborne High Spectral Resolution Lidar for profiling aerosol optical properties, Appl. Opt., 47, 6734-6752, https://doi.org/10.1364/AO.47.006734, 2008.

Hallquist, M., Wenger, J. C., Baltensperger, U., Rudich, Y., Simpson, D., Claeys, M., Dommen, J., Donahue, N. M., George, C., Goldstein, A. H., Hamilton, J. F., Herrmann, H., Hoffmann, T., Iinuma, Y., Jang, M., Jenkin, M. E., Jimenez, J. L., Kiendler-Scharr, A., Maenhaut, W., McFiggans, G., Mentel, Th. F., Monod, A., Prévôt, A. S. H., Seinfeld, J. H., Surratt, J. D., Szmigielski, R., and Wildt, J.: The formation, properties and impact of secondary organic aerosol: current and emerging issues, Atmos. Chem. Phys., 9, 5155-5236, https://doi.org/10.5194/acp9-5155-2009, 2009.

Haywood, J. M. and Shine, K. P.: The effect of anthropogenic sulfate and soot aerosol on the clear sky planetary radiation budget, Geophys. Res. Lett., 22, 603-606, 1995.

Haywood, J. M., Osborne, S. R., and Abel, S. J.: The effect of overlying absorbing aerosol layers on remote sensing retrievals of cloud effective radius and cloud optical depth, Q. J. Roy. Meteor. Soc., 130, 779-800, 2004.

Haywood, J. M., Abel, S. J., Barrett, P. A., Bellouin, N., Blyth, A., Bower, K. N., Brooks, M., Carslaw, K., Che, H., Coe, H., Cotterell, M. I., Crawford, I., Cui, Z., Davies, N., Dingley, B., Field, P., Formenti, P., Gordon, H., de Graaf, M., Herbert, R., Johnson, B., Jones, A. C., Langridge, J. M., Malavelle, F., Partridge, D. G., Peers, F., Redemann, J., Stier, P., Szpek, K., Taylor, J. W., Watson-Parris, D., Wood, R., Wu, H., and Zuidema, P.: The CLoud-Aerosol-Radiation Interaction and Forcing: Year 2017 (CLARIFY-2017) measurement campaign, Atmos. Chem. Phys., 21, 1049-1084, https://doi.org/10.5194/acp-211049-2021, 2021.

Heald, C. L., Goldstein, A. H., Allan, J. D., Aiken, A. C., Apel, E., Atlas, E. L., Baker, A. K., Bates, T. S., Beyersdorf, A. J., Blake, D. R., Campos, T., Coe, H., Crounse, J. D., DeCarlo, P. F., de Gouw, J. A., Dunlea, E. J., Flocke, F. M., Fried, A., Goldan, P., Griffin, R. J., Herndon, S. C., Holloway, J. S., Holzinger, R., Jimenez, J. L., Junkermann, W., Kuster, W. C., Lewis, A. C., Meinardi, S., Millet, D. B., Onasch, T., Polidori, A., Quinn, P. K., Riemer, D. D., Roberts, J. M., Salcedo, D., Sive, B., Swanson, A. L., Talbot, R., Warneke, C., Weber, R. J., Weibring, P., Wennberg, P. O., Worsnop, D. R., Wittig, A. E., Zhang, R., Zheng, J., and Zheng, W.: Total observed organic carbon (TOOC) in the atmosphere: a synthesis of North American observations, Atmos. 
Chem. Phys., 8, 2007-2025, https://doi.org/10.5194/acp-8-20072008, 2008.

Herbert, R. J., Bellouin, N., Highwood, E. J., and Hill, A. A.: Diurnal cycle of the semi-direct effect from a persistent absorbing aerosol layer over marine stratocumulus in large-eddy simulations, Atmos. Chem. Phys., 20, 1317-1340, https://doi.org/10.5194/acp-20-1317-2020, 2020.

Hodshire, A. L., Akherati, A., Alvarado, M. J., Brown-Steiner, B., Jathar, S. H., Jimenez, J. L., Kreidenweis, S. M., Lonsdale, C. R., Onash, T. B., Ortega, A. M., and Pierce, J. R.: Aging Effects on Biomass Burning Aerosol Mass and Composition: A Critical Review of Field and Laboratory Studies, Environ. Sci. Techno.1 53, 10007-10022, https://doi.org/10.1021/acs.est.9b02588, 2019.

Hodzic, A., Madronich, S., Kasibhatla, P. S., Tyndall, G., Aumont, B., Jimenez, J. L., Lee-Taylor, J., and Orlando, J.: Organic photolysis reactions in tropospheric aerosols: effect on secondary organic aerosol formation and lifetime, Atmos. Chem. Phys., 15, 9253-9269, https://doi.org/10.5194/acp-15-9253-2015, 2015.

Hodzic, A., Kasibhatla, P. S., Jo, D. S., Cappa, C. D., Jimenez, J. L., Madronich, S., and Park, R. J.: Rethinking the global secondary organic aerosol (SOA) budget: stronger production, faster removal, shorter lifetime, Atmos. Chem. Phys., 16, 7917-7941, https://doi.org/10.5194/acp-16-7917-2016, 2016.

Ichoku, C. and Ellison, L.: Global top-down smoke-aerosol emissions estimation using satellite fire radiative power measurements, Atmos. Chem. Phys., 14, 6643-6667, https://doi.org/10.5194/acp-14-6643-2014, 2014.

Jimenez, J. L., Canagaratna, M. R., Donahue, N. M., Prevot, A. S. H., Zhang, Q., Kroll, J. H., DeCarlo, P. F., Allan, J. D., Coe, H., Ng, N. L., Aiken, A. C., Docherty, K. S., Ulbrich, I. M., Grieshop, A. P., Robinson, A. L., Duplissy, J., Smith, J. D., Wilson, K. R., Lanz, V. A., Hueglin, C., Sun, Y. L., Tian, J., Laaksonen, A., Raatikainen, T., Rautiainen, J., Vaattovaara, P., Ehn, M., Kulmala, M., Tomlinson, J. M., Collins, D. R., Cubison, M. J. Dunlea, E. J., Huffman, J. A., Onasch, T. B., Alfarra, M. R., Williams, P. I., Bower, K., Kondo, Y., Schneider, J., Drewnick, F., Borrmann, S., Weimer, S., Demerjian, K., Salcedo, D., Cottrell, L., Griffin, R., Takami, A., Miyoshi, T., Hatakeyama, S., Shimono, A., Sun, J. Y., Zhang, Y. M., Dzepina, K., Kimmel, J. R., Sueper, D., Jayne, J. T., Herndon, S. C., Trimborn, A. M., Williams, L. R., Wood, E. C., Middlebrook, A. M., Kolb, C. E., Baltensperger, U., and Worsnop, D. R.: Evolution of organic aerosols in the atmosphere, Science, 326, 1525-1529, https://doi.org/10.1126/science.1180353, 2009.

Johnson, B. T., Shine, K. P., and Forster, P. M.: The semidirect aerosol effect: Impact of absorbing aerosols on marine stratocumulus, Q. J. Roy. Meteor. Soc., 130, 1407-1422, https://doi.org/10.1256/qj.03.61, 2004.

Jolleys, M. D., Coe, H., McFiggans, G., Taylor, J. W., O’Shea, S. J., Le Breton, M., Bauguitte, S. J.-B., Moller, S., Di Carlo, P., Aruffo, E., Palmer, P. I., Lee, J. D., Percival, C. J., and Gallagher, M. W.: Properties and evolution of biomass burning organic aerosol from Canadian boreal forest fires, Atmos. Chem. Phys., 15, 3077-3095, https://doi.org/10.5194/acp-153077-2015, 2015.

Kacarab, M., Thornhill, K. L., Dobracki, A., Howell, S. G., O’Brien, J. R., Freitag, S., Poellot, M. R., Wood, R., Zuidema, P., Redemann, J., and Nenes, A.: Biomass burning aerosol as a modulator of the droplet number in the southeast Atlantic region, At- mos. Chem. Phys., 20, 3029-3040, https://doi.org/10.5194/acp20-3029-2020, 2020.

Kacenelenbogen, M. S., Vaughan, M. A., Redemann, J., Young, S. A., Liu, Z., Hu, Y., Omar, A. H., LeBlanc, S., Shinozuka, Y., Livingston, J., Zhang, Q., and Powell, K. A.: Estimations of global shortwave direct aerosol radiative effects above opaque water clouds using a combination of A-Train satellite sensors, Atmos. Chem. Phys., 19, 4933-4962, https://doi.org/10.5194/acp19-4933-2019, 2019.

Kaiser, J. W. and Van der Werf, G. R.: Land surface properties Biomass burning, in "State of Climate in 2014", B. Am. Meteorol. Soc., 96, 56-57, 2015.

Kasten, F.: Visibility forecast in the phase of pre-condensation, Tellus, 21, 631-635, 1969.

Kato, S., Ackerman, T. P., Mather, J. H., and Clothiaux, E.: The kdistribution method and correlated-k approximation for a shortwave radiative transfer model, J. Quant. Spectrosc. Ra., 62, 109121, 1999.

Kato, S., Hinkelman, L. M., and Cheng, A.: Estimate of satellite-derived cloud optical thickness and effective radius errors and their effect on computed domainaveraged irradiances, J. Geophys. Res., 111, D17201, https://doi.org/10.1029/2005JD006668, 2006.

Kawai, H. and Shige, S.: Marine low clouds and their parameterization in climate models, J. Met. Soc. Japan, 98, 1097-1127, https://doi.org/10.2151/jmsj.2020-059, 2020.

Koch, D. and Del Genio, A. D.: Black carbon semi-direct effects on cloud cover: review and synthesis, Atmos. Chem. Phys., 10, 7685-7696, https://doi.org/10.5194/acp-10-7685-2010, 2010.

Konovalov, I. B., Beekmann, M., Golovushkin, N. A., and Andreae, M. O.: Nonlinear behavior of organic aerosol in biomass burning plumes: a microphysical model analysis, Atmos. Chem. Phys., 19, 12091-12119, https://doi.org/10.5194/acp-19-120912019, 2019.

Koren, I., Dagan, G., and Altaratz, O.: From aerosol-limited to invigoration of warm convective clouds, Science, 344, 1143-1146, https://doi.org/10.1126/science.1252595, 2014.

Kotchenruther, R. A., and Hobbs, P. V.: Humidification factors of aerosols from biomass burning in Brazil, J. Geophys. Res.Atmos., 103, 32081-32089, https://doi.org/10.1029/98JD00340, 1998.

Kratz, D. P., Gupta, S. K., Wilber, A. C., and Sothcott, V. E.: Validation of the CERES Edition-4A Surface-Only Flux Algorithms, J. Appl. Meteorol. Clim., 59, 281-295, https://doi.org/10.1175/JAMC-D-19-0068.1, 2020.

Labonne, M., Bréon, F. M., and Chevallier, F.: Injection height of biomass burning aerosols as seen from a spaceborne lidar, Geosphys. Res. Lett., 34, L11806, https://doi.org/10.1029/2007GL029311, 2007.

Li, J., Scinocca, Lazare, M., McFarelane, N., Von Salzen, K., and Soldheim, L.: Ocean Surface Albedo and Its Impact on Radiation Balance in Climate Models, 19, 6314-6333, https://doi.org/10.1175/JCLI3973.1, 2006.

Liu, X., Huey, L. G., Yokelson, R. J., Selimovic, V., Simpson, I. J., Müller, M., Jimenez, J. L., Campuzano-Jost, P., Beyersdorf, A. J., Blake, D. R., Butterfield, Z., Choi, Y., Crounse, J. D., Day, D. A., Diskin, G. S., Dubey, M. K., Fortner, E., Hanisco, T. F., Hu, W., King, L. E., Kleinman, L., Meinardi, S., Mikoviny, T., Onasch, T. B., Palm, B. B., Peischl, J., Pollack, I. B., Ryerson, T. B., Sachse, 
G. W., Sedlacek, A. J., Shilling, J. E., Springston, S., St. Clair, J. M., Tanner, D. J., Teng, A. P., Wennberg, P. O., Wisthaler, A., and Wolfe, G. M.: Airborne measurements of western U.S. wildfire emissions: Comparison with prescribed burning and air quality implications, J. Geophys. Res.-Atmos., 122, 6108-6129, 2017.

Liu, C., Chung, C. E., Yin, Y., and Schnaiter, M.: The absorption Ångström exponent of black carbon: from numerical aspects, Atmos. Chem. Phys., 18, 6259-6273, https://doi.org/10.5194/acp18-6259-2018, 2018.

Ma, P.-L., Rasch, P. J., Fast, J. D., Easter, R. C., Gustafson Jr., W. I., Liu, X., Ghan, S. J., and Singh, B.: Assessing the CAM5 physics suite in the WRF-Chem model: implementation, resolution sensitivity, and a first evaluation for a regional case study, Geosci. Model Dev., 7, 755-778, https://doi.org/10.5194/gmd-7755-2014, 2014.

Mallet, M., Solmon, F., Roblou, L., Peers, F., Turquety, S., Wa- quet, F., Jethva, H., and Torres, O.: Simulation of Optical Properties and Direct and Indirect Radiative Effects of Smoke Aerosols Over Marine Stratocumulus Clouds During Summer 2008 in California With the Regional Climate Model RegCM, J. Geophys. Res.-Atmos., 122, 10288-10313, https://doi.org/10.1002/2017JD026905, 2017.

Mallet, M., Nabat, P., Zuidema, P., Redemann, J., Sayer, A. M., Stengel, M., Schmidt, S., Cochrane, S., Burton, S., Ferrare, R., Meyer, K., Saide, P., Jethva, H., Torres, O., Wood, R., Saint Martin, D., Roehrig, R., Hsu, C., and Formenti, P.: Simulation of the transport, vertical distribution, optical properties and radiative impact of smoke aerosols with the ALADIN regional climate model during the ORACLES-2016 and LASIC experiments, Atmos. Chem. Phys., 19, 4963-4990, https://doi.org/10.5194/acp19-4963-2019, 2019.

Mallet, M., Solmon, F., Nabat, P., Elguindi, N., Waquet, F., Bouniol, D., Sayer, A. M., Meyer, K., Roehrig, R., Michou, M., Zuidema, P., Flamant, C., Redemann, J., and Formenti, P.: Direct and semi-direct radiative forcing of biomass-burning aerosols over the southeast Atlantic (SEA) and its sensitivity to absorbing properties: a regional climate modeling study, Atmos. Chem. Phys., 20, 13191-13216, https://doi.org/10.5194/acp-20-131912020, 2020.

Marshak, A., Platnick, S., Várnai, T., Wen, G., and Cahalan, R. F.: Impact of three-dimensional radiative effects on satellite retrievals of cloud droplet sizes, J. Geophys. Res., 111, D09207, https://doi.org/10.1029/2005JD006686, 2006.

Matus, A. V., L'Ecuyer, T. S., Kay, J. E., Hannay, C., and Lamarque, J.-F.: The role of clouds in modulating global aerosol direct radiative effects in spaceborne active observations and the Community Earth System Model, J. Climate, 28, 2986-3003, https://doi.org/10.1175/JCLI-D-14-00426.1, 2015.

Mayer, B. and Kylling, A.: Technical note: The libRadtran software package for radiative transfer calculations - description and examples of use, Atmos. Chem. Phys., 5, 1855-1877, https://doi.org/10.5194/acp-5-1855-2005, 2005.

McFiggans, G., Artaxo, P., Baltensperger, U., Coe, H., Facchini, M. C., Feingold, G., Fuzzi, S., Gysel, M., Laaksonen, A., Lohmann, U., Mentel, T. F., Murphy, D. M., O’Dowd, C. D., Snider, J. R., and Weingartner, E.: The effect of physical and chemical aerosol properties on warm cloud droplet activation, Atmos. Chem. Phys., 6, 2593-2649, https://doi.org/10.5194/acp-6-25932006, 2006.
McNaughton, C. S., Clarke, A. D., Howell, S. G., Pinkerton, M., Anderson, B., Thornhill, L., Hudgins, C., Winstead, E., Dibb, J. E., Scheuer, E., and Maring, H.: Results from the DC-8 Inlet Characterization Experiment (DICE): Airborne Versus Surface Sampling of Mineral Dust and Sea Salt Aerosols, Aerosol Sci. Tech., 41, 136-159, https://doi.org/10.1080/02786820601118406, 2007.

Meyer, K. G., Platnick, S. E., Oreopoulos, L., and Lee, D.: Estimating the direct radiative effect of absorbing aerosols overlying marine boundary layer clouds in the southeast Atlantic using MODIS and CALIOP, J. Geophys. Res.-Atmos., 118, 48014815, https://doi.org/10.1002/jgrd.50449, 2013.

Meyer, K., Platnick, S., and Zhang, Z.: Simultaneously inferring above-cloud absorbing aerosol optical thickness andunderlying liquid phase cloud optical and microphysical properties using MODIS, J. Geophys. Res.-Atmos., 120, 5524-5547, https://doi.org/10.1002/2015JD023128, 2015.

Minnis, P., Nguyen, L., Palikonda, R., Heck, P. W., Spangenberg, D. A., Doelling, D. R., Ayers, J. K., Smith, W. L., Khaiyer, M. M., Trepte, Q. Z., Avey, L. A., Chang, F.-L., Yost, C. R., Cheer, T. L., and Szedung, S.-M.: Near-real time cloud retrievals from operational and research meteorological satellites, in: Remote Sensing of Clouds and the Atmosphere XIII, edited by: Picard, R. H., Comeron, A., Schäfer, K., Amodeo, A., and van Weele, M., International Society for Optical Engineering, SPIE Proceedings, 7107, Cardiff, Wales, United Kingdom, 19-26, https://doi.org/10.1117/12.800344, 2008.

Minnis, P., Sun-Mack, S., Young, D. F., Heck, P. W., Garber, D. P., Chen, Y., Spangenberg, D. A., Arduini, R. F., Trepte, Q. Z., Smith, W. L., Ayers, J. K., Gibson, S. C., Miller, W. F., Hong, G., Chakrapani, V., Takano, Y., Liou, K.-N., Xie, Y., and Yang, P.: CERES Edition-2 cloud property retrievals using TRMM VIRS and Terra and Aqua MODIS data-Part I: Algorithms, IEEE Trans, Geosci. Remote Sens., 49, 4374-4400, https://doi.org/10.1109/TGRS.2011.2144601, 2011a.

Minnis, P., Sun-Mack, S., Chen, Y., Yi, Y., Ayers, J. K., Brown, R. R., Dong, X., Gibson, S. C., Heck, P. W., Lin, B., Nordeen, M. L., Nguyen, L., Palikonda, R., Smith, W. L., Spangenberg, D. A., Trepte, Q. Z., and Xi, B.: CERES Edition-2 cloud property retrievals using TRMM VIRS and Terra and Aqua MODIS data-Part II: Examples of average results and comparisons with other data, IEEE Trans, Geosci. Remote Sens., 49, 4401-4430, https://doi.org/10.1109/TGRS.2011.2144602, 2011b.

Molod, A., Takacs, L., Suarez, M., and Bacmeister, J.: Development of the GEOS-5 atmospheric general circulation model: evolution from MERRA to MERRA2, Geosci. Model Dev., 8, 1339-1356, https://doi.org/10.5194/gmd-8-1339-2015, 2015.

Nabat, P., Somot, S., Cassou, C., Mallet, M., Michou, M., Bouniol, D., Decharme, B., Drugé, T., Roehrig, R., and SaintMartin, D.: Modulation of radiative aerosols effects by atmospheric circulation over the Euro-Mediterranean region, Atmos. Chem. Phys., 20, 8315-8349, https://doi.org/10.5194/acp-208315-2020, 2020.

Nam, C., Bony, S., Dufresne, J.-L., and Chepfer, H.: The "too few, too bright" tropical low-cloud problem in CMIP5 models, Geophys. Res. Lett., 39, L21801, https://doi.org/10.1029/2012GL053421, 2012.

Niedermeier, D., Wex, H., Voigtländer, J., Stratmann, F., Brüggemann, E., Kiselev, A., Henk, H., and Heintzenberg, J.: LACIS- 
measurements and parameterization of sea-salt particle hygroscopic growth and activation, Atmos. Chem. Phys., 8, 579-590, https://doi.org/10.5194/acp-8-579-2008, 2008.

Noda, A. T. and Satoh, M.: Intermodel variances of subtropical stratocumulus environments simulated in CMIP5 models, Geophys. Res. Lett. 41, 7754-7761, https://doi.org/10.1002/2014GL061812, 2014.

O'Brien, R. E. and Kroll, J. H.: Photolytic Aging of Secondary Organic Aerosol: Evidence for a Substantial Photorecalcitrant Fraction, J. Phys. Chem. Lett., 10, 4003-4009, https://doi.org/10.1021/acs.jpclett.9b01417, 2019.

ORACLES Science Team: Suite of Aerosol, Cloud, and Related Data Acquired Aboard P3 During ORACLES 2016, Version 3, NASA Ames Earth Science Project Office [data set], https://doi.org/10.5067/Suborbital/ORACLES/P3/2016_V3, 2020a.

ORACLES Science Team: Suite of Aerosol, Cloud, and Related Data Acquired Aboard P3 During ORACLES 2017, Version 3, NASA Ames Earth Science Project Office [data set], https://doi.org/10.5067/Suborbital/ORACLES/P3/2017_V3, 2020b.

ORACLES Science Team: Suite of Aerosol, Cloud, and Related Data Acquired Aboard P3 During ORACLES 2018, Version 3, NASA Ames Earth Science Project Office [data set], https://doi.org/10.5067/Suborbital/ORACLES/P3/2018_V3, 2020c.

ORACLES Science Team: Aggregated model and observations data products, 2016-2018, Version 8, NASA Ames Earth Science Project Office [data set], available at: https://espo.nasa.gov/sites/ default/files/box_P3ER2Models_2016mmdd_R8.nc (last access: 10 March 2020), 2020d.

ORACLES Science Team: Suite of Aerosol, Cloud, and Related Data Acquired Aboard ER2 During ORACLES 2016, Version 3, NASA Ames Earth Science Project Office [data set], https://doi.org/10.5067/Suborbital/ORACLES/ER2/2016_V3, 2021.

Painemal, D., Minnis, P., and Sun-Mack, S.: The impact of horizontal heterogeneities, cloud fraction, and liquid water path on warm cloud effective radii from CERES-like Aqua MODIS retrievals, Atmos. Chem. Phys., 13, 9997-10003, https://doi.org/10.5194/acp-13-9997-2013, 2013.

Painemal, D., Xu, K.-M., Cheng, A., and Palikonda, R.: Mean structure and diurnal cycle of Southeast Atlantic boundary layer clouds: Insights from satellite observations and multiscale modeling framework simulations, J. Climate, 28, 324-341, https://doi.org/10.1175/JCLI-D-14-00368.1, 2015.

Penner, J. E., Yang, S. Y., and Chuang, C. C.: Soot and smoke aerosol may not warm climate, J. Geophys. Res., 108, 4657, https://doi.org/10.1029/2003JD003409, 2003.

Petters, M. D. and Kreidenweis, S. M.: A single parameter representation of hygroscopic growth and cloud condensation nucleus activity, Atmos. Chem. Phys., 7, 1961-1971, https://doi.org/10.5194/acp-7-1961-2007, 2007.

Pistone, K., Redemann, J., Doherty, S., Zuidema, P., Burton, S., Cairns, B., Cochrane, S., Ferrare, R., Flynn, C., Freitag, S., Howell, S. G., Kacenelenbogen, M., LeBlanc, S., Liu, X., Schmidt, K. S., Sedlacek III, A. J., Segal-Rozenhaimer, M., Shinozuka, Y., Stamnes, S., van Diedenhoven, B., Van Harten, G., and $\mathrm{Xu}, \mathrm{F}$.: Intercomparison of biomass burning aerosol optical properties from in situ and remote-sensing instruments in ORACLES-2016, Atmos. Chem. Phys., 19, 9181-9208, https://doi.org/10.5194/acp-19-9181-2019, 2019.

Pistone, K., Zuidema, P., Wood, R., Diamond, M., da Silva, A. M., Ferrada, G., Saide, P. E., Ueyama, R., Ryoo, J.-M., Pfister, L., Podolske, J., Noone, D., Bennett, R., Stith, E., Carmichael, G., Redemann, J., Flynn, C., LeBlanc, S., Segal-Rozenhaimer, M., and Shinozuka, Y.: Exploring the elevated water vapor signal associated with the free tropospheric biomass burning plume over the southeast Atlantic Ocean, Atmos. Chem. Phys., 21, 96439668, https://doi.org/10.5194/acp-21-9643-2021, 2021.

Platnick, S., King, M., and Hubanks, P.: MODIS Atmosphere L3 Daily Product, NASA MODIS Adaptive Processing System, Goddard Space Flight Center [data set], https://doi.org/10.5067/MODIS/MOD08_D3.006 (Terra), 2015a.

Platnick, S., King, M., and Hubanks, P.: MODIS Atmosphere L3 Daily Product, NASA MODIS Adaptive Processing System, Goddard Space Flight Center [data set], https://doi.org/10.5067/MODIS/MYD08_D3.006 (Aqua), 2015b.

Platnick, S., Ackerman, S. A., King, M. D., Meyer, K., Menzel, W. P., Holz, R. E., Baum, B. A., and Yang, P.: MODIS atmosphere L2 cloud product (06_L2), NASA MODIS Adaptive Processing System, Goddard Space Flight Center [data set], https://doi.org/10.5067/MODIS/MOD06_L2.006 (Terra), 2015c.

Platnick, S., Ackerman, S. A., King, M. D., Meyer, K., Menzel, W. P., Holz, R. E., Baum, B. A., and Yang, P.: MODIS atmosphere L2 cloud product (06_L2), NASA MODIS Adaptive Processing System, Goddard Space Flight Center [data set], https://doi.org/10.5067/MODIS/MYD06_L2.006 (Aqua), 2015 d.

Platnick, S., Meyer, K. G., King, M. D., Wind, G., Amarasinghe, N., Marchant, B., Arnold, G. R., Zhang, Z., Hubanks, P. A., Holz, R. E., Yang, P., Ridgway, W., and Riedi, J.: The MODIS Cloud Optical and Microphysical Products: Collection 6 Updates and Examples From Terra and Aqua, IEEE T. Geosci. Remote, 55, 502-525, https://doi.org/10.1109/TGRS.2016.2610522, 2017.

Provencal, R., Gupta, M., Owano, T. G., Baer, D. S., Ricci, K. N., O'Keefe, A., and Podolske, J. R.: Cavityenhanced quantum-cascade laser-based instrument for carbon monoxide measurements, Appl. Opt., 44, 6712-6717, https://doi.org/10.1364/AO.44.006712, 2005.

Randles, C. A., da Silva, A. M., Buchard, V., Colarco, P. R., Darmenov, A., Govindaraju, R., Smirnov, A., Holben, B., Ferrare, R., Hair, J., Shinozuka, Y., and Flynn, C. J.: The MERRA-2 Aerosol Reanalysis, 1980 Onward. Part I: System Description and Data Assimilation Evaluation, J. Climate, 30, 6823-6850, https://doi.org/10.1175/JCLI-D-16-0609.1, 2017.

Redemann, J., Wood, R., Zuidema, P., Doherty, S. J., Luna, B., LeBlanc, S. E., Diamond, M. S., Shinozuka, Y., Chang, I. Y., Ueyama, R., Pfister, L., Ryoo, J.-M., Dobracki, A. N., da Silva, A. M., Longo, K. M., Kacenelenbogen, M. S., Flynn, C. J., Pistone, K., Knox, N. M., Piketh, S. J., Haywood, J. M., Formenti, P., Mallet, M., Stier, P., Ackerman, A. S., Bauer, S. E., Fridlind, A. M., Carmichael, G. R., Saide, P. E., Ferrada, G. A., Howell, S. G., Freitag, S., Cairns, B., Holben, B. N., Knobelspiesse, K. D., Tanelli, S., L’Ecuyer, T. S., Dzambo, A. M., Sy, O. O., McFarquhar, G. M., Poellot, M. R., Gupta, S., O’Brien, J. R., 
Nenes, A., Kacarab, M., Wong, J. P. S., Small-Griswold, J. D., Thornhill, K. L., Noone, D., Podolske, J. R., Schmidt, K. S., Pilewskie, P., Chen, H., Cochrane, S. P., Sedlacek, A. J., Lang, T. J., Stith, E., Segal-Rozenhaimer, M., Ferrare, R. A., Burton, S. P., Hostetler, C. A., Diner, D. J., Seidel, F. C., Platnick, S. E., Myers, J. S., Meyer, K. G., Spangenberg, D. A., Maring, H., and Gao, L.: An overview of the ORACLES (ObseRvations of Aerosols above CLouds and their intEractionS) project: aerosolcloud-radiation interactions in the southeast Atlantic basin, Atmos. Chem. Phys., 21, 1507-1563, https://doi.org/10.5194/acp21-1507-2021, 2021.

Reid, J. S., Eck, T. S., Christopher, S. A., Hobbs, P. V., and Holben, B.: Use of the Angstrom exponent to estimate the variability of optical and physical properties of aging smoke particles in Brazil, J. Geophys. Res., 104, 27, 473-27,489, 1999.

Reid, J. S., Koppmann, R., Eck, T. F., and Eleuterio, D. P.: A review of biomass burning emissions part II: intensive physical properties of biomass burning particles, Atmos. Chem. Phys., 5, 799825, https://doi.org/10.5194/acp-5-799-2005, 2005.

Rienecker, M. M., Suarez, M. J., Todling, R., Bacmeister, J., Takacs, L.-C., Liu, H., Gu, W., Sienkiewicz, M., Koster, R. D., Gelaro, R., Stajner, I., and Nielsen, J. E.: The GEOS-5 Data Assimilation System-Documentation of Versions 5.0.1, 5.1.0, and 5.2.0, available at: https://gmao.gsfc.nasa.gov/pubs/docs/Rienecker369.pdf, last access: 15 November 2020, 2008.

Roehrig, R., Beau, I., Saint Martin, D., Alias, A., Decharme, B., Guérémy, J. F., Voldoire, A., Ahmat Younous, A.-L., Bazile, E., Belamari, S., Blein, S., Bouniol, D., Bouteloup, Y., Cattiaux, J., Chauvin, F., Chevallier, M., Colin, J., Douville, H., Marquet, P., Michou, M., Nabat, P., Oudar, T., Peyrillé, P., Piriou, J.M., Salas y Melia, D., Séférian, R., and Sénési, S.: The CNRM global atmosphere model ARPEGE Climat 6.3: Description and evaluation, J. Adv. Model. Earth Sy., 12, e2020MS002075, https://doi.org/10.1029/2020MS002075, 2020.

Rozendaal, M. A., Leovy, C. B., and Klein, S. A.: An Observational Study of Diurnal Variations of Marine Stratiform Cloud, J. Climate, 8, 1795-1809, https://doi.org/10.1175/15200442(1995)008<1795:AOSODV>2.0.CO;2, 1995.

Russell, P. B., Bergstrom, R. W., Shinozuka, Y., Clarke, A. D., DeCarlo, P. F., Jimenez, J. L., Livingston, J. M., Redemann, J., Dubovik, O., and Strawa, A.: Absorption Angstrom Exponent in AERONET and related data as an indicator of aerosol composition, Atmos. Chem. Phys., 10, 1155-1169, https://doi.org/10.5194/acp-10-1155-2010, 2010.

Ryoo, J.-M., Pfister, L., Ueyama, R., Zuidema, P., Wood, R., Chang, I., and Redemann, J.: A meteorological overview of the ORACLES (ObseRvations of Aerosols above CLouds and their intEractionS) campaign over the southeastern Atlantic during 20162018: Part 1 - Climatology, Atmos. Chem. Phys., 21, 1668916707, https://doi.org/10.5194/acp-21-16689-2021, 2021.

Saide, P. E., Gao, M., Lu, Z., Goldberg, D. L., Streets, D. G., Woo, J.-H., Beyersdorf, A., Corr, C. A., Thornhill, K. L., Anderson, B., Hair, J. W., Nehrir, A. R., Diskin, G. S., Jimenez, J. L., Nault, B. A., Campuzano-Jost, P., Dibb, J., Heim, E., Lamb, K. D., Schwarz, J. P., Perring, A. E., Kim, J., Choi, M., Holben, B., Pfister, G., Hodzic, A., Carmichael, G. R., Emmons, L., and Crawford, J. H.: Understanding and improving model representation of aerosol optical properties for a Chinese haze event mea- sured during KORUS-AQ, Atmos. Chem. Phys., 20, 6455-6478, https://doi.org/10.5194/acp-20-6455-2020, 2020.

Sakaeda, N., Wood, R., and Rasch, P. J.: Direct and semidirect aerosol effect of southern African biomass burning aerosol, J. Geophys. Res.-Atmos., 116, D12205, https://doi.org/10.1029/2010JD015540, 2011.

Samset, B. H., Myhre, G., Schulz, M., Balkanski, Y., Bauer, S., Berntsen, T. K., Bian, H., Bellouin, N., Diehl, T., Easter, R. C., Ghan, S. J., Iversen, T., Kinne, S., Kirkevåg, A., Lamarque, J.-F., Lin, G., Liu, X., Penner, J. E., Seland, Ø., Skeie, R. B., Stier, P., Takemura, T., Tsigaridis, K., and Zhang, K.: Black carbon vertical profiles strongly affect its radiative forcing uncertainty, Atmos. Chem. Phys., 13, 2423-2434, https://doi.org/10.5194/acp13-2423-2013, 2013.

Sand, M., Samset, B. H., Myhre, G., Gliß, J., Bauer, S. E., Bian, H., Chin, M., Checa-Garcia, R., Ginoux, P., Kipling, Z., Kirkevåg, A., Kokkola, H., Le Sager, P., Lund, M. T., Matsui, H., van Noije, T., Olivié, D. J. L., Remy, S., Schulz, M., Stier, P., Stjern, C. W., Takemura, T., Tsigaridis, K., Tsyro, S. G., and Watson-Parris, D.: Aerosol absorption in global models from AeroCom phase III, Atmos. Chem. Phys., 21, 15929-15947, https://doi.org/10.5194/acp-21-15929-2021, 2021.

Schuster, G. L., Dubovi, O., and Holben, B. N.: Angstrom exponent and bimodal aerosol size distributions, J. Geophys. Res., 111, D07207, https://doi.org/10.1029/2005JD006328, 2006.

Schwarz, J. P., Gao, R. S., Fahey, D. W., Thomson, D. S., Watts, L. A., Wilson, J. C., Reeves, J. M., Darbeheshti, M., Baumgardner, D. G., Kok, G. L., Chung, S. H., Schulz, M., Hendricks, J., Lauer, A., Kärcher, B., Slowik, J. G., Rosenlof, K. H., Thompson, T. L., Langford, A. O., Loewenstein, M., and Aikin, K. C.: Single-particle measurements of midlatitude black carbon and light-scattering aerosols from the boundary layer to the lower stratosphere, J. Geophys. Res., 111, D16207, https://doi.org/10.1029/2006JD007076, 2006.

Shank, L. M., Howell, S., Clarke, A. D., Freitag, S., Brekhovskikh, V., Kapustin, V., McNaughton, C., Campos, T., and Wood, R.: Organic matter and non-refractory aerosol over the remote Southeast Pacific: oceanic and combustion sources, Atmos. Chem. Phys., 12, 557-576, https://doi.org/10.5194/acp-12-5572012, 2012.

Shinozuka, Y., Saide, P. E., Ferrada, G. A., Burton, S. P., Ferrare, R., Doherty, S. J., Gordon, H., Longo, K., Mallet, M., Feng, Y., Wang, Q., Cheng, Y., Dobracki, A., Freitag, S., Howell, S. G., LeBlanc, S., Flynn, C., Segal-Rosenhaimer, M., Pistone, K., Podolske, J. R., Stith, E. J., Bennett, J. R., Carmichael, G. R., da Silva, A., Govindaraju, R., Leung, R., Zhang, Y., Pfister, L., Ryoo, J.-M., Redemann, J., Wood, R., and Zuidema, P.: Modeling the smoky troposphere of the southeast Atlantic: a comparison to ORACLES airborne observations from September of 2016, Atmos. Chem. Phys., 20, 11491-11526, https://doi.org/10.5194/acp-20-11491-2020, 2020.

Shipley, S. T., Tracy, D. H., Eloranta, E. W., Trauger, J. T., Sroga, J. T., Roesler, F. L., and Weinman, J. A.: High spectral resolution lidar to measure optical scattering properties of atmospheric aerosols. 1: Theory and instrumentation, Appl. Opt., 22, 37163724, https://doi.org/10.1364/AO.22.003716, 1983.

Slingo, A. and Schrecker, H. M.: On the shortwave radiative properties of stratiform water clouds, Q. J. Roy. Meteor. Soc., 108, 407-426, 1982. 
Stephens, M., Turner, N., and Sandberg, J.: Particle Identification by Laser-Induced Incandescence in a Solid-State Laser Cavity, Appl. Opt., 42, 3726-3736, 2003.

Stevens, B., and Feingold, G.: Untangling aerosol effects on clouds and precipitation in a buffered system, Nature, 461, 607-613, https://doi.org/10.1038/nature08281, 2009.

Stier, P., Schutgens, N. A. J., Bellouin, N., Bian, H., Boucher, O., Chin, M., Ghan, S., Huneeus, N., Kinne, S., Lin, G., Ma, X., Myhre, G., Penner, J. E., Randles, C. A., Samset, B., Schulz, M., Takemura, T., Yu, F., Yu, H., and Zhou, C.: Host model uncertainties in aerosol radiative forcing estimates: results from the AeroCom Prescribed intercomparison study, Atmos. Chem. Phys., 13, 3245-3270, https://doi.org/10.5194/acp-13-3245-2013, 2013.

Tang, I. N., Tridico, A. C., and Fung, K. H.: Thermodynamic and optical properties of sea salt aerosols, J. Geophys. Res.-Atmos., 102, 23269-23275, https://doi.org/10.1029/97jd01806, 1997.

Taylor, J. W., Wu, H., Szpek, K., Bower, K., Crawford, I., Flynn, M. J., Williams, P. I., Dorsey, J., Langridge, J. M., Cotterell, M. I., Fox, C., Davies, N. W., Haywood, J. M., and Coe, H.: Absorption closure in highly aged biomass burning smoke, Atmos. Chem. Phys., 20, 11201-11221, https://doi.org/10.5194/acp-20-112012020, 2020.

Titos, G., Cazorla, A., Zieger, P., Andrews, E., Lyamani, H., Granados-Muñoz, M. J., Olmo, F. J., and AladosArboledas, L.: Effect of hygroscopic growth on the aerosol light-scattering coefficient: A review of measurements, techniques and error sources, Atmos. Environ., 141, 494-507, https://doi.org/10.1016/j.atmosenv.2016.07.021, 2016.

Twohy, C. H., Anderson, J. R., Toohey, D. W., Andrejczuk, M., Adams, A., Lytle, M., George, R. C., Wood, R., Saide, P., Spak, S., Zuidema, P., and Leon, D.: Impacts of aerosol particles on the microphysical and radiative properties of stratocumulus clouds over the southeast Pacific Ocean, Atmos. Chem. Phys., 13, 25412562, https://doi.org/10.5194/acp-13-2541-2013, 2013.

Twomey, S.: The Influence of Pollution on the Shortwave Albedo of Clouds, J. Atmos. Sci., 34, 1149-1152, https://doi.org/10.1175/15200469(1977)034<1149:TIOPOT>2.0.CO;2, 1977.

van Marle, M. J. E., Kloster, S., Magi, B. I., Marlon, J. R., Daniau, A.-L., Field, R. D., Arneth, A., Forrest, M., Hantson, S., Kehrwald, N. M., Knorr, W., Lasslop, G., Li, F., Mangeon, S., Yue, C., Kaiser, J. W., and van der Werf, G. R.: Historic global biomass burning emissions for CMIP6 (BB4CMIP) based on merging satellite observations with proxies and fire models (1750-2015), Geosci. Model Dev., 10, 3329-3357, https://doi.org/10.5194/gmd-10-3329-2017, 2017.

Virkkula, A.: Correction of the Calibration of the 3-wavelength Par-

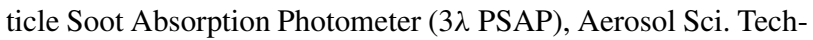
nol., 44, 706-712, 2010.

Wagstrom, K. M. and Pandis, S. N.: Determination of the age distribution of primary and secondary aerosol species using a chemical transport model, J. Geophys. Res., 114, D1430, https://doi.org/10.1029/2009jd011784, 2009.

Wilcox, E. M.: Stratocumulus cloud thickening beneath layers of absorbing smoke aerosol, Atmos. Chem. Phys., 10, 1176911777, https://doi.org/10.5194/acp-10-11769-2010, 2010.

Wild, M., Hakuba, M. Z., Folini, D., Dörig-Ott, F., Schär, C., Kato, S., and Long, C. N.: The cloud-free global energy balance and inferred cloud radiative effects: an assessment based on direct observations and climate models, Climate Dyn., 52, 4787-4812 https://doi.org/10.1007/s00382-018-4413-y, 2019.

Wilson, D. R., Bushell, A. C., Kerr-Munslow, A. M., Price, J. D., and Morcrette, C. J.: PC2: A prognostic cloud fraction and condensation scheme. I: Scheme description, Q. J. Roy. Meteor. Soc., 134, 2093-2107, 2008.

Wood, R., Bretherton, C. S., and Hartmann, D. L.: Diurnal cycle of liquid water path over the subtropical and tropical oceans, Geophys. Res. Lett., 29, 2092, https://doi.org/10.1029/2002GL015371, 2002.

Wood, R.: Stratocumulus Clouds, Mon. Weather Rev., 140, 23732423, https://doi.org/10.1175/MWR-D-11-00121.1, 2012.

Wyant, M. C., Bretherton, C. S., Chlond, A., Griffin, B. M., Kitagawa, H., Lappen, C.-L., Larson, V. E., Lock, A., Park, S., de Roode, S. R., Uchida, J., Zhao, M., and Ackerman, A. S.: A single-column model intercomparison of a heavily drizzling stratocumulus-topped boundary layer, J. Geophys. Res.-Atmos., 112, D2420, https://doi.org/10.1029/2007JD008536, 2007.

Zhang, G. J. and McFarlane, N. A.: Sensitivity of climate simulations to the parameterization of cumulus convection in the Canadian climate centre general circulation model, Atmos. Ocean, 33, 407-446, 1995.

Zhang, J. and Zuidema, P.: The diurnal cycle of the smoky marine boundary layer observed during August in the remote southeast Atlantic, Atmos. Chem. Phys., 19, 14493-14516, https://doi.org/10.5194/acp-19-14493-2019, 2019.

Zhang, Y., Chen, Y., Fan, J., and Leung, L.-Y. R.: Application of an Online-Coupled Regional Climate Model, WRF-CAM5, over East Asia for Examination of Ice Nucleation Schemes: Part II. Sensitivity to Heterogeneous Ice Nucleation Parameterizations and Dust Emissions, Climate, 3, 753-774, 2015a.

Zhang, Y., Zhang, X., Wang, K., He, J., Leung, L. R., Fan, J., and Nenes, A.: Incorporating an advanced aerosol activation parameterization into WRF-CAM5: Model evaluation and parameterization intercomparison: An Advanced Aerosol Activation Scheme, J. Geophys. Res.-Atmos., 120, 6952-6979, 2015 b.

Zhao, G. and Di Girolamo, L.: Cloud fraction errors for trade wind cumuli from EOS-Terra instruments, Geophys. Res. Lett., 33, L20802, https://doi.org/10.1029/2006GL027088, 2006.

Zhou, J., Xu, X., Zhao, W., Fang, B., Liu, Q., Cai, Y., Zhang, W., Venables, D. S., and Chen, W.: Simultaneous measurements of the relative-humidity-dependent aerosol light extinction, scattering, absorption, and single-scattering albedo with a humidified cavity-enhanced albedometer, Atmos. Meas. Tech., 13, 2623 2634, https://doi.org/10.5194/amt-13-2623-2020, 2020.

Zhu, P., Bretherton, C. S., Köhler, M., Cheng, A., Chlond, A., Geng, Q., Austin, P., Golaz, J.-C., Lenderink, G., Lock, A., and Stevens, B.: Intercomparison and interpretation of singlecolumn model simulations of a nocturnal stratocumulus-topped marine boundary layer, Mon. Weather Rev., 133, 2741-2758, https://doi.org/10.1175/MWR2997.1, 2005.

Zuidema, P., Redemann, J., Haywood, J., Wood, R., Piketh, S., Hipondoka, M., and Formenti, P.: Smoke and clouds above the Southeast Atlantic, BAMS, 97, 1131-1135, https://doi.org/10.1175/BAMS-D-15-00082.1, 2016. 